Check for updates

Cite this: J. Mater. Chem. A, 2021, 9, 20131

Received 12th May 2021

Accepted 6th August 2021

DOI: $10.1039 / \mathrm{d} 1 \mathrm{ta} 04032 \mathrm{~d}$

rsc.li/materials-a

\section{Tuning the intrinsic catalytic activities of oxygen- evolution catalysts by doping: a comprehensive review}

\begin{abstract}
Sivasankara Rao Ede and Zhiping Luo (D)*
Electrochemical water splitting produces clean hydrogen fuel as one of the pivotal alternative energies to fossil fuels in the near future. However, the anodic oxygen evolution reaction (OER) is a significant bottleneck that curtails large-scale applications of electrochemical water splitting technology, owing to its sluggish reaction kinetics. In the past few decades, various methods have been proposed to improve the OER kinetics. Among them, doping is a simple and efficient method to mold the OER kinetics of a catalyst by incorporating different or hetero atoms into the host lattice. These efforts are vital to design highly efficient OER catalysts for real-world applications. However, the OER mechanism of a doped catalyst varies, depending on the host lattice and the dopant. This review highlights different doping strategies and associated OER mechanisms of state-of-the-art catalysts, including oxides (noble metal oxides, perovskite oxides, spinel oxides, hydroxides and others), non-oxides (metal sulfides, metal selenides, metal phosphides, metal nitrides and metal carbides), and carbon-based catalysts (graphene, carbon nanotubes and others). Fundamental understanding of the doping effects on the OER from combined experimental and theoretical research provides guidelines for designing efficient catalysts.
\end{abstract}

\section{Introduction}

The demand for transitioning the world's energy from fossil fuels to eco-friendly renewable energy is rapidly increasing, in order to cope with the depletion of fossil fuels and to curtail the associated $\mathrm{CO}_{2}$ emission. ${ }^{1}$ Currently, sunlight and wind are the main contributors to renewable energy, but they are highly intermittent. $^{2}$ To overcome this challenge, researchers have been working on new energy storage techniques that can sustain the erratic behavior of solar, wind and tidal energies. ${ }^{3}$ Instead, we can store these excess energies in the form of hydrogen through water electrolysis (eqn (1)), ${ }^{4}$ and the stored hydrogen is readily available as a fuel cell for energy production in a clean way without $\mathrm{CO}_{2}$ emission (eqn (2)). ${ }^{5}$

$$
\begin{gathered}
2 \mathrm{H}_{2} \mathrm{O} \stackrel{\text { electrolysis }}{\longrightarrow} \mathrm{O}_{2}+2 \mathrm{H}_{2} \\
2 \mathrm{H}_{2}+\mathrm{O}_{2} \rightarrow 2 \mathrm{H}_{2} \mathrm{O}+\text { heat }
\end{gathered}
$$

Hydrogen production through water electrolysis is a thermodynamically infeasible process that requires additional energy to drive this reaction, and theoretically, $1.23 \mathrm{~V}(\mathrm{pH}=0)$ electric potential is required. ${ }^{6}$ However, the oxygen evolution reaction (OER) during the water electrolysis is associated with a sluggish reaction kinetics that comprises $\mathrm{O}=\mathrm{O}$ bond

Department of Chemistry, Physics and Materials Science, Fayetteville State University, Fayetteville, North Carolina 28301, USA. E-mail: zluo@uncfsu.edu formation with a loss of $4 \mathrm{e}^{-} / 4 \mathrm{H}^{+}$, requiring an even higher electric potential than the theoretical prediction. ${ }^{7}$ The excess potential above the theoretical prediction is known as overpotential $(\eta)$, which is one of the major benchmarks for denoting OER activity, along with high current density and low Tafel slope values. ${ }^{8}$ Over the past few decades, significant research has been conducted to improve the OER kinetics through various strategies for economically viable hydrogen production. ${ }^{9}$ So far, $\mathrm{RuO}_{2}$ and $\mathrm{IrO}_{2}$ catalysts have been proven to be two of the most efficient types of electrocatalyst for the OER in both acidic and alkaline media. However, the high cost associated with these catalysts hinders their large-scale water electrolysis application. ${ }^{\mathbf{1 0}}$ In alkaline media, researchers can replace these expensive catalysts with earth-abundant transition metal (TM)-based catalysts, ${ }^{11}$ as they are stable in such alkaline environments, while being unstable in acidic media. ${ }^{12,13}$ The catalyst stability is also an important factor for consideration.

The OER catalytic activity can be improved by enhancing the number of active sites on the surface of the catalyst, which is termed as the intrinsic activity of the catalyst. ${ }^{14-22}$ The intrinsic activity of the OER catalyst can be augmented by introducing elemental dopants, creating vacancies, optimizing the morphology, decreasing the particle size, or via surface reconstruction during the OER process. ${ }^{23}$ Among them, elemental doping is the most efficient way to engineer the activity of OER catalysts. ${ }^{9}$ However, a fundamental understanding of OER mechanisms is required in catalyst design to shift its efficiency closer to the thermodynamic limit. ${ }^{24}$ In the past few decades, 
several reaction mechanisms for the OER have been unveiled to fabricate efficient OER catalysts. ${ }^{25}$

To date, the current literature on OER catalysts lacks a comprehensive review on the doping effect in the OER mechanisms of catalysts. In this review, by corroborating experimental and theoretical results, we illustrate how particular elemental doping can improve the OER efficiency of a catalyst. In the beginning, OER intermediates by doping are listed. In particular materials, the OER mechanisms are presented, including the influence of dopant on improving the intrinsic activity through optimizing OER descriptors, such as $\mathrm{e}_{\mathrm{g}}$ orbital occupancy, metal-oxygen covalency, and structural parameters like $\mathrm{M}-\mathrm{O}$ bond binding energy, length, and angle. Various types of material that have exhibited efficient doping in the OER are reviewed. Understanding of these OER mechanisms will guide the design of new efficient OER catalysts.

\section{OER mechanisms}

Generally, in the OER, four electrons and protons are generated and combine on the surface of a catalyst. Several mechanisms are proposed for alkaline and acidic electrolytes; however, the research community primarily accepts the oxide ${ }^{26}$ and electrochemical oxide ${ }^{26}$ mechanisms. Karsil'shchikov ${ }^{27}$ and WadeHackerman $^{28}$ pathways are the two known mechanisms in an acidic medium for the OER. ${ }^{28}$ Here, the symbol * denotes an active catalytic site on the surface of the OER catalyst. In one of the reaction steps below, $2 * \mathrm{O} \rightarrow 2 *+\mathrm{O}_{2(\mathrm{~g})}$ in both oxide mechanisms (Fig. 1a and c) or the electrochemical oxide mechanism (Fig. 1b and d), oxygen gas is generated. In case of recombination of two *O intermediates or generation of oxygen from the ${ }^{*} \mathrm{O}$ intermediate, oxygen evolution is impossible because of a substantial thermodynamic barrier. The oxygen gas is generated from the active catalytic site after two steps via the formation of intermediate ${ }^{*} \mathrm{O}-\mathrm{OH}$, a step which is the most sluggish one out of all rate-determining steps (RDSs) in the OER.

In acidic media, the cathodic reaction is expressed as

$$
4 \mathrm{H}^{+}+4 \mathrm{e}^{-} \rightarrow 2 \mathrm{H}_{2}
$$

and the anodic reaction is

$$
2 \mathrm{H}_{2} \mathrm{O} \rightarrow \mathrm{O}_{2(\mathrm{~g})}+4 \mathrm{H}^{+}+4 \mathrm{e}^{-}
$$

The elementary steps of the oxide and electrochemical oxide mechanisms are described below: ${ }^{26}$

(a) Oxide mechanism (Fig. 1a), including reaction steps of *+ $\mathrm{H}_{2} \mathrm{O} \rightarrow{ }^{*} \mathrm{OH}+\mathrm{H}^{+}(\mathrm{aq})+\mathrm{e}^{-}, 2^{*} \mathrm{OH} \rightarrow * \mathrm{O}+\mathrm{H}_{2} \mathrm{O}, 2^{*} \mathrm{O} \rightarrow 2^{*}+\mathrm{O}_{2}$ $(\mathrm{g}), 2 * \mathrm{O}+\mathrm{H}_{2} \mathrm{O} \rightarrow{ }^{*} \mathrm{O}-\mathrm{OH}+\mathrm{H}^{+}+\mathrm{e}^{-}$, and ${ }^{*} \mathrm{O}-\mathrm{OH}+\mathrm{H}_{2} \mathrm{O} \rightarrow *+\mathrm{O}_{2}$ (g) $+\mathrm{H}^{+}+\mathrm{e}^{-}$.

(b) Electrochemical oxide mechanism (Fig. 1b), including reaction steps of ${ }^{*}+\mathrm{H}_{2} \mathrm{O} \rightarrow{ }^{*} \mathrm{OH}+\mathrm{H}^{+}(\mathrm{aq})+\mathrm{e}^{-}, 2 * \mathrm{OH} \rightarrow{ }^{*} \mathrm{O}+$ $\mathrm{H}^{+}(\mathrm{aq})+\mathrm{e}^{-}, 2^{*} \mathrm{O} \rightarrow 2^{*}+\mathrm{O}_{2}(\mathrm{~g}), 2 * \mathrm{O}+\mathrm{H}_{2} \mathrm{O} \rightarrow * \mathrm{O}-\mathrm{OH}+\mathrm{H}^{+}+\mathrm{e}^{-}$, and ${ }^{*} \mathrm{O}-\mathrm{OH}+\mathrm{H}_{2} \mathrm{O} \rightarrow *+\mathrm{O}_{2}(\mathrm{~g})+\mathrm{H}^{+}+\mathrm{e}^{-}$.

Likewise, in the alkaline medium, the cathodic reaction is

$$
4 \mathrm{H}_{2} \mathrm{O}+4 \mathrm{e}^{-} \rightarrow 2 \mathrm{H}_{2}+4 \mathrm{OH}^{-}
$$

and the anodic reaction is

$$
4 \mathrm{OH}^{-} \rightarrow 2 \mathrm{O}_{2}(\mathrm{~g})+2 \mathrm{H}_{2} \mathrm{O}+4 \mathrm{e}^{-}
$$

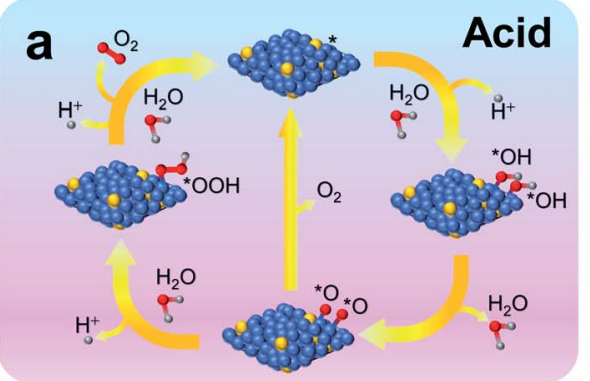

Oxide mechanism

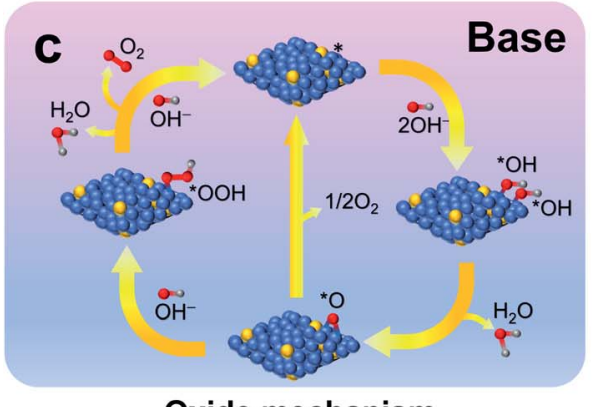

Oxide mechanism

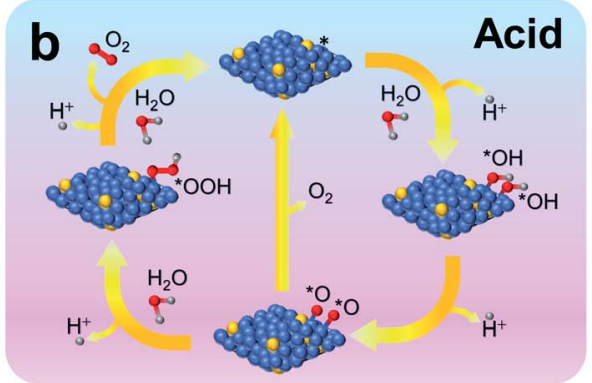

Electrochemical oxide mechanism

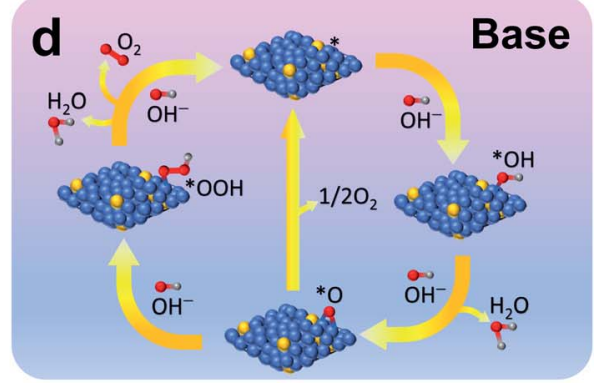

Electrochemical oxide mechanism

Fig. 1 Schematic illustrations of oxide ( $a$ and $c$ ) and electrochemical oxide ( $b$ and d) mechanisms of the OER in acid ( $a$ and b) and base (c and d) electrolytes, respectively. 
The elementary steps of the oxide and electrochemical oxide mechanisms are described below: ${ }^{26}$

(a) Oxide mechanism (Fig. 1c), including reaction steps of *+ $\mathrm{OH}^{-} \rightarrow{ }^{*} \mathrm{OH}+\mathrm{e}^{-}, 2 * \mathrm{OH} \rightarrow{ }^{*} \mathrm{O}+\mathrm{H}_{2} \mathrm{O}, 2 * \mathrm{O} \rightarrow 2 *+\mathrm{O}_{2}(\mathrm{~g}),{ }^{*} \mathrm{O}+$ $\mathrm{OH}^{-} \rightarrow * \mathrm{O}-\mathrm{OH}+\mathrm{e}^{-}$, and ${ }^{*} \mathrm{O}-\mathrm{OH}+\mathrm{OH}^{-} \rightarrow *+\mathrm{O}_{2}(\mathrm{~g})+\mathrm{H}_{2} \mathrm{O}$.

(b) Electrochemical oxide mechanism (Fig. 1d), including reaction steps of ${ }^{*}+\mathrm{OH}^{-} \rightarrow{ }^{*} \mathrm{OH}+\mathrm{e}^{-},{ }^{*} \mathrm{OH}+\mathrm{OH}^{-} \rightarrow * \mathrm{O}+\mathrm{H}_{2} \mathrm{O}$ $+\mathrm{e}^{-}, 2^{*} \mathrm{O} \rightarrow 2^{*}+\mathrm{O}_{2}(\mathrm{~g}),{ }^{*} \mathrm{O}+\mathrm{OH}^{-} \rightarrow{ }^{*} \mathrm{O}-\mathrm{OH}+\mathrm{e}^{-}$, and ${ }^{*} \mathrm{O}-\mathrm{OH}+$ $\mathrm{OH}^{-} \rightarrow *+\mathrm{O}_{2}(\mathrm{~g})+\mathrm{H}_{2} \mathrm{O}$.

There are three other well-known mechanisms proposed by, namely, Karsil'shchikov, ${ }^{27}$ Yeager, ${ }^{29}$ and Bockris,${ }^{30}$ in addition to the primarily recognized oxide and electrochemical oxide mechanisms. ${ }^{26,28}$

\section{Why doping?}

Besides the electrocatalyst type and chemical stability, the geometry and electronic structure are the key parameters for optimization in developing efficient OER catalysts. ${ }^{31}$

Geometrical surface area is the most fundamental and critical parameter, and it can be improved by synthesizing nanoforms of an electrocatalyst. By improving the specific surface area of the catalyst, the mass transfer rate and density of active catalytic sites can be accelerated. ${ }^{32}$ However, nanomaterials are often aggregated, resulting in poor stability during long-term service. ${ }^{9}$

Tuning the electronic structure is another critical factor in improving the OER activities, and elemental doping is one of the best ways of tuning the electronic structure. ${ }^{33}$ The tuning of the electronic structure by doping influences the binding energy of OER intermediates, such as *O, ${ }^{*} \mathrm{OH}$, and ${ }^{*} \mathrm{O}-\mathrm{OH}$. Hence, compared with other approaches for improving OER activities, doping provides an effective way to achieve large-scale activity and long-term stability under harsh applied anodic overpotentials.

The dopant is present in trace or small amounts. Doping generates ionizable species within the host material by incorporating impurities. The ionizable species could lead to the shift of the Fermi level $\left(E_{\mathrm{F}}\right)$, enabling carrier transport with superior catalytic activity. Doping can be performed through (a) gating for direct carrier injection; (b) antisites and vacancies as structural defects; and (c) photodoping through generation of transient carrier species via photo-excitation. Incorporation of foreign atoms that do not produce free carriers is not considered as doping. ${ }^{34}$

In the following sections, we will elaborate on the influences of doping in the following common catalytic systems, including various oxides (noble metal oxides, perovskite oxides, spinel oxides, hydroxides and other oxides), non-oxides (metal sulfides, metal selenides, metal phosphides, metal nitrides, and metal carbides), and carbon-based catalysts. Fig. 2 shows the overpotential at $10 \mathrm{~mA} \mathrm{~cm}{ }^{-2}$ and Tafel slope of the representative types of catalyst (data collected from the following sections). Lower overpotential and lower Tafel slopes are desirable for high catalytic performance. The effects of doping and its impacts on OER activity in the various prescribed electrocatalysts are finely discussed hereafter in terms of accelerating OER kinetics with less energy input.

\section{Doping of oxide electrocatalysts}

\subsection{Noble metal (Ir and Ru) oxides}

Table 1 provides a summary of some representative doped noble metal oxides and their catalytic performances. Both $\mathrm{IrO}_{2}$ and $\mathrm{RuO}_{2}$ are considered as benchmark catalysts for the OER in basic and acidic electrolytes. Under OER conditions, $\mathrm{IrO}_{2}$ is more stable than $\mathrm{RuO}_{2}$, but both oxides are unstable at high anodic potentials. $\mathrm{RuO}_{2}$ leaches out into the electrolyte in the form of $\mathrm{RuO}_{4}$ at high anodic potentials. ${ }^{35}$ Likewise, $\mathrm{IrO}_{2}$ also dissolves in the electrolyte by forming $\mathrm{IrO}_{3}$ at high anodic potentials. ${ }^{36}$ However, $\mathrm{IrO}_{2}$ shows considerably higher stability but lower OER performance, compared to $\mathrm{RuO}_{2}$.

Researchers doped $\mathrm{RuO}_{2}$ with a small amount of $\mathrm{Ir}\left(\mathrm{Ru}_{x}\right.$ $\left.\mathrm{Ir}_{1-x} \mathrm{O}_{2}\right)$ and observed a significant improvement in stability without sacrificing the OER performance. ${ }^{37}$ Another way of enhancing the OER activity with lower total noble metal content is doping with earth-abundant metals, such as $\mathrm{Cu},{ }^{38,39} \mathrm{Ni}^{40}$ $\mathrm{Co},{ }^{40,41} \mathrm{Mn},{ }^{42} \mathrm{Cr},{ }^{43,44} \mathrm{Ce},{ }^{45} \mathrm{~W},{ }^{46} \mathrm{Mg},{ }^{47}$ and $\mathrm{Zn} .{ }^{48}$ For example, $\mathrm{Cu}-$ doped $\mathrm{IrO}_{2}\left(\mathrm{Cu}_{0.3} \mathrm{Ir}_{0.7} \mathrm{O}_{\delta}\right)$ displays improved OER activity in acidic, neutral and basic media, compared to pristine $\mathrm{IrO}_{2} \cdot{ }^{39}$ The enhanced OER activity of $\mathrm{Cu}_{0.3} \mathrm{Ir}_{0.7} \mathrm{O}_{\delta}$ is primarily imputed to the Jahn-Teller distortion in $\mathrm{IrO}_{6}$ octahedra induced by $\mathrm{Cu}$, as well as oxygen vacancies induced by $\mathrm{Cu}$ doping. Density functional theory (DFT) calculations revealed the improved OER
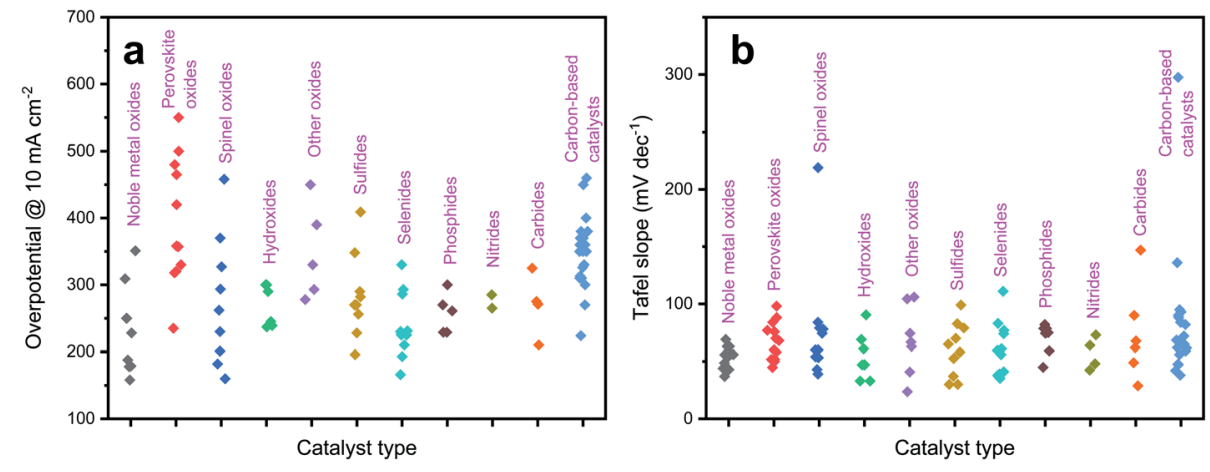

Fig. 2 Catalytic performance of representative types of catalyst: (a) overpotential a $10 \mathrm{~mA} \mathrm{~cm}^{-2}$; (b) Tafel slope. 
Table 1 Summary of representative doped noble metal oxides and perovskite oxides and their catalytic performances

\begin{tabular}{|c|c|c|c|c|}
\hline Catalyst & $\begin{array}{l}\text { Overpotential at a specific } \\
\text { current density }\end{array}$ & $\begin{array}{l}\text { Tafel slope } \\
\left(\mathrm{mV} \mathrm{dec}^{-1}\right)\end{array}$ & Durability & Electrolyte \\
\hline \multicolumn{5}{|l|}{ Noble metal oxides } \\
\hline $\mathrm{Ce}_{0.2}-\mathrm{IrO}_{2} @ \mathrm{NPC}^{45}$ & $224 \mathrm{mV}$ @ $10 \mathrm{~mA} \mathrm{~cm}{ }^{-2}$ & 55.9 & $100 \mathrm{~h}$ @ $10 \mathrm{~mA} \mathrm{~cm}{ }^{-2}$ & $0.5 \mathrm{M} \mathrm{H}_{2} \mathrm{SO}_{4}$ \\
\hline Co-doped $\mathrm{RuO}_{2}$ (ref. 41) & $169 \mathrm{mV}$ @ $10 \mathrm{~mA} \mathrm{~cm}{ }^{-2}$ & 63 & $50 \mathrm{~h} @ 10 \mathrm{~mA} \mathrm{~cm}{ }^{-2}$ & $0.5 \mathrm{M} \mathrm{H}_{2} \mathrm{SO}_{4}$ \\
\hline Cr-doped $\mathrm{IrO}_{x}$ (ref. 43) & $250 \mathrm{mV} @ 10 \mathrm{~mA} \mathrm{~cm}-2$ & 69 & $25 \mathrm{~h}$ @ $10 \mathrm{~mA} \mathrm{~cm}{ }^{-2}$ & $0.5 \mathrm{M} \mathrm{H}_{2} \mathrm{SO}_{4}$ \\
\hline $\mathrm{Cr}_{0.6} \mathrm{Ru}_{0.4} \mathrm{O}_{2}$ (ref. 44$)$ & $178 \mathrm{mV} @ 10 \mathrm{~mA} \mathrm{~cm}{ }^{-2}$ & 56 & $10 \mathrm{~h}$ @ $10 \mathrm{~mA} \mathrm{~cm}-2$ & $0.5 \mathrm{M} \mathrm{H}_{2} \mathrm{SO}_{4}$ \\
\hline $\mathrm{Cu}$-doped $\mathrm{RuO}_{2}$ (ref. 38) & $188 \mathrm{mV} @ 10 \mathrm{~mA} \mathrm{~cm}-2$ & 43.96 & $8 \mathrm{~h}$ @ $10 \mathrm{~mA} \mathrm{~cm}-2$ & $0.5 \mathrm{M} \mathrm{H}_{2} \mathrm{SO}_{4}$ \\
\hline $\mathrm{Cu}$-doped $\mathrm{IrO}_{2}$ (ref. 39) & $351 \mathrm{mV} @ 10 \mathrm{~mA} \mathrm{~cm}{ }^{-2}$ & 63 & $6000 \mathrm{~s} @ 1.68 \mathrm{~V}$ vs. RHE & $0.1 \mathrm{M} \mathrm{HClO}_{4}$ \\
\hline IrCoNi nanocrystals ${ }^{40}$ & $309 \mathrm{mV} @ 10 \mathrm{~mA} \mathrm{~cm}-2$ & 53.8 & - & $0.5 \mathrm{M} \mathrm{H}_{2} \mathrm{SO}_{4}$ \\
\hline Mg-doped $\mathrm{RuO}_{2}$ (ref. 47) & $228 \mathrm{mV}$ @ $10 \mathrm{~mA} \mathrm{~cm}-2$ & 48.66 & $30 \mathrm{~h}$ @ $1.15 \mathrm{~V} v s . \mathrm{RHE}$ & $0.5 \mathrm{M} \mathrm{H}_{2} \mathrm{SO}_{4}$ \\
\hline Mn-doped $\mathrm{RuO}_{2}$ (ref. 42) & $158 \mathrm{mV}$ @ $10 \mathrm{~mA} \mathrm{~cm}-2$ & 42.94 & $10 \mathrm{~h}$ @ $10 \mathrm{~mA} \mathrm{~cm}{ }^{-2}$ & $0.5 \mathrm{M} \mathrm{H}_{2} \mathrm{SO}_{4}$ \\
\hline W-doped $\mathrm{IrO}_{2}$ (ref. 46$)$ & $250 \mathrm{mV} @ 10 \mathrm{~mA} \mathrm{~cm}-2$ & 56.6 & - & $0.1 \mathrm{M} \mathrm{HClO}_{4}$ \\
\hline Zn-doped $\mathrm{RuO}_{2}$ (ref. 48) & $179 \mathrm{mV}$ @ $10 \mathrm{~mA} \mathrm{~cm}-2$ & 36.9 & $20 \mathrm{~h} @ 10 \mathrm{~mA} \mathrm{~cm}-2$ & $0.5 \mathrm{M} \mathrm{H}_{2} \mathrm{SO}_{4}$ \\
\hline \multicolumn{5}{|l|}{ Perovskite oxides } \\
\hline $\mathrm{Ba}_{2} \mathrm{CoMo}_{0.5} \mathrm{Nb}_{0.5} \mathrm{O}_{6-\delta}{ }^{49}$ & $445 \mathrm{mV}$ @ $10 \mathrm{~mA} \mathrm{~cm}-2$ & 77 & $2 \mathrm{~h}$ @ $10 \mathrm{~mA} \mathrm{~cm}{ }^{-2}$ & $0.1 \mathrm{M} \mathrm{KOH}$ \\
\hline $\mathrm{Ba}_{0.5} \mathrm{Sr}_{0.5} \mathrm{Co}_{0.8} \mathrm{Fe}_{0.2} \mathrm{O}_{3-\delta}{ }^{50}$ & $340 \mathrm{mV}$ @ $10 \mathrm{~mA} \mathrm{~cm}-2$ & 70 & $10 \mathrm{~h}$ @ $10 \mathrm{~mA} \mathrm{~cm}-2$ & $1 \mathrm{M} \mathrm{KOH}$ \\
\hline $\mathrm{CaMn}_{0.75} \mathrm{Nb}_{0.25} \mathrm{O}_{3-\delta}{ }^{51}$ & $550 \mathrm{mV} @ 10 \mathrm{~mA} \mathrm{~cm}-2$ & 98 & $7000 \mathrm{~s}$ @ $1.65 \mathrm{~V} v s . \mathrm{RHE}$ & $0.1 \mathrm{M} \mathrm{KOH}$ \\
\hline Co-doped $\mathrm{SrIrO}_{3}$ (ref. 52) & $235 \mathrm{mV}$ @ $10 \mathrm{~mA} \mathrm{~cm}-2$ & 51.8 & $20 \mathrm{~h}$ @ $10 \mathrm{~mA} \mathrm{~cm}-2$ & $0.1 \mathrm{M} \mathrm{HClO}_{4}$ \\
\hline $\mathrm{Pr}_{0.5} \mathrm{Ba}_{0.5} \mathrm{CoO}_{3-\delta}{ }^{53}$ & $320 \mathrm{mV}$ @ $10 \mathrm{~mA} \mathrm{~cm}{ }^{-2}$ & 60 & $120 \mathrm{~min} @ 5 \mathrm{~mA} \mathrm{~cm} \mathrm{c}^{-2}$ & $0.1 \mathrm{M} \mathrm{KOH}$ \\
\hline $\mathrm{PrBa}_{0.5} \mathrm{Sr}_{0.5} \mathrm{Co}_{1.5} \mathrm{Fe}_{0.5} \mathrm{O}_{5+\delta}{ }^{54}$ & $358 \mathrm{mV} @ 10 \mathrm{~mA} \mathrm{~cm}-2$ & 52 & $12 \mathrm{~h}$ (a) $10 \mathrm{~mA} \mathrm{~cm}^{-2}$ & $0.1 \mathrm{M} \mathrm{KOH}$ \\
\hline P-doped $\mathrm{LaFeO}_{3-\delta}{ }^{55}$ & $465 \mathrm{mV}$ @ $10 \mathrm{~mA} \mathrm{~cm}{ }^{-2}$ & 50 & - & $0.1 \mathrm{M} \mathrm{KOH}$ \\
\hline $\mathrm{SCFW}_{0.4}-\mathrm{BM}^{56}$ & $357 \mathrm{mV}$ @ $10 \mathrm{~mA} \mathrm{~cm}{ }^{-2}$ & 58 & $18 \mathrm{~h}$ @ $10 \mathrm{~mA} \mathrm{~cm}{ }^{-2}$ & $0.1 \mathrm{M} \mathrm{KOH}$ \\
\hline $\mathrm{Sr}_{2} \mathrm{Co}_{1.5} \mathrm{Fe}_{0.5} \mathrm{O}_{6-\delta}{ }^{57}$ & $318 \mathrm{mV}$ @ $10 \mathrm{~mA} \mathrm{~cm}-2$ & 44.8 & $10 \mathrm{~h}$ @ $10 \mathrm{~mA} \mathrm{~cm}-2$ & $1 \mathrm{M} \mathrm{KOH}$ \\
\hline $\mathrm{SrCo}_{0.95} \mathrm{P}_{0.05} \mathrm{O}_{3-\delta}{ }^{58}$ & $480 \mathrm{mV} @ 10 \mathrm{~mA} \mathrm{~cm}{ }^{-2}$ & 84 & $7000 \mathrm{~s}$ @ $1.65 \mathrm{~V}$ vs. RHE & $0.1 \mathrm{M} \mathrm{КОН}$ \\
\hline Sr-doped $\mathrm{PrBaCo}_{2} \mathrm{O}_{5+\delta} 59$ & $420 \mathrm{mV}$ @ $10 \mathrm{~mA} \mathrm{~cm} \mathrm{~cm}^{-2}$ & 75.8 & $10 \mathrm{~h} @ 0.1 \mathrm{~mA} \mathrm{~cm}{ }^{-2}$ & $1 \mathrm{M} \mathrm{KOH}$ \\
\hline $\mathrm{SrCo}_{0.9} \mathrm{Ti}_{0.1} \mathrm{O}_{3-\delta} 60$ & $500 \mathrm{mV} @ 10 \mathrm{~mA} \mathrm{~cm}-2$ & 88 & $10 \mathrm{~h} @ 10 \mathrm{~mA} \mathrm{~cm}-2$ & $0.1 \mathrm{M} \mathrm{KOH}$ \\
\hline Yb-doped $\mathrm{CaMnO}_{3}$ (ref. 61) & $330 \mathrm{mV} @ 10 \mathrm{~mA} \mathrm{~cm}{ }^{-2}$ & 68 & $1500 \mathrm{~s}$ @ $520 \mathrm{mV}$ & $0.1 \mathrm{M} \mathrm{KOH}$ \\
\hline
\end{tabular}

activity mechanism by the $\mathrm{Cu}$ doping. With the increase in $\mathrm{Cu}-$ doping, $\sigma$ and $\pi$ bonding regions become broader and shift to a lower energy level because of the occupancy of $\sigma$ states. The partial density of states suggests that with an increase in $\mathrm{Cu}$ doping, the antibonding states of $\mathrm{d}_{x y}$ shift up; in contrast, $\mathrm{d}_{z^{2}}$ shifts down. The $\mathrm{d}_{x z}$ and $\mathrm{d}_{y z}$ orbitals were crossed by the Fermi level $E_{\mathrm{F}}$, while the $\mathrm{d}_{x^{2}-y^{2}}$ orbital is unchanged. Because of electrons hopping from $\mathrm{d}_{x z}$ and $\mathrm{d}_{y z}\left(\mathrm{t}_{2 \mathrm{~g}}\right)$ to $\mathrm{d}_{z^{2}}$, the $\mathrm{e}_{\mathrm{g}}$ level is partially filled as a consequence of enhanced degeneracy in Ir $5 \mathrm{~d}$ orbitals by $\mathrm{Cu}$ doping. The strong interaction of $\mathrm{e}_{\mathrm{g}}$ and $\mathrm{O} 2 \mathrm{p}$ orbitals facilitates bonding with oxygen intermediates during $\sigma$ bond formation, which is more advantageous than the $\pi$ bonding of $\mathrm{t}_{2 \mathrm{~g}}$ orbitals. ${ }^{39}$

Suntivch et al. postulated that the OER catalyst, specifically perovskite oxide with the $e_{g}$ value close to unity, will exhibit superior OER performance. ${ }^{62}$ Later, other scientists found that the $e_{g}$ filling values in some oxides also have a similar effect. ${ }^{63}$ Site-specific deposition of a meager amount of Ir on facets of $\mathrm{Ni}$ nano-frameworks led to excellent OER activity in an acidic electrolyte and the catalyst even outperformed an Ir/C catalyst. ${ }^{62}$ The oxygen adsorption of TMs was effectively tuned by doping with Ir. Similarly, Feng et al. reported porous IrCoNi nanocrystals as an efficient OER catalyst in highly corrosive $\mathrm{HClO}_{4}$ electrolyte. ${ }^{40}$ Fig. 3a shows the schematic illustration of IrCoNi porous hollow nanocrystals (PHNCs). A two-step process was followed to synthesize PHNCs. In the first step, IrCo single nanocrystals (SNCs) were prepared in oleylamine; and in the second step, IrCoNi PHNCs were obtained from SNCs by etching with $\mathrm{Fe}^{3+}$ in hexane/ethanol at room temperature. Fig. 3b shows a transmission electron microscopy (TEM) image of the as-synthesized IrCoNi PHNCs, presenting uniform hollow nanocrystals. The polarization curves of $\operatorname{IrCo} / \mathrm{C}, \operatorname{IrCoNi} / \mathrm{C}$, and $\mathrm{IrNi} / \mathrm{C}$ PHNCs are compared with that of the $\mathrm{Ir} / \mathrm{C}$ catalyst in Fig. 3c. The IrCoNi/C catalyst shows superior activity with an onset potential of $1.46 \mathrm{~V}$ and requires only $303 \mathrm{mV}$ overpotential to achieve $10 \mathrm{~mA} \mathrm{~cm}^{-2}$ current density. The projected density of states (PDOS) of the d-band of Ir and IrCoNi catalysts is displayed in Fig. 3d, which shows the left side shift of the d-band center of IrCoNi from the Fermi level. The shift in the Fermi level facilitates the desired charge and discharge of OER intermediates. The schematic representation of OER reaction paths, as shown in Fig. 3e, reveals that the adsorption of OER intermediates becomes weaker when Ir is alloyed with $\mathrm{Co}$ and $\mathrm{Ni}$, compared to pristine Ir. In another study, porous W-doped $\mathrm{IrO}_{2}$ nanodendrites were found to exhibit superior OER performance under all $\mathrm{pH}$ conditions. ${ }^{46}$ DFT calculations suggested that $\mathrm{W}$ doping stabilizes the $\mathrm{IrO}_{2}$ at harsh anodic potentials by lowering the binding energies of oxygen intermediates. Qu et al. synthesized $\mathrm{Cr}$-doped $\mathrm{IrO}_{x}$ nanowires and evaluated their OER activity in $0.5 \mathrm{M} \mathrm{H}_{2} \mathrm{SO}_{4}$ electrolyte. ${ }^{43}$ The catalyst exhibits excellent OER activity with $25 \mathrm{~h}$ durability without any decay in activity. This high activity was ascribed to an increase in active site number and facile adsorption of OER intermediates via electronic structure tuning.

Like $\mathrm{IrO}_{2}$, the OER performance and stability of $\mathrm{RuO}_{2}$ were also enhanced by doping. Cu-doped $\mathrm{RuO}_{2}$ porous nano- 

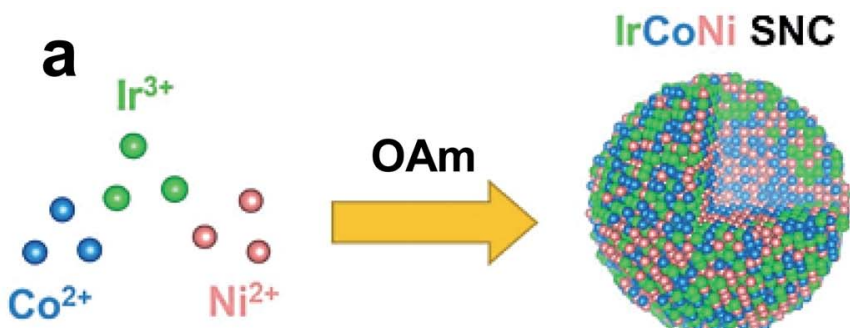

\section{IrCoNi PHNC}
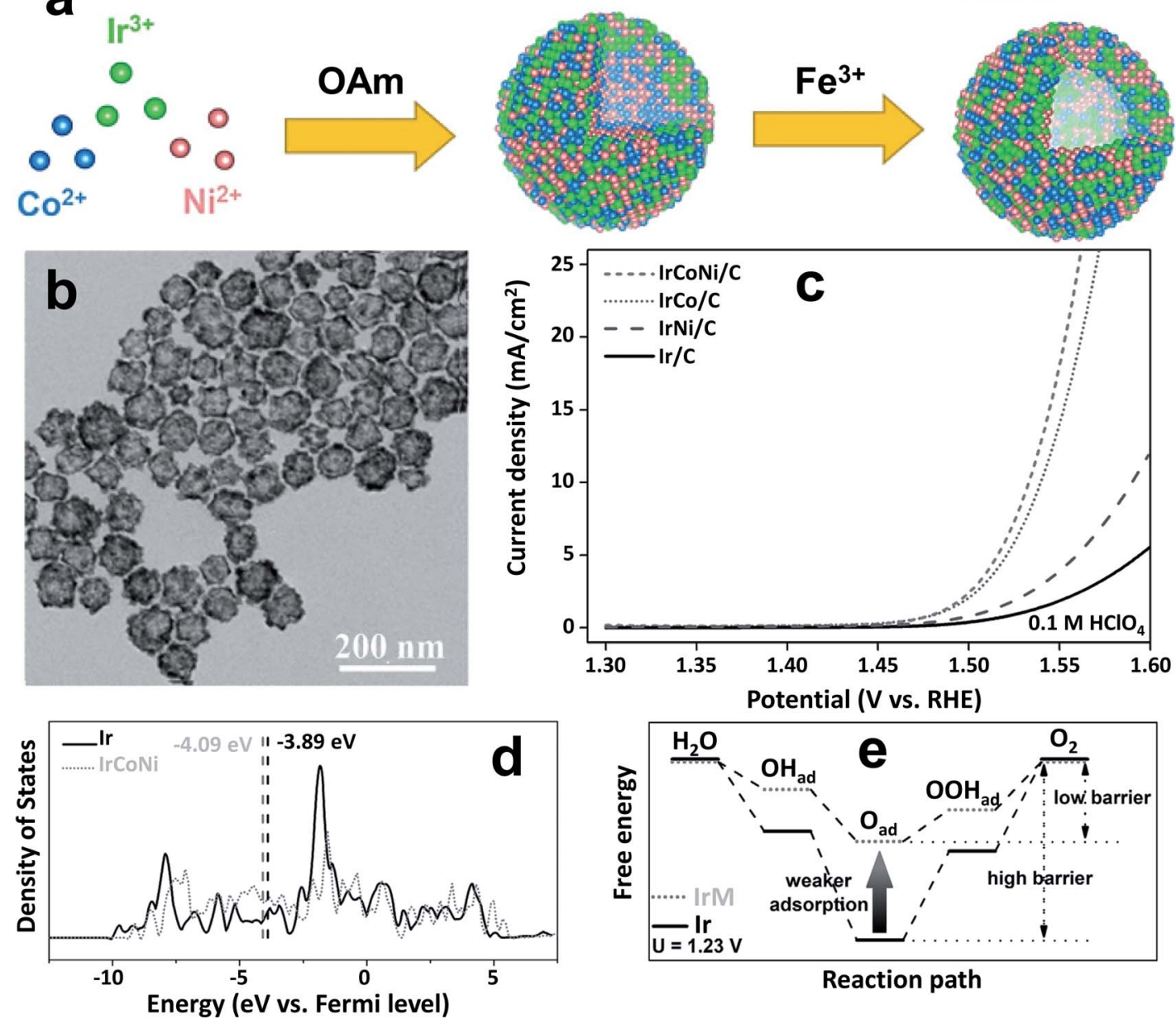

Fig. 3 (a) Schematic illustration of the formation process of IrCoNi PHNCs; (b) TEM image of the as-prepared IrCoNi PHNCs; (c) polarization curves of IrCo, IrCoNi, and IrNi for the OER with 95\% iR-compensation; (d) projected DOS of d bands of Ir (solid) and IrCoNi models (dotted) with the corresponding $d$-band center denoted by dashed lines; (e) schematic illustration of reaction paths for the OER, indicating that alloying Ir with $\mathrm{M}$ leads to weaker adsorption of oxygen-based intermediates, thus decreasing the barrier in the reaction path. ${ }^{40}$ Reproduced from ref. 40 with permission, @ 2017 John Wiley and Sons.

polyhedra, derived from organic frameworks, are probably one of the best examples for enhancing OER activity via the formation of oxygen vacancies. ${ }^{38}$ Here, most oxygen vacancies formed near $\mathrm{Cu}$, causing the adjacent $\mathrm{Ru}$ atom to become more negative, and thus shifting the $\mathrm{O} 2 \mathrm{p}$ band center towards the Fermi level for superior OER activity. Recently, Chen's group reported $\mathrm{Cr}$-doped $\mathrm{RuO}_{2}$ as an efficient OER catalyst in an acidic medium derived from a metal-organic framework (MOF). ${ }^{44}$ The schematic representation of the synthetic approach of this catalyst is shown in Fig. 4a. Initially, $\mathrm{RuCl}_{3}$ was incorporated into the MOF of $\mathrm{Cr}$. The resulting composite was annealed between 450 and $600{ }^{\circ} \mathrm{C}$ for $4 \mathrm{~h}$, and the composite which was annealed at $550{ }^{\circ} \mathrm{C}$ showed the formation of $\mathrm{Cr}_{0.6} \mathrm{Ru}_{0.4} \mathrm{O}_{2}$. Among $\mathrm{Cr}_{1-x} \mathrm{Ru}_{x} \mathrm{O}_{2}$ catalysts, $\mathrm{Cr}_{0.6} \mathrm{Ru}_{0.4} \mathrm{O}_{2}$ showed superior OER activity with a low overpotential of $178 \mathrm{mV}$ at $10 \mathrm{~mA} \mathrm{~cm}{ }^{-2}$ current density, and at the same current density, it maintained its stability for $10 \mathrm{~h}$. Chromium incorporation optimizes the DOS for $\mathrm{RuO}_{2}$ and decreases the Fermi energy level from 2.01 to
$1.07 \mathrm{eV}$, which stabilizes the crystal structure of Cr-doped $\mathrm{RuO}_{2}$. Fig. 4b displays the $\mathrm{Ru}$ site, which is coordinated with five atoms that act as an adsorption site for OER intermediates, and the formation of * $\mathrm{OOH}$ is found to be a RDS. The free energy change in the RDS is calculated to be $1.87 \mathrm{eV}$ for the doped one, which is nearly $0.1 \mathrm{eV}$ less than the free energy on the $\mathrm{RuO}_{2}$ surface. ${ }^{44}$ It was predicted that Mn doping also has a similar effect on improving the OER activity of $\mathrm{RuO}_{2}$. Very recently, Chen et al. reported Mn-doped $\mathrm{RuO}_{2}$ as an OER catalyst in an acid with a record low overpotential of $158 \mathrm{mV}$ at $10 \mathrm{~mA} \mathrm{~cm}{ }^{-2}$, which was stable up to 5000 cycles at a scan rate of $100 \mathrm{mV} \mathrm{s}^{-1}$. $^{42}$ Recently, Chen and co-workers demonstrated considerable improvement of OER activity of $\mathrm{RuO}_{2}$ in an acid medium by doping with $\mathrm{Mg}$ in a one-step annealing of a Ru-exchanged MOF. ${ }^{47}$ DFT calculations indicate the formation of oxygen vacancies on account of different oxidation states of $\mathrm{Mg}\left(2^{+}\right)$and $\mathrm{Ru}\left(4^{+}\right)$, significantly bringing down the energy barrier for the RDS. $^{47}$ 
a

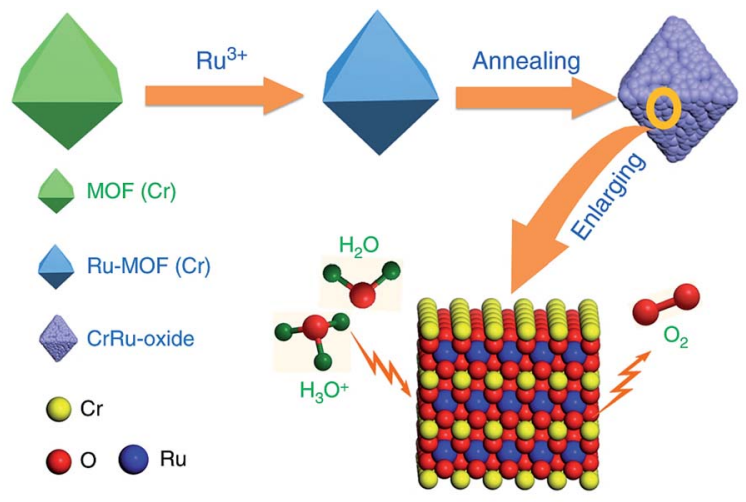

b
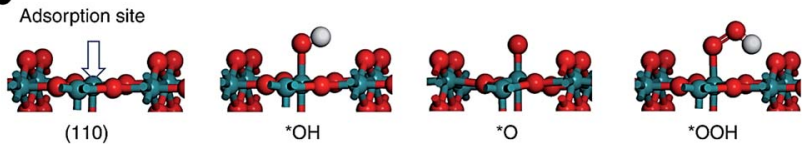

Fig. 4 (a) Schematic illustration of the preparation of $\mathrm{Cr}_{0.6} \mathrm{Ru}_{0.4} \mathrm{O}_{2}$ electrocatalysts for OER application in acid media; (b) four-step OER process. ${ }^{44}$ Reproduced with open access.

Creating defect-containing $\mathrm{RuO}_{2}$ via doping and dopant leaching is another way of improving the OER activity and stability in acidic medium. For example, Tian et al. doped $\mathrm{RuO}_{2}$ with zinc and leached it out by aging in an acid, and the catalyst displayed $179 \mathrm{mV}$ overpotential and $20 \mathrm{~h}$ stability at a current density of $10 \mathrm{~mA} \mathrm{~cm}^{-2} .88$ The high catalytic activity is accredited to the synergetic effect of active sites and tuning of the electronic structure. Recently, an oxygen-defect-containing $\mathrm{Ru}-$ based catalyst was synthesized by doping with cobalt, which showed $169 \mathrm{mV}$ overpotential and $50 \mathrm{~h}$ endurance at $10 \mathrm{~mA}$ $\mathrm{cm}^{-2}$ current density. ${ }^{41}$ The doping generated a large amount of oxygen defects, following a vacancy-related lattice oxygen oxidation mechanism (LOM) rather than an adsorbate evolution reaction mechanism (AEM). Both computational and experimental studies elucidate this mechanism. All these studies revealed the effectiveness of doping Ir and Ru oxides for enabling higher activity and longer stability.

\subsection{Perovskite oxides}

Perovskite oxides are a large family of catalysts with the general formula $\mathrm{ABO}_{3}$, where $\mathrm{A}$ is either an alkaline earth metal or a rare earth metal, and B is a TM. Table 1 provides a summary of some representative doped perovskite oxides and their catalytic performances. The ideal perovskite oxide displays a cubic crystal structure. The TMs are in the oxidation states of $+3,+4$, or a mixture of them, governed by the metal on the A-site. ${ }^{18,64}$ The OER activity can be tailored by doping at either the A-site, Bsite, or both sites to create oxygen vacancies in the perovskite. ${ }^{18}$ The metal-oxygen hybridization depends upon the oxidation state of TMs, and the electronic properties of these perovskites rely on this parameter. The TMs with high electronegativity show high metal-oxygen hybridization, and the d-band center of the TM oxide moves closer to $\mathrm{O} 2 \mathrm{p}$ states as the electronegativity increases. However, besides the metal-oxygen hybridization, octahedral tilting, Jahn-Teller distortion, and displacement of B-site cations also play significant roles in governing the electronic properties of perovskite oxides. ${ }^{18,65,66}$

4.2.1 A-site doping. The activity and durability of $\mathrm{SrRuO}_{3}$ perovskite are enhanced mainly by doping the $\mathrm{Sr}$ site with $\mathrm{Na}$ $\left(\mathrm{Sr}_{0.95} \mathrm{Na}_{0.05} \mathrm{RuO}_{3}\right)$, which results in a decrease in octahedral distortion and an increase in the oxidation state. ${ }^{67}$ Na-doping results in no distortion in octahedra because of the change in the oxidation state of Ru with the inclusion of Na. DFT studies reveal that Na doping weakens the bonding between OER intermediates and $\mathrm{Ru}$, allowing release of oxygen freely. ${ }^{67}$ The increase in the oxidation state of $\mathrm{Ru}$ in Na-doped $\mathrm{SrRuO}_{3}$ further improves its stability at high anodic potentials in an acidic medium. Doping of the La site of $\mathrm{LaCoO}_{3}$ with $\mathrm{Sr}$ induces the formation of cobalt species with higher oxidation states, which influence its crystal structure in such a way that $\mathrm{O}-\mathrm{Co}-\mathrm{O}$ is aligned at $180^{\circ}$. As a consequence, Co $3 \mathrm{~d}$ and $\mathrm{O} 2 \mathrm{p}$ orbitals are mixed efficiently to enhance the intrinsic OER activity of the perovskite. $^{68}$

Grimaud et al. doped a series of lanthanides ( $\mathrm{Ln}=\mathrm{Pr}, \mathrm{Sm}$, $\mathrm{Gd}$ and $\mathrm{Ho}$ ) at the A-site of $\mathrm{BaCoO}_{3-\delta}$ to optimize the $\mathrm{e}_{\mathrm{g}}$ filling values, thus improving the OER activity. ${ }^{53}$ Among Ln-doped perovskites, $\mathrm{Pr}_{0.5} \mathrm{Ba}_{0.5} \mathrm{CoO}_{3-\delta}$ shows superior activity. Estimated from X-ray absorption spectroscopy (XAS) and chemical titrations, the $e_{g}$ filling values of all Ln-doped compounds are close to unity. However, DFT calculations suggest that hybridization of Co $3 \mathrm{~d}$ and O 2p orbitals decreases from Pr to Ho, because of the decreased Co oxidation state with an increase in electronegativity of dopants from Pr to Ho. Similarly, when the A-site of $\mathrm{CaMnO}_{3}$ is doped with $\mathrm{Yb}\left(\mathrm{Ca}_{0.9} \mathrm{Yb}_{0.1} \mathrm{MnO}_{3}\right)$, the OER activity is found to be 100 times higher than that of the pristine sample. ${ }^{61}$ The excellent OER performance of $\mathrm{Ca}_{0.9} \mathrm{Yb}_{0.1} \mathrm{MnO}_{3}$ is attributed to the increased $\mathrm{Mn}^{3+} / \mathrm{Mn}^{4+}$ ratio, which provides the double exchange of electrons and optimized $e_{g}$ filling value of $\sim 0.81$. The OER activity of double perovskites was also tuned by doping the A-site; for instance, $\mathrm{Sr}$ doping of the Ba site of $\mathrm{PrBaCO}_{2} \mathrm{O}_{5+\delta}$ improves the population of $\mathrm{Co}^{4+}$ ions on the surface. ${ }^{59}$ The doping enhances the ease of adsorption and deprotonation of *OOH intermediates from the catalyst surface, thus improving the OER performance of the perovskite.

4.2.2 B-site doping. It is critical to tune the electronic structure of the B site to regulate the electrochemical behavior of perovskite oxides; hence, doping the B-site is the most facile way of governing the OER performance. ${ }^{49,56}$ For instance, Shao's group demonstrated that B-site doping of $\mathrm{SrTiO}_{3}$ with cobalt and iron elements resulted in an improved electrocatalyst for the OER.$^{60}$ Among doped perovskites, $\mathrm{SrCo}_{0.9} \mathrm{Ti}_{0.1} \mathrm{O}_{3-\delta}$ displayed enhanced OER activity owing to its optimized $e_{g}$ filling value of 1.16, and formation of redox-active oxygen deficiency. In another report, the $\mathrm{Mn}$ site of $\mathrm{CaMnO}_{3}$ is doped with $\mathrm{Nb}$ $\left(\mathrm{CaMn}_{0.75} \mathrm{Nb}_{0.25} \mathrm{O}_{3-\delta}\right)$, which enhances the OER performance in terms of current density by onefold, and mass activity by sevenfold, compared to the undoped perovskite..$^{51}$ The significant enhancement of electrochemical activity is imputed to the reduction of the oxidation state of $\mathrm{Mn}$ from +4 to +3 caused by doping with $\mathrm{Nb}^{5+}$, which in turn tunes the $e_{g}$ value close to unity. 
Recently, researchers turned their attention to dope nonmetals like phosphorus, sulfur, and silicon at the B-site to stabilize the crystal structure of perovskite oxides. An important reason for doping, specifically phosphorus, for improving electrocatalytic properties is that it has greater affinity towards combining with oxygen. Phosphorus doping at the B-site of $\mathrm{SrCoO}_{3-\delta}$ (SC) perovskite results in tetragonal perovskite oxide $\mathrm{SrCo}_{0.95} \mathrm{P}_{0.05} \mathrm{O}_{3-\delta}(\mathrm{SCP})$, which shows a considerable increase in OER performance in terms of activity and endurance relative to the parent compound. ${ }^{58}$ Fig. $5 \mathrm{a}$ and $\mathrm{b}$ show linear sweep voltammetry (LSV) curves of SC and SCP before and after the accelerated degradation test (ADT) conducted by repetition of $1000 \mathrm{CV}$ cycles. The ADT results show a decrease in the activity of SC after ADT, while SCP shows an increase in OER activity after the ADT. The enhanced OER activity during the ADT of SCP is due to the presence of $\mathrm{P}$ dopant. The high-resolution TEM (HR-TEM) images presented Fig. $5 \mathrm{c}$ and $\mathrm{d}$ suggest that the decrease in the activity of SC is because of the formation of a 10$15 \mathrm{~nm}$ thick amorphous layer after the ADT, which curtails the diffusion by blocking active sites, while SCP shows an only 1$2 \mathrm{~nm}$ thick amorphous layer (Fig. 5d). Fig. 5e shows a schematic illustration of the OER mechanism on SCP during the ADT, which indicates improved interaction between active cobalt sites and electrolyte through leaching of either $\mathrm{Sr}^{2+}$ or $\mathrm{P}^{5+}$ from the surface of the catalyst.

Likewise, Liu's group demonstrated the universality of $\mathrm{P}$ doping at the B-site of $\mathrm{LaFeO}_{3-\delta}, \mathrm{LaCoO}_{3-\delta}$ and $\mathrm{LaNiO}_{3-\delta}$ perovskites for improving the electrochemical water oxidation capacity. ${ }^{55}$ The superior activity is attributed largely to the generation of a large amount of $\mathrm{O}_{2}{ }^{2-} / \mathrm{O}^{-}$species, and DFT calculation suggests a change in the oxidation state of the $\mathrm{B}$ cation that optimizes the $\mathrm{e}_{\mathrm{g}}$ value $(\sim 1)$. Zou et al. doped a series of TMs at the B-site of $6 \mathrm{H}-\mathrm{SrIrO}_{3}$ for improving its OER activity in an acidic medium. ${ }^{52}$ Among them, cobalt doping was found to enhance the OER activity of $6 \mathrm{H}-\mathrm{SrIrO}_{3}$ significantly. Fig. $6 \mathrm{a}$ presents the crystal structure of $6 \mathrm{H}-\mathrm{SrIrO}_{3}$ having two types of $\mathrm{IrO}_{6}$ octahedron: one is face sharing (red), and the other one is corner-sharing isolated (olive green). Thus, the doped TMs can replace the Ir present in either the face sharing octahedra or corner-sharing octahedra. Fig. 6b displays the SEM image of Codoped $6 \mathrm{H}-\mathrm{SrIrO}_{3}$ having plate-like morphology and the thickness of these plates decreased after doping. Fig. 6c shows the polarization curves of pristine and Co-doped catalysts in $0.1 \mathrm{M}$ $\mathrm{HClO}_{4}$ electrolyte. The catalyst with a $0.2: 1$ ratio of Co and Ir shows superior activity with the lowest overpotential of $235 \mathrm{mV}$ at $10 \mathrm{~mA} \mathrm{~cm}^{-2}$, and the catalytic activity is 2.5 times higher than that of the pristine catalyst. A comparison between the mass activities of pristine and Co-doped catalysts is presented in Fig. 6d, which suggests that the catalyst with the $0.2: 1$ ratio of $\mathrm{Co}$ and Ir has 3 times higher mass activity than $6 \mathrm{H}-\mathrm{SrIrO}_{3}$. However, both catalysts show nearly the same OER kinetics with Tafel values of $51.8 \mathrm{mV} \mathrm{dec}{ }^{-1}$ for the catalyst with the $0.2: 1$

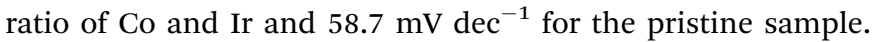
Computational studies suggest that in the pristine sample, a downshift of the Ir $5 \mathrm{~d}$ band center away from the Fermi level is observed. In contrast, the $\mathrm{O} 2 \mathrm{p}$ band moves close to the Fermi level in the doped $6 \mathrm{H}-\mathrm{SrIrO}_{3}$, which thus results in enhanced covalency and increases the OER activity. ${ }^{52}$

Very recently, our group doped Fe on the B-site of $\mathrm{SrCoO}_{3-\delta}$ and observed the formation of a tetragonal intermediate structure between perovskite and brownmillerite, with a stoichiometric formula of $\mathrm{Sr}_{2} \mathrm{Co}_{1.5} \mathrm{Fe}_{0.5} \mathrm{O}_{6-\delta} \cdot{ }^{57}$ Fig. 7a presents the OER activity of Sr-Co-Fe-oxides, which shows that $\mathrm{Sr}_{2} \mathrm{Co}_{1.5^{-}}$ $\mathrm{Fe}_{0.5} \mathrm{O}_{6-\delta}$ exhibits superior OER activity among all doped oxides. The enhanced OER activity is ascribed to the unique stacking of octahedral (oh) and tetrahedral (th) layered units of the tetragonal structure, as shown in Fig. 7b, providing facile interactions between the electrode and electrolyte surface. The stability of the $\mathrm{Sr}_{2} \mathrm{Co}_{1.5} \mathrm{Fe}_{0.5} \mathrm{O}_{6-\delta}$ catalyst was evaluated at $1.55 \mathrm{~V}$ for $10 \mathrm{~h}$ as shown in Fig. 7c, and it presents good stability with
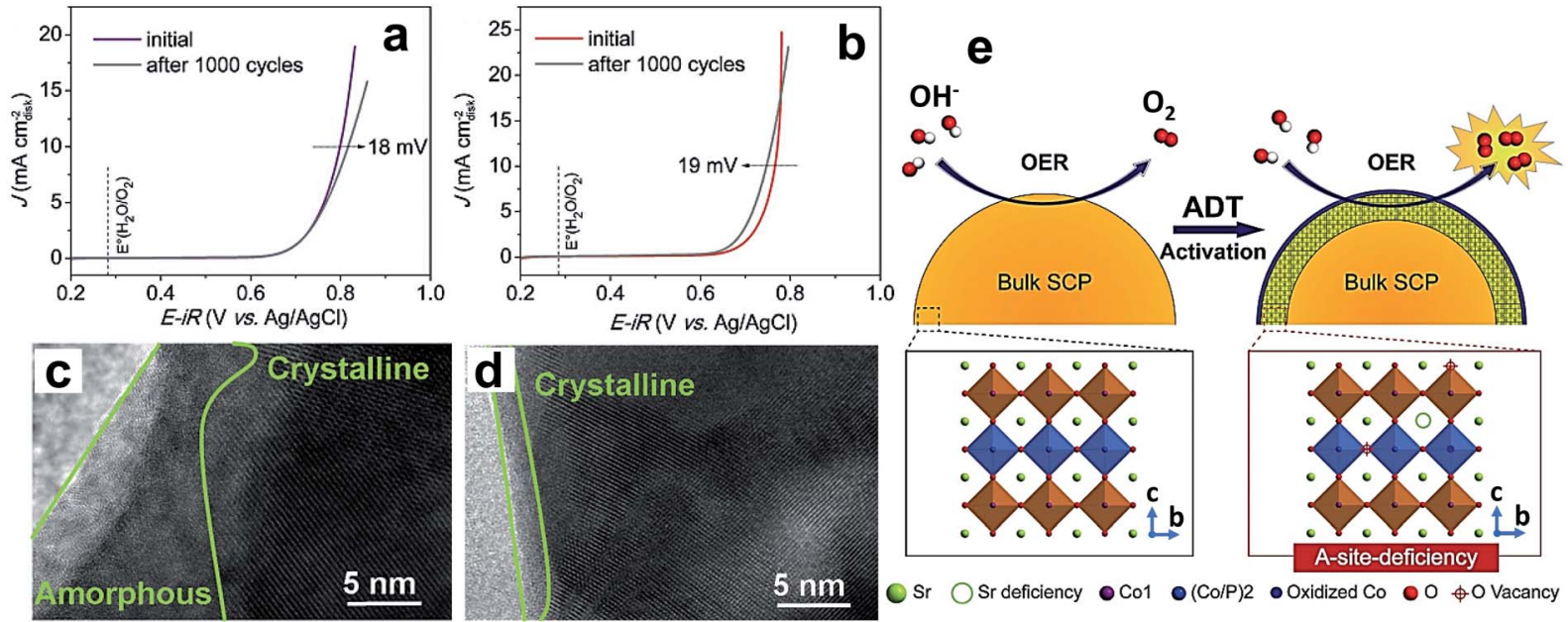

Fig. 5 ( $a$ and b) LSV curves for the OER on a RDE (1600 rpm) for the (a) SC and (b) SCP samples before and after an ADT of 1000 cycles in $\mathrm{O}_{2}$ saturated $0.1 \mathrm{M} \mathrm{KOH}$ solution; HRTEM images of the surface regions of (c) SC and (d) SCP after an ADT of 1000 cycles; (e) schematic illustration of the main origin of the OER activation for the SCP sample during the ADT. ${ }^{58}$ Reproduced from ref. 58 with permission, (c) 2017 John Wiley and Sons. 

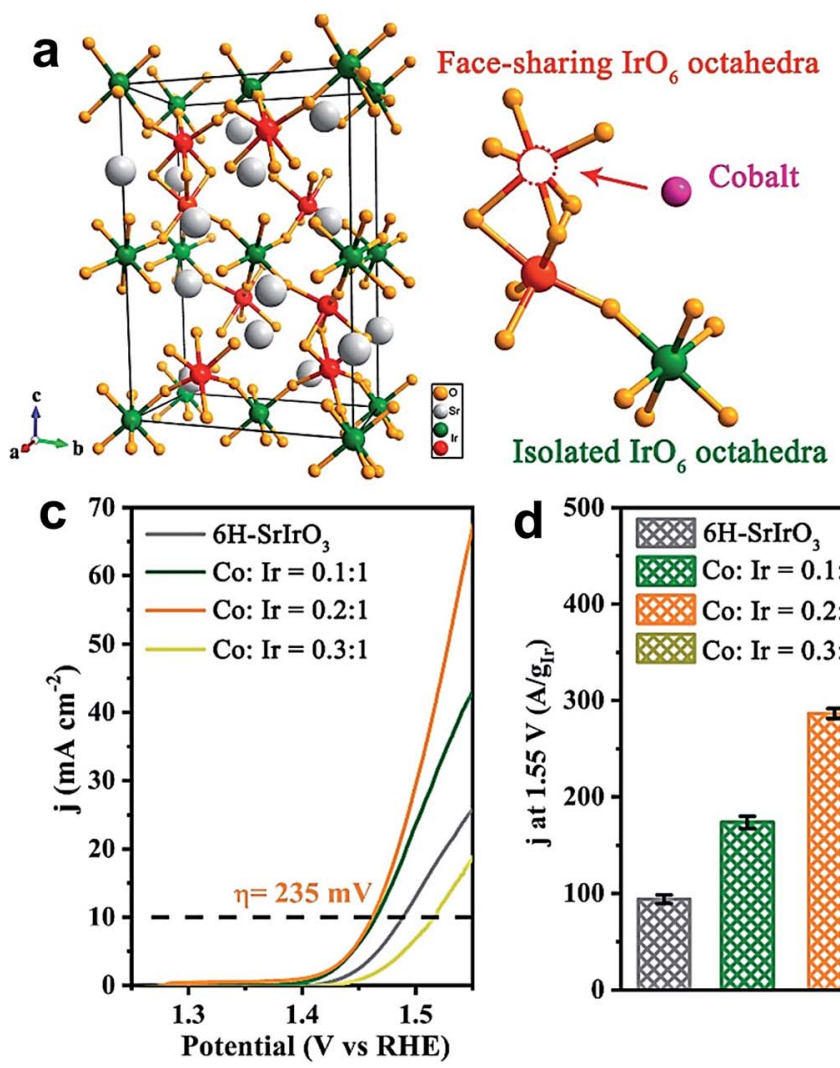
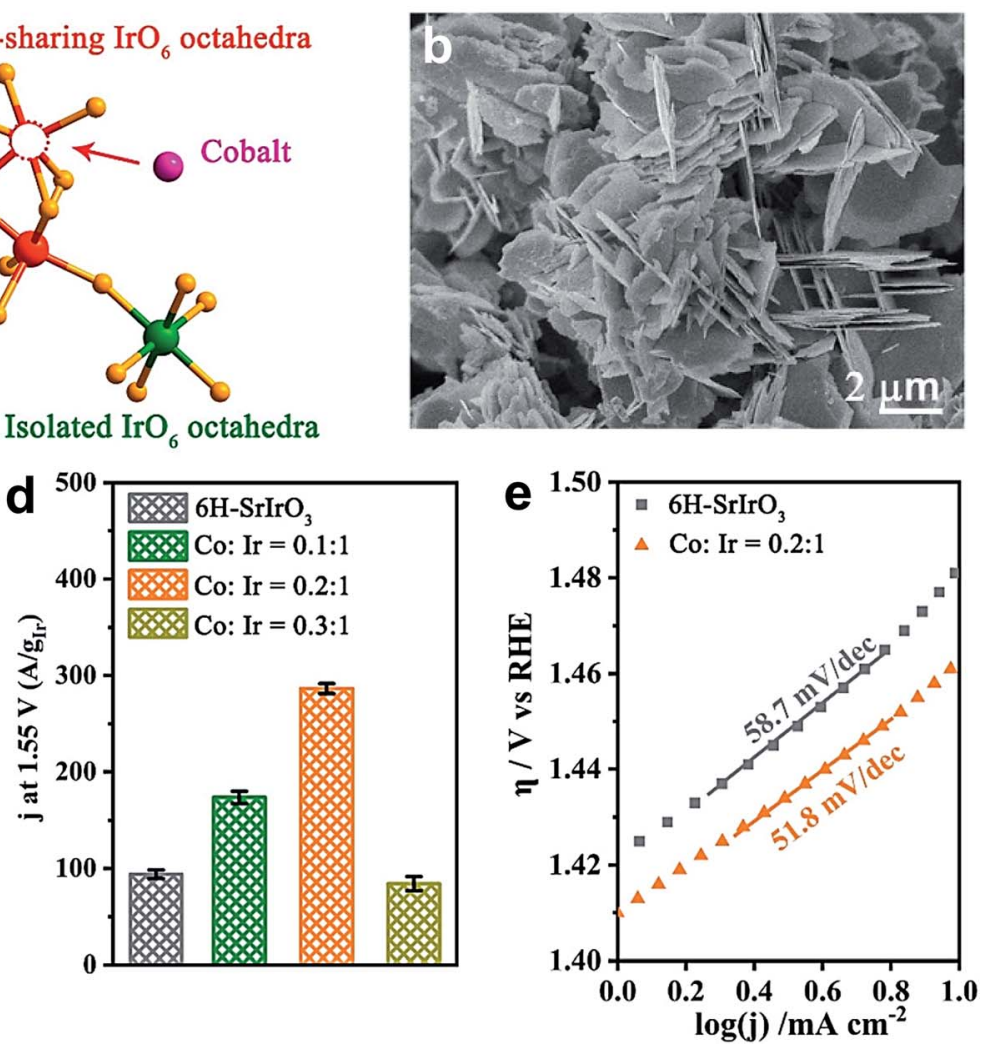

Fig. 6 (a) Crystal structure of $6 \mathrm{H}-\mathrm{SrlrO}_{3}$, and two kinds of Ir site for $\mathrm{Co}$ substitution. The iridium atom at face-sharing $\mathrm{IrO}_{6}$ octahedra is marked by a red color and that at isolated $\mathrm{IrO}_{6}$ octahedra is marked by an olive green color; (b) SEM image of Co doped 6H-SrlrO 3 ; (c) polarization curves of pure $6 \mathrm{H}-\mathrm{SrIrO}_{3}$ and $\mathrm{Co}$-doped $\mathrm{SrlrO}_{3}\left(\mathrm{Co}: \mathrm{Ir}=0.1: 1,0.2: 1\right.$, and $0.3: 1$ ) in $0.1 \mathrm{M} \mathrm{HClO}_{4}$ solution with $85 \%$ iR compensation; (d) iridium amount-normalized mass activity of $6 \mathrm{H}-\mathrm{SrlrO}_{3}$ and $\mathrm{Co}$-doped $\mathrm{SrIrO}_{3}(\mathrm{Co}: \mathrm{Ir}=0.1: 1,0.2: 1$, and $0.3: 1)$; (e) Tafel slopes of $6 \mathrm{H}-\mathrm{SrlrO}_{3}$ and $\mathrm{Co}_{-}$ doped $6 \mathrm{H}-\mathrm{SrIrO}_{3}{ }^{52}$ Reproduced from ref. 52 with permission, @ 2019 American Chemical Society.

a slight increase in overpotential of $16 \mathrm{mV}$ as depicted in Fig. $7 \mathrm{~d}$. Furthermore, theoretical calculations suggest that the enhanced covalency of $\mathrm{Co} 3 \mathrm{~d}$ and $\mathrm{O} 2 \mathrm{p}$ is another prime contributor to the augmented OER performance of $\mathrm{Sr}_{2} \mathrm{Co}_{1.5^{-}}$ $\mathrm{Fe}_{0.5} \mathrm{O}_{6-\delta}$. This tetragonal intermediate structure presents a model for developing advanced catalysts in other systems.

4.2.3 Both A- and B-site doping, and controlled formation of oxygen vacancies. Tuning the electrocatalytic activity of perovskites is also possible by simultaneously doping both $\mathrm{A}$ and $\mathrm{B}$ sites. $\mathrm{Ba}_{0.5} \mathrm{Sr}_{0.5} \mathrm{Co}_{0.8} \mathrm{Fe}_{0.2} \mathrm{O}_{3-\delta}$ (BSCF) is a well-studied dual-doped perovskite, and it displayed significant intrinsic activity as a catalyst for the OER, which is an order magnitude higher than that of the benchmark catalyst $\mathrm{IrO}_{2} \cdot{ }^{50}$ The higher activity of BSCF originates from having the $\mathrm{e}_{\mathrm{g}}$ value close to unity, which is revealed by Shao-Horn's group by comparing several perovskite catalysts. ${ }^{65}$ The doping of the Ba site with $\mathrm{Sr}$ and Co site with $\mathrm{Fe}$ in the double perovskite $\mathrm{PrBaCo}_{2} \mathrm{O}_{5+\delta}$ crystal structure significantly improves the OER performance. ${ }^{54}$ Specifically, the perovskite nanofibers with the composition of $\mathrm{PrBa}_{0.5} \mathrm{Sr}_{0.5} \mathrm{Co}_{1.5} \mathrm{Fe}_{0.5} \mathrm{O}_{5+\delta}$ displayed superior intrinsic activity that is way higher than that of the BSCF catalyst, and DFT calculations indicated that the $\mathrm{O} 2 \mathrm{p}$ band center was neither too close to nor too far away from the Fermi energy level. The adsorption scenarios of OER intermediates reveal that the ${ }^{*} \mathrm{OH}$ to ${ }^{*} \mathrm{O}$ conversion is the RDS, and the $\mathrm{Fe}$ site of $\mathrm{Sr} / \mathrm{Fe}$ dual-doped $\mathrm{PrBaCo}_{2} \mathrm{O}_{5+\delta}$ requires a low overpotential $(0.6 \mathrm{~V})$ to initiate the reaction, while the Co site needs $0.7 \mathrm{~V}^{69}$ The best way to generate the oxygen vacancies in perovskites is doping a high valence A-site cation with a low valent dopant. For example, $\mathrm{Sr}$ doping at the A-site of $\mathrm{LaCoO}_{3}$ results in ligand hole/oxygen deficiency. This deficiency increases with an increase in the Sr doping level. ${ }^{70}$ The rise in oxygen vacancy leads to electroneutrality of the Co ion which improves the intermixing of Co $3 \mathrm{~d}$ and $\mathrm{O} 2 \mathrm{p}$ orbitals. The evaluation of OER activity of a $\mathrm{La}_{1-x^{-}}$ $\mathrm{Sr}_{x} \mathrm{CoO}_{3-\delta}$ perovskite series $(x=0,0.2,0.4,0.6,0.8$, and 1) suggests that with the increase in Sr content, the catalytic activity is improved. Furthermore, the authors evaluated ex situ electronic conductivity as a function of current density and found that the OER activity of the perovskite was enhanced with a large amount of Sr because of high electronic conductivity.

\subsection{Spinel oxides}

The general formula of spinel oxides is $\mathrm{AB}_{2} \mathrm{O}_{4}$. $\mathrm{A}$ and $\mathrm{B}$ are metal cations in general, which belong to the first row of TMs, or group 2 or group 13 in the periodic table. Table 2 provides a summary of representative doped spinel oxides and their catalytic performances. The structure of spinel oxides is complicated, because of the presence of two crystallographic 

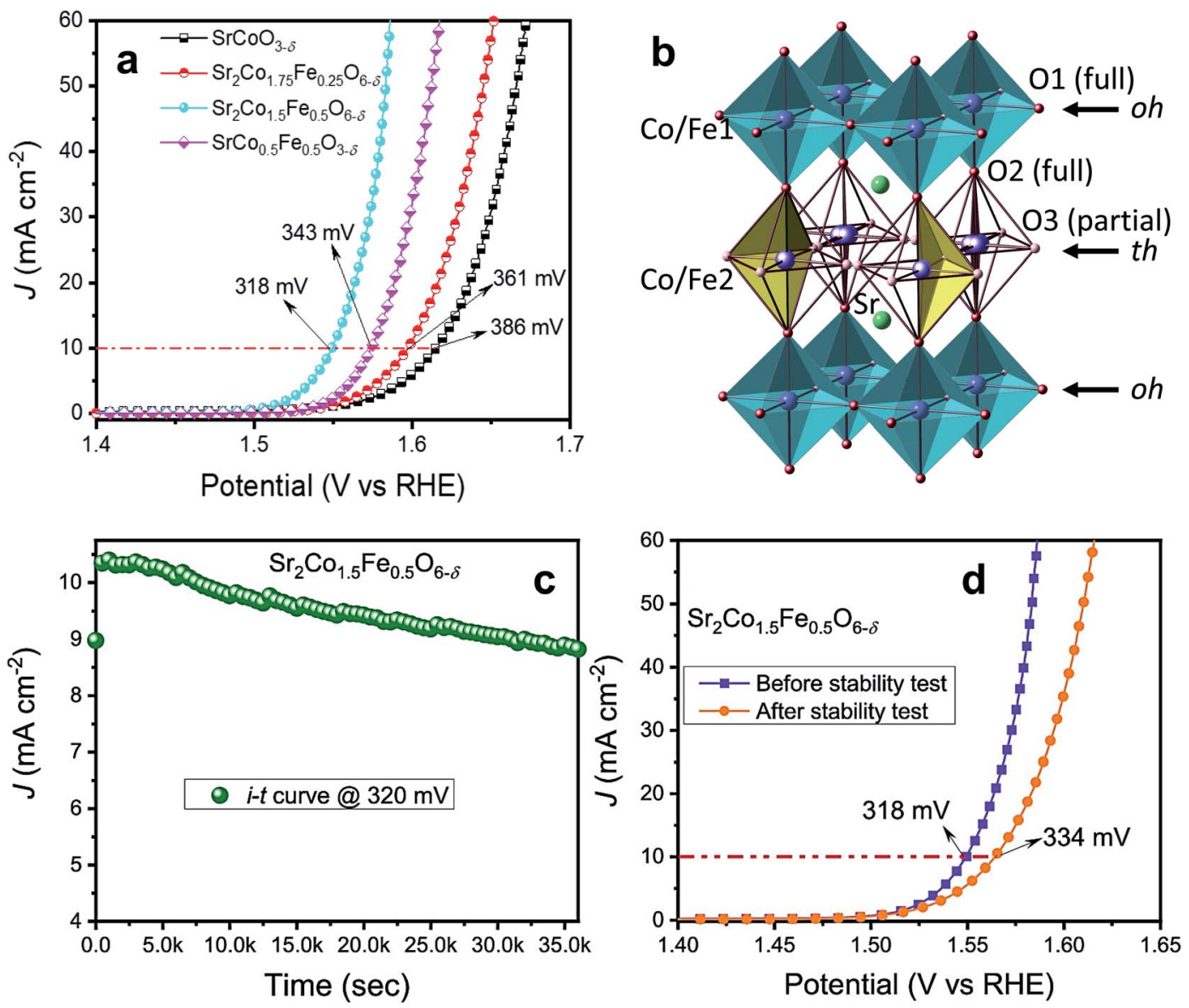

Fig. 7 (a) LSV plots of $\mathrm{SrCoO}_{3-\delta}, \mathrm{Sr}_{2} \mathrm{CO}_{1.75} \mathrm{Fe}_{0.25} \mathrm{O}_{6-\delta}, \mathrm{Sr}_{2} \mathrm{Co}_{1.5} \mathrm{Fe}_{0.5} \mathrm{O}_{6-\delta}$ and $\mathrm{SrCO}_{0.5} \mathrm{Fe}_{0.5} \mathrm{O}_{3-\delta}$ oxides; (b) structural model of the intermediate tetragonal phase containing a sequence of alternating octahedral (oh) and tetrahedral (th) layers (...oh-th-oh-th...), where only two randomly orientated tetrahedra are shown for clarity; (c) stability test of $\mathrm{Sr}_{2} \mathrm{CO}_{1.5} \mathrm{Fe}_{0.5} \mathrm{O}_{6-\delta}$ oxide at $1.550 \mathrm{~V}$ vs. RHE for $10 \mathrm{~h}$; (d) LSV plots of samples before and after the stability test. ${ }^{57}$ Reproduced from ref. 57 with permission, (c) 2021 American Chemical Society.

sites, namely octahedral oh and tetrahedral th sites, respectively, in a single structure..$^{22}$ Based on the arrangement of these crystallographic sites, they are classified into two types: one is spinel comprising $\mathrm{A}^{2+}$ on the th site and $\mathrm{B}^{3+}$ on the oh site, and the other one is inverse spinel containing $\mathrm{A}^{2+}$ on the oh site and $\mathrm{B}^{3+}$ on the th site. According to crystal field theory, the TM ions present in the oh and th sites show different d-orbital splitting, i.e., $\mathrm{t}_{2 \mathrm{~g}} \mathrm{e}_{\mathrm{g}}$ for oh and $\mathrm{e}_{\mathrm{g}} \mathrm{t}_{2 \mathrm{~g}}$ for th. This difference in d-orbital splitting plays a significant role in tuning the electronic properties of spinel oxides and optimizing OER performance. ${ }^{71,72}$ Spinel oxides are highly stable in a basic medium with good electrical conductivity under harsh OER conditions. Mn-, Fe-, and Co-based spinel oxides are mostly reported as catalysts for the OER. ${ }^{72}$

4.3.1 $\mathrm{MMn}_{2} \mathrm{O}_{4} \cdot \mathrm{Mn}_{3} \mathrm{O}_{4}$ is a normal spinel with $\mathrm{Mn}^{2+}$ on the th site and $\mathrm{Mn}^{3+}$ on the oh site, and its OER activity in the neutral medium is tuned by doping with various $3 \mathrm{~d}$-block elements such as $\mathrm{Zn}, \mathrm{Cu}, \mathrm{Ni}, \mathrm{Co}, \mathrm{Fe}$, and $\mathrm{Cr}^{80}$ Among them, $5 \% \mathrm{Ni}$ doping showed enhanced OER activity with better OER kinetics. Structural analysis suggests lattice distortion because $\mathrm{Ni}$ doping is a primary reason for improved OER activity. ${ }^{80}$ Doping divalent metals such as $\mathrm{Co}, \mathrm{Zn}$, and $\mathrm{Mg}$ on the th site of
$\mathrm{Mn}_{3} \mathrm{O}_{4}$ spinel results in good electrochemical properties. Specifically, Co doping is proven to be more effective in improving OER activity, and a tetragonal form of $\mathrm{Co}_{x} \mathrm{Mn}_{3-x} \mathrm{O}_{4}$ shows a superior activity compared to the cubic phase. ${ }^{107}$ Enhanced OER activity of the tetragonal phase is made possible by optimizing the binding energies of OER intermediates with the defective Co $(-0.26)$ and $\mathrm{Mn}(-0.60)$ sites, and the bonding energy is much lower than those of the cubic phase sites, with suppressed Jahn-Teller distortion. In $\mathrm{LiMn}_{2} \mathrm{O}_{4}$, lithium is on the th site, and doping of the Mn site significantly improves the OER activity. For instance, Manthiram et al. synthesized different morphologies (cubic, spherical, octahedral, and truncated octahedral) of $\mathrm{LiNi}_{x} \mathrm{Mn}_{2-x} \mathrm{O}_{4}$ and evaluated the electrochemical behavior for oxygen evolution. ${ }^{108} \operatorname{LiNi}_{0.5} \mathrm{Mn}_{1.5} \mathrm{O}_{4}$ displayed enhanced OER activity with octahedral morphology because of the high surface area and fast reaction kinetics facilitated by the $\{111\}$ crystal plane. Dismukes et al. doped $\mathrm{Mg}$ and $\mathrm{Zn}$ in the $\mathrm{Li}$ site and $\mathrm{Co}$ in the $\mathrm{Mn}$ site and found that spinel with the composition of $\mathrm{LiMn}_{0.25} \mathrm{Co}_{1.75} \mathrm{O}_{4}$ exhibits augmented OER activity within this series. ${ }^{78}$ From the mechanism, the superior OER activity is found to be linked with the reduction potential of the $\mathrm{Mn}$ (Iv) cation, and greater reduction potential 
Table 2 Summary of representative doped spinel oxides, hydroxides and other oxides and their catalytic performances

\begin{tabular}{|c|c|c|c|c|}
\hline Catalyst & $\begin{array}{l}\text { Overpotential at a specific } \\
\text { current density }\end{array}$ & $\begin{array}{l}\text { Tafel slope } \\
\left(\mathrm{mV} \mathrm{dec}{ }^{-1}\right)\end{array}$ & Durability & Electrolyte \\
\hline \multicolumn{5}{|l|}{ Spinel oxides } \\
\hline Ag-doped $\mathrm{Co}_{3} \mathrm{O}_{4}$ (ref. 73) & $680 \mathrm{mV} @ 10 \mathrm{~mA} \mathrm{~cm}{ }^{-2}$ & 219 & $10 \mathrm{~h}$ @ $370 \mathrm{mV}$ & $0.5 \mathrm{M} \mathrm{H}_{2} \mathrm{SO}_{4}$ \\
\hline $\mathrm{Co}_{2.25} \mathrm{Cr}_{0.75} \mathrm{O}_{4}$ (ref. 74) & $350 \mathrm{mV}$ @ $10 \mathrm{~mA} \mathrm{~cm}{ }^{-2}$ & 60 & $24 \mathrm{~h} @ 10 \mathrm{~mA} \mathrm{~cm}{ }^{-2}$ & $1 \mathrm{M} \mathrm{NaOH}$ \\
\hline $\mathrm{Cu}$-doped $\mathrm{Co}_{3} \mathrm{O}_{4} \mathrm{NAs} / \mathrm{NF}^{75}$ & $230 \mathrm{mV} @ 10 \mathrm{~mA} \mathrm{~cm} \mathrm{~cm}^{-2}$ & 84 & $20 \mathrm{~h}$ @ $10 \mathrm{~mA} \mathrm{~cm}^{-2}$ & $1 \mathrm{M} \mathrm{KOH}$ \\
\hline Fe-doped $\mathrm{Co}_{3} \mathrm{O}_{4}$ (ref. 76) & $262 \mathrm{mV} @ 10 \mathrm{~mA} \mathrm{~cm} \mathrm{~cm}^{-2}$ & 43 & $50 \mathrm{~h} @ 100 \mathrm{~mA} \mathrm{~cm}{ }^{-2}$ & $1 \mathrm{M} \mathrm{KOH}$ \\
\hline Fe-doped $\mathrm{Co}_{3} \mathrm{O}_{4}$ (ref. 77) & $160 \mathrm{mV} @ 10 \mathrm{~mA} \mathrm{~cm}{ }^{-2}$ & 78 & 〜160 min @1.63 V vs. RHE & $0.1 \mathrm{M} \mathrm{KOH}$ \\
\hline Fe-doped $\mathrm{NiCo}_{2} \mathrm{O}_{4}$ (ref. 33) & $201 \mathrm{mV}$ @ $10 \mathrm{~mA} \mathrm{~cm}{ }^{-2}$ & 39 & $12 \mathrm{~h}$ @ $10 \mathrm{~mA} \mathrm{~cm}{ }^{-2}$ & $1 \mathrm{M} \mathrm{KOH}$ \\
\hline $\mathrm{LiMn}_{0.25} \mathrm{Co}_{1.75} \mathrm{O}_{4}$ (ref. 78) & $370 \mathrm{mV}$ @ $10 \mathrm{~mA} \mathrm{~cm} \mathrm{~cm}^{-2}$ & 60 & - & $1 \mathrm{M} \mathrm{NaOH}$ \\
\hline $\mathrm{Mn}_{1.4} \mathrm{Co}_{1.6} \mathrm{O}_{4}$ (ref. 79) & $327 \mathrm{mV} @ 10 \mathrm{~mA} \mathrm{~cm}{ }^{-2}$ & 79 & $25 \mathrm{~h} @ 1.53 \mathrm{~V} v s . \mathrm{RHE}$ & $1 \mathrm{M} \mathrm{KOH}$ \\
\hline Ni-doped $\mathrm{Mn}_{3} \mathrm{O}_{4}$ (ref. 80 ) & $458 \mathrm{mV} @ 10 \mathrm{~mA} \mathrm{~cm}{ }^{-2}$ & 74.4 & $21 \mathrm{~h}$ @ $10 \mathrm{~mA} \mathrm{~cm}{ }^{-2}$ & $3 \mathrm{M} \mathrm{NaCl}$ \\
\hline NPCoO-UCSs ${ }^{81}$ & $182 \mathrm{mV}$ @ $10 \mathrm{~mA} \mathrm{~cm}{ }^{-2}$ & 54 & $50000 \mathrm{~s} @ 1.42 \mathrm{~V} v s . \mathrm{RHE}$ & $0.1 \mathrm{M} \mathrm{KOH}$ \\
\hline $\mathrm{P}_{8.6}-\mathrm{Co}_{3} \mathrm{O}_{4} / \mathrm{NF}^{82}$ & $260 \mathrm{mV}$ @ $20 \mathrm{~mA} \mathrm{~cm}^{-2}$ & 60 & $25 \mathrm{~h}$ @ $1.53 \mathrm{~V} v s . \mathrm{RHE}$ & $1 \mathrm{M} \mathrm{KOH}$ \\
\hline $\mathrm{P}-\mathrm{Co}_{3} \mathrm{O}_{4}$ (ref. 83) & $280 \mathrm{mV} @ 20 \mathrm{~mA} \mathrm{~cm}{ }^{-2}$ & 51.6 & $40000 \mathrm{~s}$ @ $280 \mathrm{mV}$ & $1 \mathrm{M} \mathrm{KOH}$ \\
\hline $\mathrm{Se} / \mathrm{Ni}-\mathrm{Co}_{3} \mathrm{O}_{4}$ (ref. 84) & $290 \mathrm{mV} @ 20 \mathrm{~mA} \mathrm{~cm}{ }^{-2}$ & 62.9 & - & $1 \mathrm{M} \mathrm{KOH}$ \\
\hline V-doped $\mathrm{Co}_{3} \mathrm{O}_{4}$ (ref. 85) & $293.6 \mathrm{mV} @ 10 \mathrm{~mA} \mathrm{~cm}{ }^{-2}$ & 53.3 & $30 \mathrm{~h}$ @ $5 \mathrm{~mA} \mathrm{~cm}{ }^{-2}$ & $1 \mathrm{M} \mathrm{KOH}$ \\
\hline \multicolumn{5}{|l|}{ Hydroxides } \\
\hline Ce-doped NiFe LDH/CNT ${ }^{86}$ & $227 \mathrm{mV}$ @ $10 \mathrm{~mA} \mathrm{~cm}{ }^{-2}$ & 33 & $30000 \mathrm{~s} @ 10 \mathrm{~mA} \mathrm{~cm}{ }^{-2}$ & $1 \mathrm{M} \mathrm{KOH}$ \\
\hline $\mathrm{Co}_{0.54} \mathrm{Fe}_{0.46} \mathrm{OOH}^{87}$ & $290 \mathrm{mV}$ @ $10 \mathrm{~mA} \mathrm{~cm}{ }^{-2}$ & 47 & - & $0.1 \mathrm{M} \mathrm{KOH}$ \\
\hline $\mathrm{Cu}$-doped $\mathrm{Co}(\mathrm{OH})_{2}$ (ref. 88) & $300 \mathrm{mV} @ 10 \mathrm{~mA} \mathrm{~cm}{ }^{-2}$ & 47 & $36 \mathrm{~h}$ @ $1.55 \mathrm{~V} v s . \mathrm{RHE}$ & $1 \mathrm{M} \mathrm{KOH}$ \\
\hline Fe-doped $\mathrm{Co}(\mathrm{OH})_{2}$ (ref. 89) & $290 \mathrm{mV}$ @ $10 \mathrm{~mA} \mathrm{~cm}{ }^{-2}$ & 69 & $12 \mathrm{~h}$ @ $10 \mathrm{~mA} \mathrm{~cm}{ }^{-2}$ & $1 \mathrm{M} \mathrm{KOH}$ \\
\hline $\mathrm{Fe}-\mathrm{NiOOH}^{90}$ & $181 \mathrm{mV}$ @ $50 \mathrm{~mA} \mathrm{~cm}{ }^{-2}$ & 43.2 & $56 \mathrm{~h}$ @ $20 \mathrm{~mA} \mathrm{~cm}{ }^{-2}$ & $1 \mathrm{M} \mathrm{NaOH}$ \\
\hline Mn and $\mathrm{F}$ dual-doped $\mathrm{Ni}(\mathrm{OH})_{2}$ (ref. 91) & $233 \mathrm{mV}$ @ $20 \mathrm{~mA} \mathrm{~cm}^{-2}$ & 56.9 & $10 \mathrm{~h} @ 20 \mathrm{~mA} \mathrm{~cm}{ }^{-2}$ & $1 \mathrm{M} \mathrm{KOH}$ \\
\hline Ni-doped $\mathrm{Co}(\mathrm{OH})_{2}$ (ref. 92) & $300 \mathrm{mV} @ 10 \mathrm{~mA} \mathrm{~cm} \mathrm{~cm}^{-2}$ & 47 & $36 \mathrm{~h}$ @ $1.55 \mathrm{~V} v s . \mathrm{RHE}$ & $1 \mathrm{M} \mathrm{KOH}$ \\
\hline Ni-doped FeOOH ${ }^{93}$ & $239 \mathrm{mV}$ @ $10 \mathrm{~mA} \mathrm{~cm}{ }^{-2}$ & 90.4 & - & $1 \mathrm{M} \mathrm{KOH}$ \\
\hline $\mathrm{Ni}_{0.83} \mathrm{Fe}_{0.17}(\mathrm{OH})_{2}$ (ref. 94) & $245 \mathrm{mV}$ @ $10 \mathrm{~mA} \mathrm{~cm}{ }^{-2}$ & 61 & $10 \mathrm{~h}$ @ $10 \mathrm{~mA} \mathrm{~cm}{ }^{-2}$ & $1 \mathrm{M} \mathrm{KOH}$ \\
\hline Se-doped $\mathrm{FeOOH}^{95}$ & $348 \mathrm{mV} @ 500 \mathrm{~mA} \mathrm{~cm}{ }^{-2}$ & 54 & $100 \mathrm{~h} @ 100 \mathrm{~mA} \mathrm{~cm}{ }^{-2}$ & $1 \mathrm{M} \mathrm{KOH}$ \\
\hline W-doped $\mathrm{Ni}(\mathrm{OH})_{2}($ ref. 96) & 237 mV@10 mA cm ${ }^{-2}$ & 33 & - & $1 \mathrm{M} \mathrm{KOH}$ \\
\hline \multicolumn{5}{|l|}{ Other oxides } \\
\hline Ce-doped NiO-Au ${ }^{97}$ & $244 \mathrm{mV} @ 100 \mathrm{~mA} \mathrm{~cm}{ }^{-2}$ & & $>24 \mathrm{~h}$ @ $50 \mathrm{~mA} \mathrm{~cm}{ }^{-2}$ & $1 \mathrm{M} \mathrm{KOH}$ \\
\hline Co-doped $\mathrm{CuO}^{98}$ & $299 \mathrm{mV} @ 50 \mathrm{~mA} \mathrm{~cm}{ }^{-2}$ & 134 & $15 \mathrm{~h}$ @ $300 \mathrm{mV}$ & $1 \mathrm{M} \mathrm{KOH}$ \\
\hline $\mathrm{Co}-\mathrm{MnO}_{2} / \mathrm{O}_{\mathrm{V}}{ }^{99}$ & $279 \mathrm{mV}$ @ $20 \mathrm{~mA} \mathrm{~cm}^{-2}$ & 75 & $12 \mathrm{~h}$ @ $10 \mathrm{~mA} \mathrm{~cm}{ }^{-2}$ & $1 \mathrm{M} \mathrm{KOH}$ \\
\hline Co-doped $\mathrm{ZnO}^{100}$ & $450 \mathrm{mV}$ @ $10 \mathrm{~mA} \mathrm{~cm}{ }^{-2}$ & 106 & $18 \mathrm{~h} @ 1.68 \mathrm{~V} v s . \mathrm{RHE}$ & 0.1 M phosphate-buffered saline \\
\hline $\mathrm{Fe}-\mathrm{CoO} / \mathrm{C}$ nanofibers ${ }^{101}$ & $362 \mathrm{mV} @ 10 \mathrm{~mA} \mathrm{~cm} \mathrm{~cm}^{-2}$ & 74.4 & - & $1 \mathrm{M} \mathrm{KOH}$ \\
\hline $\mathrm{Ni}_{x} \mathrm{Co}_{1-x} \mathrm{O}^{102}$ & $450 \mathrm{mV} @ 10 \mathrm{~mA} \mathrm{~cm}{ }^{-2}$ & 66.8 & - & $1 \mathrm{M} \mathrm{KOH}$ \\
\hline Ni-doped $\mathrm{MnO}_{2}$ (ref. 103) & $330 \mathrm{mV}$ @ $10 \mathrm{~mA} \mathrm{~cm}{ }^{-2}$ & 23.7 & $>3 \mathrm{~h}$ @ $10 \mathrm{~mA} \mathrm{~cm}{ }^{-2}$ & $1 \mathrm{M} \mathrm{KOH}$ \\
\hline $\mathrm{V}-, \mathrm{Fe}-, \mathrm{Co}-$ and Ni-doped $\mathrm{MnO}_{2}$ (ref. 104) & $390 \mathrm{mV} @ 10 \mathrm{~mA} \mathrm{~cm}{ }^{-2}$ & 104.4 & $>27 \mathrm{~h}$ @ $20 \mathrm{~mA} \mathrm{~cm}{ }^{-2}$ & $1 \mathrm{M} \mathrm{KOH}$ \\
\hline $\mathrm{Y}_{2-x} \mathrm{Ba}_{x} \mathrm{Ru}_{2} \mathrm{O}_{7}$ (ref. 105) & $278 \mathrm{mV}$ @ $10 \mathrm{~mA} \mathrm{~cm}{ }^{-2}$ & 40.8 & $5 \mathrm{~h} @ 10 \mathrm{~mA} \mathrm{~cm}-2$ & $0.5 \mathrm{M} \mathrm{H}_{2} \mathrm{SO}_{4}$ \\
\hline Zn-doped $\mathrm{CoO}^{106}$ & $293 \mathrm{mV} @ 10 \mathrm{~mA} \mathrm{~cm} \mathrm{~cm}^{-2}$ & 63 & $24 \mathrm{~h}$ @ $10 \mathrm{~mA} \mathrm{~cm}^{-2}$ & $1 \mathrm{M} \mathrm{KOH}$ \\
\hline
\end{tabular}

facilitates improved kinetics by directly driving surface oxidation.

4.3.2 $\mathrm{MFe}_{2} \mathrm{O}_{4} \cdot \mathrm{CoFe}_{2} \mathrm{O}_{4}$ is an inverse spinel, in which oneeighth of the th sites are occupied by $\mathrm{Fe}^{3+}$ and one-half of the oh sites are occupied by $\mathrm{Co}^{2+}$ ions. The presence of such an arrangement provides good electrical conductivity as a consequence of electron hopping between valence states of cations on oh sites. It thus facilitates good electrochemical activity and produces longer stability in electrocatalytic reactions. ${ }^{109-111}$ Doping of $\mathrm{Co}$ and Fe sites significantly influences the electrocatalytic activity of $\mathrm{CoFe}_{2} \mathrm{O}_{4}$. For example, $\mathrm{Ni}$ and $\mathrm{Mn}$ are doped in $\mathrm{CoFe}_{2} \mathrm{O}_{4}$ at the $\mathrm{Fe}$ site by stoichiometric mixing of $\mathrm{Co}_{3} \mathrm{O}_{4}$, $\mathrm{Fe}_{2} \mathrm{O}_{3}$, NiO, and $\mathrm{MnO}_{2}$ using a solid-state synthesis. ${ }^{109}$ The Nidoped one displayed the lowest overpotential of $260 \mathrm{mV}$, which is attributed to $\mathrm{Co}(\mathrm{II} / \mathrm{III})$ on oh sites along with $\mathrm{Co}(\mathrm{III})$ on th sites of the inverse spinel. Similarly, Ni doping at the Co site was also evaluated by synthesizing hollow nanospheres via a hydrothermal route. The inverse spinel $\mathrm{Ni}_{0.75} \mathrm{Co}_{0.25} \mathrm{Fe}_{2} \mathrm{O}_{4}$ showed the best OER activity, which is ascribed to the oxygen defects and cation distribution ratio on th and oh sites. ${ }^{109}$ Singh et al. reported improved OER activity of $\mathrm{CoFe}_{2} \mathrm{O}_{4}$ through $\mathrm{Cr}$ doping at $\mathrm{Fe}$ site $\left(\mathrm{CoFe}_{2-x} \mathrm{Cr}_{x} \mathrm{O}_{4}\right)$, and the catalyst with the $\mathrm{CoFeCrO}_{4}$ composition shows high OER activity because of fast discharge of $\mathrm{OH}^{-}{ }^{111} \mathrm{Cr}$ doping of $\mathrm{NiFe}_{2} \mathrm{O}_{4}$ at the Fe site also shows a similar result, and $\mathrm{NiFeCrO}_{4}$ displayed superior activity within this series. Cr doping at the $\mathrm{Fe}$ site of $\mathrm{MnFe}_{2} \mathrm{O}_{4}$ and $\mathrm{CuFe}_{2} \mathrm{O}_{4}$ inverse spinels also showed improved OER activity. Doping pentavalent $\mathrm{V}$ into the lattice of $\mathrm{NiFe}_{2} \mathrm{O}_{4}$ significantly improves OER activity as well as its stability, which could be a consequence of the increased amount of $\mathrm{Fe}_{2} \mathrm{O}_{3}$ in the host lattice, along with enriched surface porosity. ${ }^{110}$

4.3.3 $\mathrm{MCo}_{2} \mathrm{O}_{4} \cdot \mathrm{Co}_{3} \mathrm{O}_{4}$ is a normal spinel, whose $\mathrm{Co}^{2+}$ ions occupy th sites, while $\mathrm{Co}^{3+}$ ions occupy oh sites. It has been a well-known electrocatalyst for the OER in the past few decades 
in alkaline media, owing to its high activity, long stability and low cost. However, pristine $\mathrm{Co}_{3} \mathrm{O}_{4}$ suffers from poor electrocatalytic activity on account of its low electronic conductivity. Doping elements like $\mathrm{V},{ }^{85} \mathrm{Cr},{ }^{74} \mathrm{Fe},{ }^{76,77} \mathrm{Ni},{ }^{112} \mathrm{Cu},{ }^{75} \mathrm{Zn},{ }^{81} \mathrm{Ag},{ }^{73}$ and $\mathrm{Li}^{113}$ into the lattice of $\mathrm{Co}_{3} \mathrm{O}_{4}$ spinel tunes its electronic structure, thus significantly improving OER activity. Incorporation of vanadium into the lattice of $\mathrm{Co}_{3} \mathrm{O}_{4}$ through doping produces a highly disordered and defect-rich surface lattice, which essentially contributes to the OER and increases its stability in an extreme OER environment. Furthermore, DFT calculations and a methanol oxidation probing method revealed that decreased energy of the RDS barrier is key to the superior activity of $\mathrm{V}$-doped $\mathrm{Co}_{3} \mathrm{O}_{4} \cdot{ }^{85}$ The DFT calculations were performed on pristine and doped $\mathrm{Co}_{3} \mathrm{O}_{4}$ (100) surfaces with different OER intermediates. After V doping, the Gibbs free energy change is decreased from $1.73 \mathrm{eV}$ (pristine) to $1.57 \mathrm{eV}$ for the RDS, which is in accordance with methanol oxidation probing. ${ }^{85}$ McCrory's group demonstrated the augmentation of OER performance of $\mathrm{Co}_{3} \mathrm{O}_{4}$ by the inclusion of a discrete amount of chromium $\left(\mathrm{Co}_{3-x} \mathrm{Cr}_{x} \mathrm{O}_{4}\right) \cdot{ }^{74} \mathrm{Co}_{2.25} \mathrm{Cr}_{0.75} \mathrm{O}_{4}$ is the most active one within the series, and its high activity is found to be caused by the increased electrophilic nature of $\mathrm{Co}^{2+}$ ions, thus enhancing the interaction between ${ }^{*} \mathrm{O},{ }^{*} \mathrm{OH}$, and ${ }^{*} \mathrm{OOH}$ and active sites. Lou's group doped 13 metal atoms into the lattice of ultrathin nanosheets on the th sites of $\mathrm{Co}_{3} \mathrm{O}_{4}$ via a cooperative etching-coordination-reorganization approach. ${ }^{76}$ Among these 13 atoms, doping of a discrete amount of Fe greatly increases the electrocatalytic OER activity. Fig. 8a shows the schematic representation of the synthesis of Fe-doped $\mathrm{Co}_{3} \mathrm{O}_{4}$ hierarchically hollow NPs $\left(\mathrm{Fe}-\mathrm{Co}_{3} \mathrm{O}_{4} \mathrm{HHNPs}\right)$. Fig. 8b-e show the SEM, HR-TEM, high-angle annular dark-field scanning TEM (HAADFSTEM), and elemental mapping images of $\mathrm{Fe}-\mathrm{Co}_{3} \mathrm{O}_{4} \mathrm{HHNPs}$, respectively, which reveal that NPs are uniform having an edge size of $900 \mathrm{~nm}$ and a uniform distribution of a small amount of Fe. From the DFT calculations, it was found that decreased adsorption energy from 1.90 to $1.54 \mathrm{eV}$ for converting *OH to *O species is a major cause.

In another report, Swaminathan et al. demonstrated how minute changes in the amount of Fe doping influenced the OER activity of $\mathrm{Co}_{3} \mathrm{O}_{4} \cdot{ }^{77}$ They doped $3,4.5$, and $6 \%$ of Fe into the host

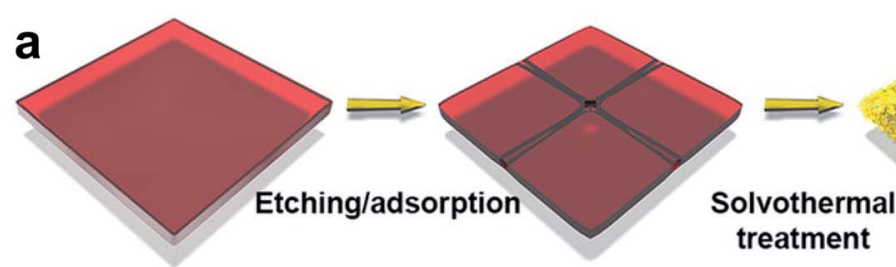

ZIF-67 nanoplate (NP)
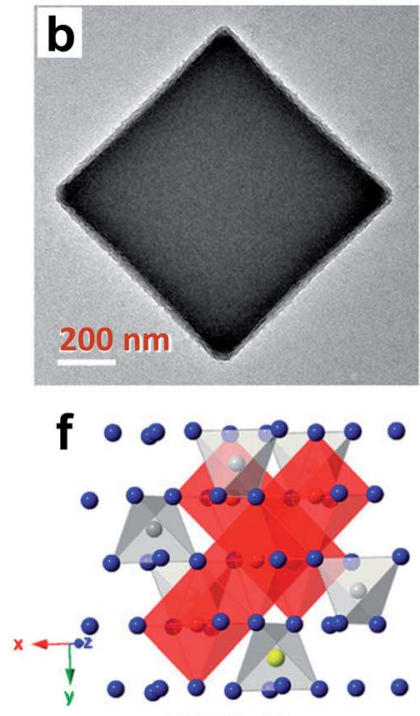

$-313.58 \mathrm{eV}$
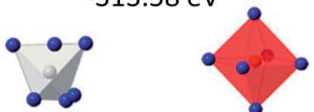

Tetrahedral site Octahedral site
Fe-ZIF-67 NP
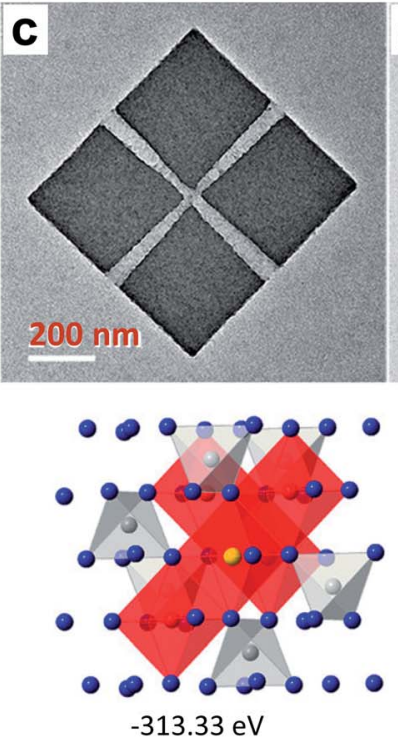

- $\mathrm{Ni}$ or Co $\mathrm{Fe}$

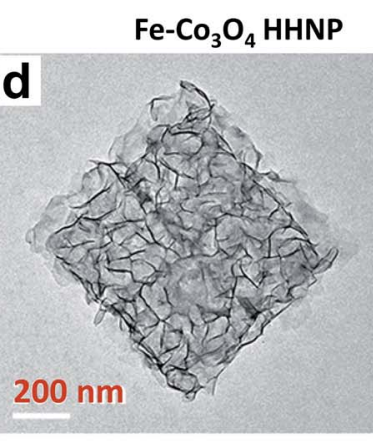

g

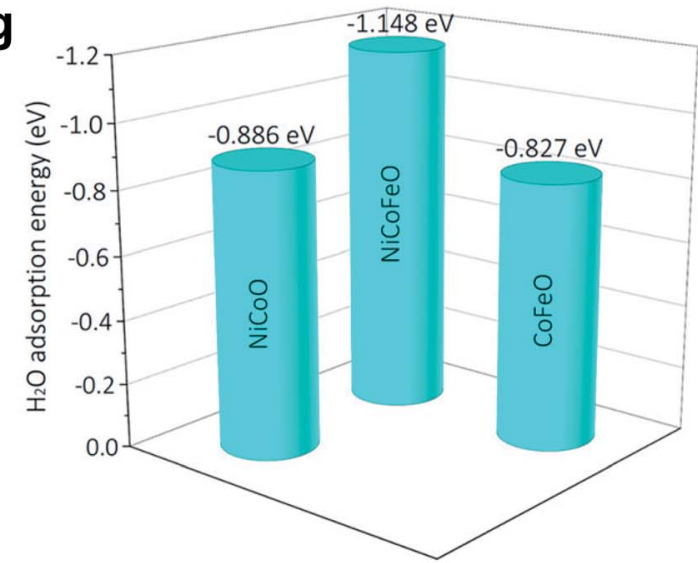

Fig. 8 (a) Schematic synthesis process of cross-channeled $\mathrm{Fe}-\mathrm{CO}_{3} \mathrm{O}_{4}$ hierarchically hollow NPs (HHNPs); (b-d) TEM images of ZIF-67 NPs; (e) HAADF-STEM image and elemental mapping images of one $\mathrm{Fe}-\mathrm{CO}_{3} \mathrm{O}_{4} \mathrm{HHNP}{ }^{76}$ Reproduced with open access. (f) Schematic illustration of the preference of Fe doping into tetrahedral sites of $\mathrm{Ni}-\mathrm{Co}-\mathrm{O}$ spinel oxides, and (g) adsorption energy of an $\mathrm{H}_{2} \mathrm{O}$ molecule on the (001) surface of $\mathrm{Ni}-\mathrm{Co}-\mathrm{O}, \mathrm{Co}-\mathrm{Fe}-\mathrm{O}$, and $\mathrm{Ni}-\mathrm{Co}-\mathrm{Fe}-\mathrm{O}$ spinels. ${ }^{33}$ Reproduced from ref. 33 with permission, () 2019 American Chemical Society. 
lattice and observed that above or below the optimum level of $\mathrm{Fe}$ doping, fading of OER activity occurred. The 4.5\% Fe doping caused superior activity, and the DFT study identified a considerable downshift of the Fermi energy level, originating from the optimized adsorption energy of reaction intermediates. By comparing $\mathrm{Ni}, \mathrm{Cu}$, and Li dopants, Vitanov et al. studied the effectiveness of doping in improving the OER activity of $\mathrm{Co}_{3} \mathrm{O}_{4}$ spinel and noticed that doping with $\mathrm{Li}\left(\mathrm{Li}_{x} \mathrm{Co}_{3-x} \mathrm{O}_{4}\right)$ produced a promising activity. ${ }^{113}$ The raised activity of $\mathrm{Li}_{x^{-}}$ $\mathrm{Co}_{3-x} \mathrm{O}_{4}$ spinel is ascribed to faster reaction kinetics owing to the formation of active sites with high transfer coefficients, and a shortened reaction pathway to generate oxygen. Tian et al. revealed the $\mathrm{Cu}$ doping effect on improving the OER activity of $\mathrm{Co}_{3} \mathrm{O}_{4}$ nanosheets prepared on nickel foam, which outperforms the benchmark catalyst $\mathrm{IrO}_{2}$ on nickel foam. ${ }^{75}$ The high OER activity is found to have resulted from an increase in $\mathrm{Co}$ (III) species in the crystal lattice, along with highly uncovered active sites. Ding et al. demonstrated the improved OER performance of $\mathrm{Co}_{3} \mathrm{O}_{4}$ nanosheets by creation of oxygen vacancies upon $\mathrm{Zn}$ doping, which even surpassed that of the Ir/C catalyst. ${ }^{\mathbf{} 1}$

The stability and activity of $\mathrm{Co}_{3} \mathrm{O}_{4}$ spinel could be significantly enhanced in acidic electrolyte through $\mathrm{Ag}$ doping. Ag doping plays a crucial role in the growth of $\mathrm{Co}_{3} \mathrm{O}_{4}$ nanowire arrays, improving the surface area and stability under harsh acidic conditions and OER activity by providing shortened reaction paths. ${ }^{73} \mathrm{Ni}_{x} \mathrm{Co}_{2-x} \mathrm{O}_{4}$ is an inverse spinel, in which $\mathrm{Ni}(\mathrm{II} / \mathrm{III})$ is present in $16 \mathrm{~d}$ oh sites and $\mathrm{Co}(\mathrm{II} / \mathrm{III})$ is present in both $8 \mathrm{a}$ th sites and $16 \mathrm{~d}$ oh sites. By tuning the Ni doping level, this inverse spinel's OER activity significantly increased, because the $\mathrm{Ni}^{2+} / \mathrm{Ni}^{3+}$ ratio plays a key role in governing the conductivity, surface roughness, and density of active sites. For example, Zhang et al. systematically studied the influence of an increase in the $\mathrm{Ni}$ dopant level to improve the overall OER performance of $\mathrm{Ni}_{x} \mathrm{Co}_{2-x} \mathrm{O}_{4} \cdot{ }^{112}$ When $x=1$, it shows superior OER activity. In this composition, $\mathrm{Ni}$ is in the +3 oxidation state. The enhanced OER activity is a result of the $0.27 \mathrm{eV}$ upshifting of the valence band maximum toward the Fermi level, which creates a new hole. Such an electronic configuration favors the adsorption of OER intermediates. ${ }^{112}$ The doping of $\mathrm{Fe}$ at the Ni site of $\mathrm{NiCO}_{2} \mathrm{O}_{4}$ induces oxygen vacancies, which impacts the OER activity considerably. The $\mathrm{Fe}_{0.1} \mathrm{Ni}_{0.9} \mathrm{Co}_{2} \mathrm{O}_{4}$ composition shows superior activity within the doped series, which is accredited to the presence of an optimum amount of oxygen defects for triggering electrocatalytic activity. ${ }^{\mathbf{1 1 4}}$ Huang's group reported doping Fe into the th site of the $\mathrm{NiCo}_{2} \mathrm{O}_{4}$ lattice to improve its OER activity through a theoretical prediction. ${ }^{33}$ As displayed in Fig. 8f, incorporation of $\mathrm{Fe}$ into the th site requires a lower energy $(313.33 \mathrm{eV})$ compared to the oh site (313.58 eV) according to DFT calculations. Fig. $8 \mathrm{~g}$ shows the DFT estimated $\mathrm{H}_{2} \mathrm{O}$ adsorptive ability where the Fe-doped one is superior to the pristine one and $\mathrm{CoFe}_{2} \mathrm{O}_{4}$, which is highly favorable for improving OER performance to increase active sites. Furthermore, X-ray absorption spectroscopy confirms the successful incorporation of $\mathrm{Fe}$ into the th site of $\mathrm{NiCo}_{2} \mathrm{O}_{4}$, which enhances the OER performance by increasing the population of $\mathrm{Ni}^{3+}$ and $\mathrm{Co}^{2+}$ ions in oh sites. $\mathrm{Mn}_{x} \mathrm{Co}_{2-x} \mathrm{O}_{4}$ is also an inverse spinel, and Mn cations preferably occupy oh sites. Lankauf et al. described $\mathrm{Mn}_{x} \mathrm{Co}_{2-x} \mathrm{O}_{4}$ spinel by adjusting the composition of $\mathrm{Mn}(x=0-2)$ using a soft chemistry method, and the spinel with a moderate content of Mn shows better OER activity. ${ }^{79}$ The high activity was attributed to the improved oxidizing ability and better electronic conductivity. Chi et al. noticed that the change in copper content in the $\mathrm{Cu}_{x} \mathrm{Co}_{2-x} \mathrm{O}_{4}$ spinel could influence its OER properties. ${ }^{115}$ When $x$ was increased from 0.7 to 0.9 , more $\mathrm{Cu}^{2+}$ ions displaced $\mathrm{Co}^{3+}$ ions from oh sites. They occupy th sites, and thus the $\mathrm{Co}^{3+}$ ion population on th sites was significantly increased, resulting in superior OER performance.

$\mathrm{Li}$ and coworkers reported an increase in the OER performance of the $\mathrm{NiCo}_{2} \mathrm{O}_{4}$ catalyst through double-exchange interaction (DEI). ${ }^{72}$ The DEI is induced by synergistic creation of oxygen vacancies $\left(\mathrm{V}_{\mathrm{O}}\right)$ via doping with $\mathrm{Fe}$ and creating a heterojunction with $\mathrm{MoS}_{2}\left(\mathrm{MoS}_{2} / \mathrm{rFe}-\mathrm{NiCO}_{2} \mathrm{O}_{4}\right)$ as shown in Fig. 9a. Fig. 9b and c show the SEM and TEM images of the $\mathrm{MoS}_{2} / \mathrm{rFe}-\mathrm{NiCo}_{2} \mathrm{O}_{4}$ catalyst, which is in the form of nanowires having a diameter of 50-60 nm, decorated with $\mathrm{MoS}_{2}$ on $\mathrm{Fe}-\mathrm{NiCO}_{2} \mathrm{O}_{4}$. Fig. 9d displays the comparative OER activity of $\mathrm{NoCo}_{2} \mathrm{O}_{4}, \mathrm{Fe}-\mathrm{NoCo}_{2} \mathrm{O}_{4}, \mathrm{MoS}_{2} / \mathrm{Fe}-$ $\mathrm{NoCo}_{2} \mathrm{O}_{4}, \mathrm{rFe}-\mathrm{NoCo}_{2} \mathrm{O}_{4}$ and $\mathrm{MoS}_{2} / \mathrm{rFe}-\mathrm{NoCo}_{2} \mathrm{O}_{4}$ catalysts, which reveals that DEI has the most powerful effect on enhancing OER activity. Fig. 9e shows the schematic representation of the effect of DEI on enhancing the OER activity of $\mathrm{MoS}_{2} / \mathrm{rFe}-\mathrm{NiCo}_{2} \mathrm{O}_{4}$ through improving electrical conductivity, number of OER active sites, and reactivity of active centers. Recently, non-metal doping into $\mathrm{Co}_{3} \mathrm{O}_{4}$ was studied for improving electrochemical activity. For instance, Sun's group reported P-doped $\mathrm{Co}_{3} \mathrm{O}_{4}$ nanowires as an efficient OER catalyst in basic electrolyte. ${ }^{82}$ The P-doped $\mathrm{Co}_{3} \mathrm{O}_{4}$ nanowires on nickel foam were prepared by low-temperature annealing using $\mathrm{NaH}_{2} \mathrm{PO}_{2}$. First-principles calculations revealed that $\mathrm{P}$ doped $\mathrm{Co}_{3} \mathrm{O}_{4}$ nanowires have a much lower free-energy value for the rate-determining step than pristine $\mathrm{Co}_{3} \mathrm{O}_{4} \cdot{ }^{82}$ Wang et al. synthesized P-doped $\mathrm{Co}_{3} \mathrm{O}_{4}$ spinel by filling the in situ generated oxygen vacancies using an Ar plasma etching technique, and observed excellent OER activities after doping. ${ }^{83}$ When oxygen vacancies were created in $\mathrm{Co}_{3} \mathrm{O}_{4}$, more electrons migrated into oh $\mathrm{Co}^{3+} 3 \mathrm{~d}$ orbitals than th $\mathrm{Co}^{2+} 3 \mathrm{~d}$ orbitals. With $\mathrm{P}$ doping, electrons are transferred out of the Co $3 \mathrm{~d}$ states, resulting in more $\mathrm{Co}^{2+}$ on th sites than $\mathrm{Co}^{3+}$ on oh sites in $\mathrm{P}-\mathrm{Co}_{3} \mathrm{O}_{4}$. Hence, the superior OER activity of the P-doped $\mathrm{Co}_{3} \mathrm{O}_{4}$ is linked with the presence of a greater number of $\mathrm{Co}^{2+}$ ions. Zhang et al. reported doping of $\mathrm{Co}_{3} \mathrm{O}_{4}$ with $\mathrm{S}$ by using facile solution-combustion and thioacetamide-sulfidation methods. ${ }^{\mathbf{1 1 6}}$ The S-doping enhances the OER performance of $\mathrm{Co}_{3} \mathrm{O}_{4}$ in terms of activity as well as stability in an alkaline medium. The formation of S-substituted CoO layers on the surface of $\mathrm{Co}_{3} \mathrm{O}_{4}$ is a major reason for the superior activity. Theoretical calculations indicate that improving the electronic conductivity by $\mathrm{S}$ doping was beneficial for overall electrochemical activity. Dual doping of $\mathrm{Co}_{3} \mathrm{O}_{4}$ on both cation and anion sites with $\mathrm{Ni}$ and Se, respectively, resulted in a significant increase in its OER performance. ${ }^{84}$ The Se doping enhances the active sites on the surface of a catalyst by inducing oxygen vacancies, and $\mathrm{Ni}$ doping helps in generating highly active $\mathrm{Co}^{4+}$ species.

\subsection{Hydroxides}

Hydroxides, oxyhydroxides, and layered double hydroxides (LDHs) of oxides of TMs, such as Ni, Co, Fe, Mn, and V, are 

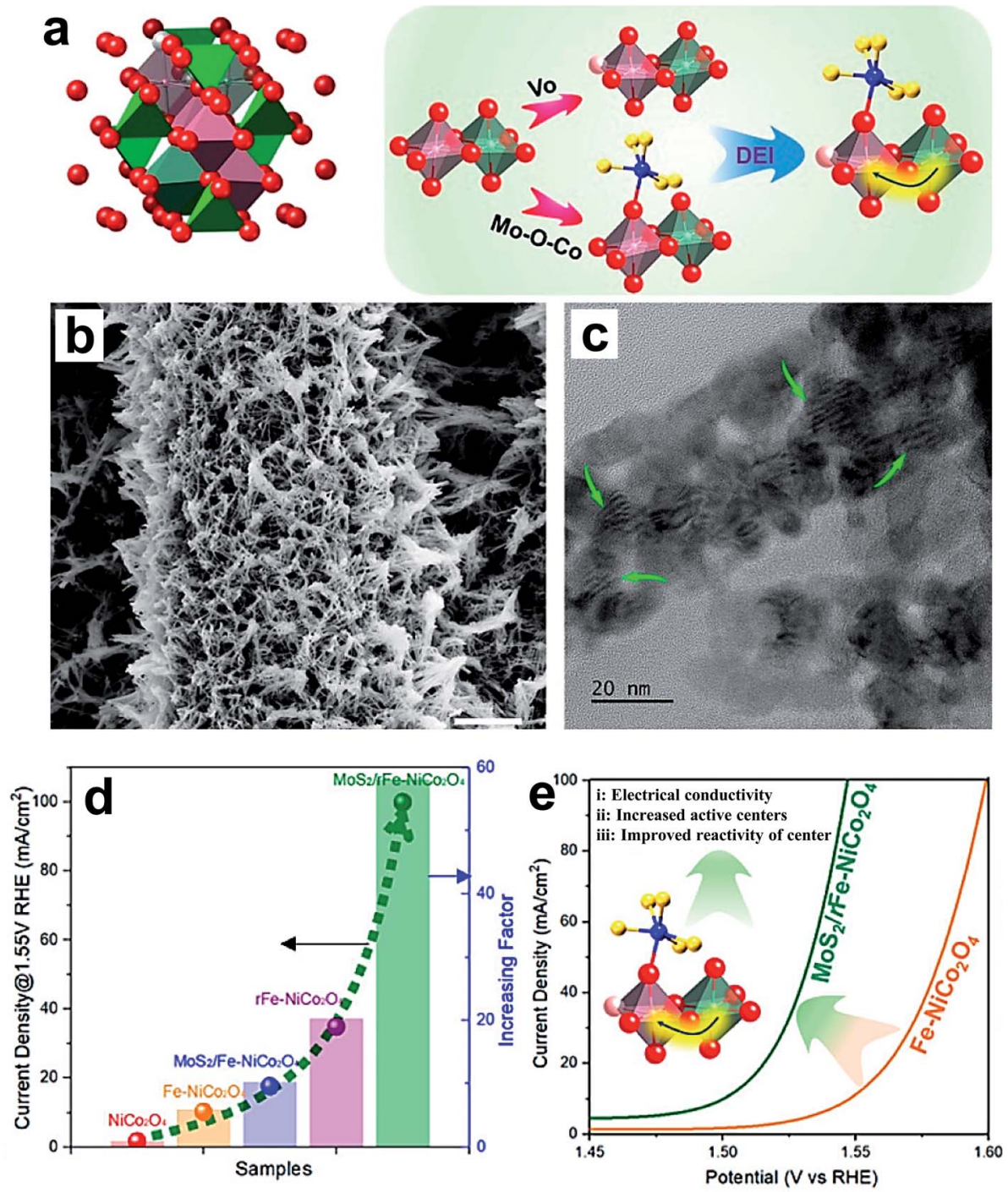

Fig. 9 (a) Crystal structure of spinel oxides, and the creation of a double-exchange interaction (DEI); (b) SEM and (c) TEM images of MoS $2 / r F e-$ $\mathrm{NiCO}_{2} \mathrm{O}_{4}$; (d) OER performance of the electrocatalysts $\mathrm{NiCO}_{2} \mathrm{O}_{4}, \mathrm{Fe}-\mathrm{NiCO}_{2} \mathrm{O}_{4}, \mathrm{MoS}_{2} / \mathrm{Fe}-\mathrm{NiCO}_{2} \mathrm{O}_{4}, \mathrm{rFe}-\mathrm{NiCO}_{2} \mathrm{O}_{4}$, and $\mathrm{MoS}_{2} / \mathrm{rFe}-\mathrm{NiCO} \mathrm{O}_{4}$ with respect to current density at $1.55 \mathrm{~V}$ RHE and the current density increasing factor; (e) schematic representation of the enhanced $\mathrm{OER}$ arising from the DEl effect. ${ }^{72}$ Reproduced from ref. 72 with permission, ( 2020 American Chemical Society.

highly active in the electrocatalytic oxygen evolution reaction. ${ }^{\mathbf{8 6 1 1 7 , 1 1 8}}$ They exhibit typical layered stacking conformation with proton sandwiching between layers, and the metal is centered in the octahedron surrounded by oxygen anions at the corners as $\mathrm{MO}_{6} \cdot{ }^{117}$ Some representative hydroxides and their catalytic performances are listed in Table 2 .

Fe doping of TM hydroxides is most widely reported in the literature for enhancing their OER performance. ${ }^{119}$ Specifically, Fe doping in $\mathrm{Ni}(\mathrm{OH})_{2}$ (ref. 94 and 120-123) and $\mathrm{Co}(\mathrm{OH})_{2}$ (ref. 89 and 124-126) has been widely studied. In 1901, Edison, ${ }^{127}$ for the first time, noticed an increase in the OER activity of $\mathrm{Ni}(\mathrm{OH})_{2}$ because of Fe impurity in the electrolyte in a Ni-based alkaline battery. ${ }^{\mathbf{1 2 0 , 1 2 8}}$ Because of oxygen evolution, the capacitance and cycle life of the battery were decreased considerably by the incorporation of $\mathrm{Fe}$ into the $\mathrm{Ni}(\mathrm{OH})_{2}$ electrode. Later, researchers revealed that the OER activity of $\mathrm{Ni}(\mathrm{OH})_{2}$ shortened the voltage window of the battery owing to the presence of Fe in the electrolyte, and they also found that the presence of a discrete amount of Fe $(<1 \%)$ considerably contributed to augmentation of OER activity. ${ }^{\mathbf{1 2 9}}$ Corrigan demonstrated that the presence of $0.01 \%$ Fe impurity in electrolytes substantially decreased the discharge capacitance. ${ }^{\mathbf{1 3 0}}$

Boettcher's group studied the role of Fe doping in enhancing the OER performance of $\mathrm{Ni}(\mathrm{OH})_{2}$ thin films and provided more insights on catalytic reactions at the electrode/electrolyte interface. ${ }^{\mathbf{1 2 2 , 1 2 4 - 1 2 6}}$ They witnessed an increase in conductivity of thin films with systematically increasing the doping amount from 5 to $25 \%$. Still, the CV curves show drastic changes, which signify the change in surface reconstruction with varying dopant levels. ${ }^{122}$ Klaus et al. studied the Fe inclusion by aging the thin films in an electrolyte with or without Fe impurities for 6 days. ${ }^{131}$ The sample aged in the electrolyte with Fe impurity 
shows an increase in OER activity gradually from the first day to the $6^{\text {th }}$ day. In contrast, the other one without Fe shows a decrease in activity gradually upon aging, and the enhanced OER activity is attributed to the increase in conductivity. Landon et al. noticed a rise in the coordination number of Fe in the OER environment using an in situ extended X-ray absorption fine structure (EXAFS) method. ${ }^{132}$ They proposed that forming a new phase $\left(\mathrm{NiFe}_{2} \mathrm{O}_{4}\right)$ through reconstruction increased the coordination number of Fe. Nevertheless, the formation of $\mathrm{NiFe}_{2} \mathrm{O}_{4}$ is rejected by other researchers with the aid of in situ Raman spectroscopy. ${ }^{133}$ They did not notice any signals for $\mathrm{NiFe}_{2} \mathrm{O}_{4}$ formation in the in situ Raman spectra $\left(700 \mathrm{~cm}^{-1}\right)$, even after aging in $\mathrm{KOH}$ electrolyte with $\mathrm{Fe}$ at high OER potentials. In contrast, they observed two peaks which are characteristic of the $\mathrm{NiOOH}$ phase at 555 and $475 \mathrm{~cm}^{-1}$, even in the presence of a high percentage of Fe.

Recently, Zhao's group studied the effect of doping Co and $\mathrm{Fe}$ into the lattice of $\mathrm{Ni}(\mathrm{OH})_{2}$ for improving the OER performance, and they conducted electron energy-loss spectroscopy (EELS) characterization and Hubbard corrected density functional theory $(\mathrm{DFT}+U)$ calculations to understand the activity trend. ${ }^{\mathbf{9 0}}$ The Fe-doped sample shows superior OER activity to Co and Fe co-doped or Co-doped samples..$^{\mathbf{9}}$ EELS analysis suggests electronic interactions between $\mathrm{Ni}$, Co, and Fe dopants even after surface reconstruction during the OER process. A DFT $+U$ study reveals that the d-band center of the Fe-doped sample is much closer to the Fermi level than that of the others, enhancing the binding energy values of OER intermediates to an optimal value. Wang et al. demonstrated an enhancement in OER activity of $\mathrm{Ni}(\mathrm{OH})_{2}$ by co-doping $\mathrm{Mn}$ and $\mathrm{F}$ elements. ${ }^{91} \mathrm{~A}$ considerable increase in oxygen deficiencies was found after doping, which reduced the energy barrier for the key OER of ${ }^{*} \mathrm{OH} \rightarrow{ }^{*} \mathrm{O}$. Ma's group doped a single atom of $\mathrm{W}^{6+}$ into the lattice of $\mathrm{Ni}(\mathrm{OH})_{2}$ and studied its electrocatalytic oxygen evolution behavior. ${ }^{96}$ Interestingly, $\mathrm{W}$ doping significantly enhances the OER activity compared to the pristine sample, and the superior activity is ascribed to the boosting of carrier migration at the interface of the electrode and electrolyte. Furthermore, a DFT study reveals that low spin $\mathrm{W}^{6+}\left(\mathrm{d}^{0}\right)$ stabilizes the $\mathrm{O}^{*}$ and thus helps in the formation of $\mathrm{O}-\mathrm{O}$.

The augmentation of OER activity was also reported for the $\mathrm{Co}(\mathrm{OH})_{2}$ catalyst by Fe doping. Boettcher's group reported the effect of Fe doping on the OER activity of electrodeposited films of $\mathrm{Co}(\mathrm{OH})_{2} \cdot{ }^{124}$ They observed an enhancement of OER performance by 100 fold when the stoichiometric ratio of Co and Fe was $1: 0.6-0.7$. The reason for the superior OER activity is increased $\mathrm{Co}^{3+}$ population and improved thin-film conductivity with Fe doping. Unlike $\mathrm{Ni}(\mathrm{OH})_{2}, \mathrm{Co}(\mathrm{OH})_{2}$ requires a huge amount of $\mathrm{Fe}$ doping $(60-70 \%)$ to display enhanced OER activity, while $\mathrm{Ni}(\mathrm{OH})_{2}$ shows a significant effect even with $0.01 \%$ Fe inclusion. Above the $60-70 \%$ level, the OER activity started decreasing for $\mathrm{Co}(\mathrm{OH})_{2}$. Researchers also doped other TMs into $\mathrm{Co}(\mathrm{OH})_{2}$ to improve its OER performance. For example, Chen et al. doped $\mathrm{Cu}$ into the lattice of $\mathrm{Co}(\mathrm{OH})_{2}$, which significantly enhances its OER activity and outperforms the state-of-the-art catalyst $\mathrm{IrO}_{2}$. The considerable increase in the catalytic performance is attributed to an increase in $\mathrm{Co}^{3+}$ population after doping with $\mathrm{Cu}^{88}$ Koel's group studied the doping effect on the OER behavior of $\mathrm{CoOOH}$ nanowires by doping with Ni and $\mathrm{Mn} .{ }^{92}$ Among them, Ni doping turned out to be fruitful compared to Mn doping because of Ni's ability to stabilize the OER intermediates. Similarly, FeOOH was also doped with different elements such as $\mathrm{Ni}, \mathrm{Co}$, and Se to enhance its OER performance. Tolstoy et al. doped $\mathrm{Ni}^{2+}$ into the lattice of $\mathrm{FeOOH}$ nanocrystals, and $25 \% \mathrm{Ni}^{2+}$ doping was proven to improve the OER activity considerably. ${ }^{93}$ Zhang et al. doped Co into $\mathrm{FeOOH}$, and the $\mathrm{Co}_{0.54} \mathrm{Fe}_{0.46} \mathrm{OOH}$ composition showed superior activity to other doped samples because Co inclusion created more active sites at the edges of the three-dimensional hierarchical structures. ${ }^{87}$ Recently, Niu et al. reported doping of Se into $\mathrm{FeOOH}$ via electrochemical oxidation of an FeSe/iron foam (IF) pre-catalyst by applying a constant $10 \mathrm{~mA} \mathrm{~cm} \mathrm{~cm}^{-2}$ current density for 4 h. ${ }^{95}$ XRD patterns, as shown in Fig. 10a, display the complete disappearance of diffraction peaks of FeSe which was converted into Se-doped FeOOH. However, the electrochemical oxidation did not disturb the nanosheet morphology as revealed by SEM and TEM images in Fig. 10b and c, respectively. Fig. 10d shows the polarization curves of the as-prepared catalysts, and among them, $\mathrm{FeOOH}(\mathrm{Se}) / \mathrm{IF}$ delivers industrial scale $500 \mathrm{~mA} \mathrm{~cm}{ }^{-2}$ current density at $348 \mathrm{mV}$ overpotential. Tafel plots of these catalysts are presented in the inset of Fig. 10d, which shows that the $\mathrm{FeOOH}(\mathrm{Se}) / \mathrm{IF}$ catalyst possesses OER kinetics with the lowest Tafel slope value of $54 \mathrm{mV} \mathrm{dec}^{-1}$. As a unary Fe-based catalyst, $\mathrm{FeOOH}(\mathrm{Se}) / \mathrm{IF}$ shows comparative activity and even outperforms $\mathrm{Ni}$ and Co-based OER catalysts as observed in Fig. 10e. Furthermore, DFT calculations revealed a considerable decrease in the energy barrier for the RDS from $3.20 \mathrm{eV}$ to $1.45 \mathrm{eV}$ after Se inclusion, which accounts for the superior OER activity.

\subsection{Other oxides}

TM oxides, such as $\mathrm{NiO}, \mathrm{CoO}$, and $\mathrm{MnO}_{2}$, are widely reported as catalysts for the OER owing to their high durability and low cost. ${ }^{5}$ Some other representative oxides and their catalytic performances are listed in Table 2 . The electrochemical activity of these oxides was further improved by tuning their electronic structure through the inclusion of various dopants. For instance, lithium-doped NiO $\left(\mathrm{Li}_{x} \mathrm{Ni}_{1-x} \mathrm{O}\right)$ has shown unprecedented OER performance and even outperformed non-noble benchmark perovskite catalysts, such as BSCF and $\mathrm{LaNiO}_{3}{ }^{134}$ Zhang et al. studied the role of lithium incorporation into the lattice of NiO. ${ }^{134}$ Fig. 11a shows the BET surface area normalized LSV curves of pristine and Li-doped NiO catalysts, and among them, the catalyst with a $1: 1$ ratio of $\mathrm{Li}$ and Ni shows 11 fold higher activity than pristine NiO. The inset of Fig. 11a presents cyclic voltammogram (CV) curves, which further reveals a positive shift in redox potential with an increase in Li content. A combinatorial study of the electronic structure of $\mathrm{Li}_{x} \mathrm{Ni}_{1-x} \mathrm{O}$ was conducted using X-ray absorption spectroscopy and synchrotron-based photoemission spectroscopy. The schematic illustration of covalency of Ni 3d-O 2p from DFT calculations is shown in Fig. 11b, which reveals the formation of a new hole state near the Fermi level, and the increased covalency of $\mathrm{Ni}$ $3 \mathrm{~d}-\mathrm{O} 2 \mathrm{p}$ that ensured higher OER activity. 


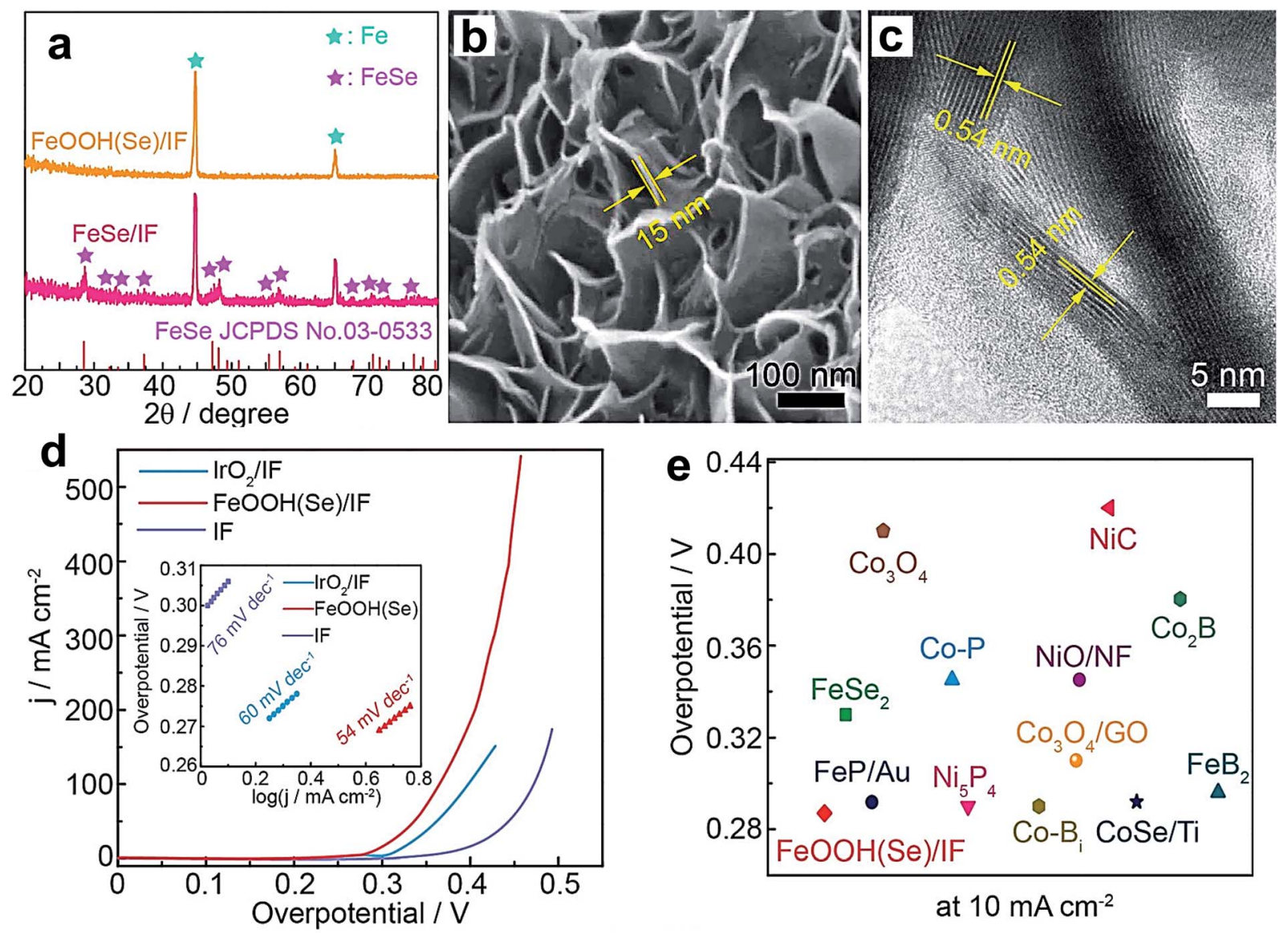

Fig. 10 (a) XRD patterns of FeSe/iron foam (IF) and FeOOH(Se)/IF; (b) SEM image of FeSe/IF; (c) HRTEM image of FeSe/IF; (d) LSV curves of the asprepared catalysts (inset: Tafel plots); (e) overpotential comparison of FeOOH(Se)/IF and state-of-the-art unary metal-based OER electrocatalysts. ${ }^{95}$ Reproduced from ref. 95 with permission, (c) 2019 American Chemical Society.

Enhancement in the OER activity of the NiO catalyst with Fe doping was first observed by Corrigan in $1987,{ }^{130}$ and Fe doping into the NiO thin film was found to be affected by the impurities present in $\mathrm{KOH}$ electrolyte. ${ }^{135}$ Recently, Nocera et al. identified the essential role of Fe doping in improving the electrocatalytic activity of Ni oxides. ${ }^{136} 5-10 \%$ doping of Fe increased the population of $\mathrm{Ni}^{4+}$ ions, as revealed by coulometric titrations. Consequently, $\mathrm{O}$ and Ni K-edge spectra indicated an increase in hybridization between $\mathrm{Ni} 3 \mathrm{~d}$ and $\mathrm{O} 2 \mathrm{p}$ orbitals. Both experimental and computational studies showed that $\mathrm{Fe}^{3+}$ is a Lewis
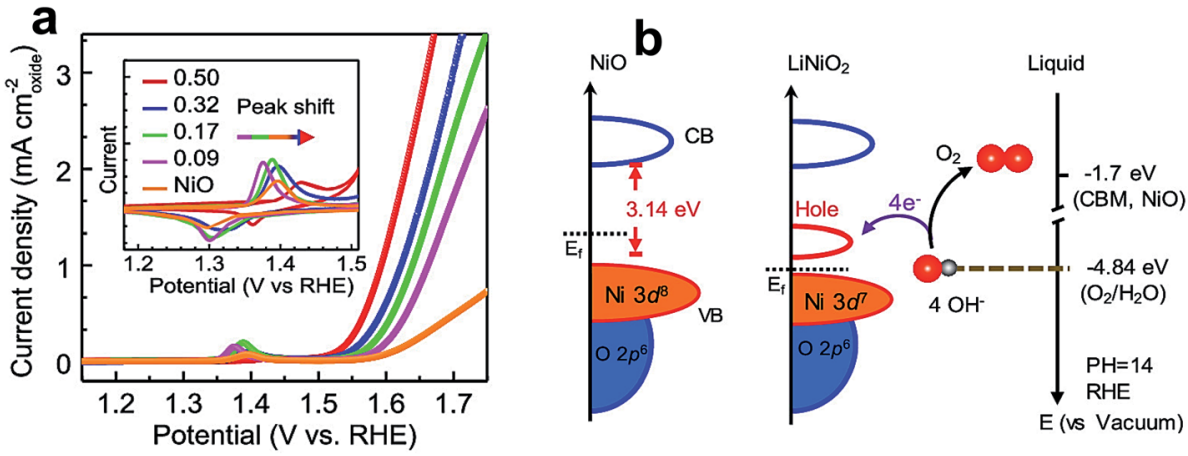

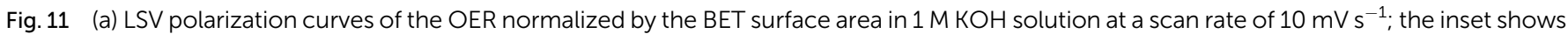
cyclic voltammogram curves at a scan rate of $10 \mathrm{mV} \mathrm{s}^{-1}$; (b) schematic diagram for electronic structures of $\mathrm{NiO}^{(l e f t)}$ and $\mathrm{LiNiO} \mathrm{O}_{2}$ (middle), and energy diagram at the oxide-liquid interface on the vacuum level scale at $\mathrm{pH}=14$ (right); the redox level for $\mathrm{O}_{2} / \mathrm{H}_{2} \mathrm{O}(\mathrm{red}$ dashed line) is $-4.84 \mathrm{eV}$, the conduction band minimum (CBM) level for $\mathrm{NiO}$ is $-1.7 \mathrm{eV}$ according to the formula $E_{\mathrm{CBM}}=E_{\text {bandgap }}-E_{\text {ionization }}\left(E_{\text {bandgap }}=3.7\right.$ eV, $\left.E_{\text {ionization }}=5.4 \mathrm{eV}\right){ }^{134}$ Reproduced from ref. 134 with permission, $\odot 2019$ American Chemical Society. 
acid with $p \mathrm{~K}_{\mathrm{a}}=2.2$, and is the most acidic among TMs. Hence, the incorporation of $\mathrm{Fe}^{3+}$ into Ni oxides helps in enhancing the acidity of $\mathrm{OH}_{x}$ moieties coordinated with $\mathrm{Ni}$, which increases the population of $\mathrm{Ni}^{4+}$ ions by lowering the $\mathrm{Ni}^{3+} / \mathrm{Ni}^{4+}$ reduction potential. ${ }^{136} \mathrm{Ce}$-doped $\mathrm{NiO}_{x}$ deposited on a Au substrate shows significantly higher OER performance than pristine $\mathrm{NiO}_{x} \cdot{ }^{97}$ The enhanced OER activity is accredited to the modification of the local environment favorable for binding of OER intermediates.

A nickel-doped rock-salt-structured OER catalyst, $\mathrm{Ni}_{x^{-}}$ $\mathrm{Co}_{1-x} \mathrm{O}$, was synthesized using a solid-state method. ${ }^{\mathbf{1 0 2}}$ The inclusion of a discrete amount of $\mathrm{Ni}$ into the lattice of $\mathrm{CoO}$ stabilizes the crystal structure and tunes its $\mathrm{e}_{\mathrm{g}}$ value. Within the doped series, the $\mathrm{Ni}_{0.3} \mathrm{Co}_{0.7} \mathrm{O}$ catalyst displays the highest OER activity with an $\mathrm{e}_{\mathrm{g}}$ value of $\sim 1.3$. Huo et al. reported the improved OER performance of $\mathrm{COO}$ nanoflowers by doping with Zn. ${ }^{106}$ A DFT study confirmed that OER active sites were increased by $\mathrm{Zn}$ doping, and the high surface area of nanoflowers was another contributor to the improved catalytic activity. Like in $\mathrm{NiO}, \mathrm{Fe}$ doping of $\mathrm{CoO}$ could also greatly enhance its electrocatalytic performance by increasing the number of OER active sites. ${ }^{101}$ Ye et al. prepared V-, Fe-, Co-, and Ni-doped $\mathrm{MnO}_{2}$ ultrathin nanosheets on carbon fiber paper (CFP) using an electrodeposition method as shown in Fig. 12a, and studied their OER activity in a basic medium. ${ }^{\mathbf{1 0 4}}$ Fig. 12b and c show the doped $\mathrm{MnO}_{2}$ ultrathin nanosheet/CFP composite electrode at low and high magnifications, which shows very dense nanoclusters with $5 \mathrm{~nm}$ thick nanosheets. Fig. 12d shows the LSV curves of CFP, pure $\mathrm{MnO}_{2} / \mathrm{CFP}$, metalion-doped $\mathrm{MnO}_{2}$ ultrathin nanosheet/CFP, and $\mathrm{IrO}_{2} / \mathrm{CFP}$ composite electrodes in $1 \mathrm{M} \mathrm{KOH}$ with a scan rate of $5 \mathrm{mV} \mathrm{s}^{-1}$.
The authors noticed that doping with these TM cations vastly enhances $\mathrm{MnO}_{2}$ conductivity, resulting in higher catalytic activity compared to the pristine sample. The electrochemical stability of doped and pristine $\mathrm{MnO}_{2}$ compared with $\mathrm{IrO}_{2}$ evaluated at $20 \mathrm{~mA} \mathrm{~cm}{ }^{-2}$ is shown in Fig. 12e. Doped $\mathrm{MnO}_{2}$ ultrathin nanosheet/CFP shows significant stability compared to the pristine sample with a slight increase in overpotential.

Yang et al. intercalated $3 \mathrm{~d}$ block metal cations such as $\mathrm{Zn}^{2+}$, $\mathrm{Cu}^{2+}, \mathrm{Ni}^{2+}, \mathrm{Co}^{2+}$, and $\mathrm{Fe}^{3+}$ into $\mathrm{MnO}_{2}$ nanosheets to enhance OER activity. ${ }^{103}$ Among them, the inclusion of $\mathrm{Ni}^{2+}$ ions was more effective in enhancing the OER activity of $\mathrm{MnO}_{2}$ nanosheets. The increased activity is associated with strengthening the $\mathrm{Mn}-\mathrm{O}$ bond perpendicular to layered chains to promote the catalysis between two Mn sites. Oxygen vacancy formation in $\mathrm{MnO}_{2}$ nanosheets by Co doping is demonstrated by Zhao et al. ${ }^{99}$ Co doping enhances the OER activity of $\mathrm{MnO}_{2}$ considerably by enhancing its conductivity and decreasing the energy barrier for adsorption of OER intermediates on the catalyst surface. Interestingly, a small amount of cobalt doping (3.47\%) could activate the OER activity of ZnO. Theoretical studies suggest that Co activates inherently inactive adjacent $\mathrm{Zn}$ sites by increasing conductivity, which act as OER active sites for adsorption of OER intermediates. ${ }^{100}$ Co doping also activates the OER activity in CuO. Sun et al. demonstrated a multifold enhancement of OER activity in a basic electrolyte after doping with $\mathrm{Co}$ on a $\mathrm{Cu}$ foam substrate, ${ }^{98}$ which was related to a change in the electronic structure of $\mathrm{CuO}$ by Co doping. Meyer et al. reported the fabrication of an OER catalyst by modifying fluorine-doped tin oxide (FTO) by $\mathrm{Co}^{2+}$ single-atom doping. ${ }^{137} \mathrm{X}$ ray photoelectron spectroscopy (XPS) and TEM reveal that
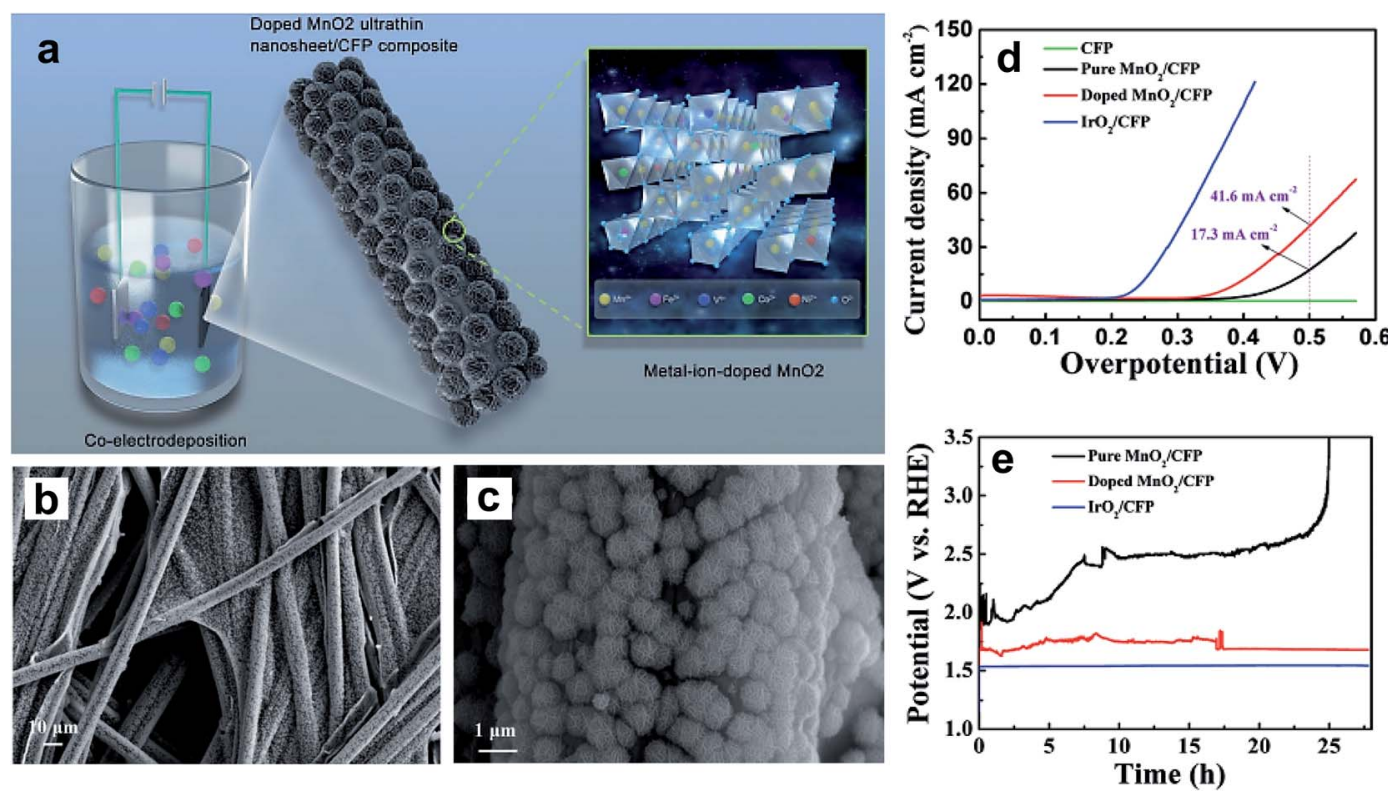

Fig. 12 (a) Schematic representation for the preparation of the metal-ion (Fe, V, Co, and $\mathrm{Ni}$ )-doped $\mathrm{MnO}_{2}$ ultrathin nanosheet/CFP composite; (b and C) FESEM images showing the morphology of the metal-ion-doped $\mathrm{MnO}_{2}$ ultrathin nanosheet/CFP composite electrode at different magnifications; (d) LSV curves of the CFP, the metal-ion-doped $\mathrm{MnO}_{2}$ ultrathin nanosheet/CFP and the IrO $/$ CFP composite electrodes measured in $1 \mathrm{M} \mathrm{KOH}$ with a scan rate of $5 \mathrm{mV} \mathrm{s}^{-1}$, where the current is normalized by the geometrical area of the carbon fiber paper; (e) galvanostatic measurements at a current density of $20 \mathrm{~mA} \mathrm{~cm}{ }^{-2}$ for the different composite electrodes. ${ }^{104}$ Reproduced from ref. 104 with permission, @ 2017 John Wiley and Sons. 
doping $\mathrm{Co}^{2+}$ into FTO by replacing $\mathrm{Sn}^{4+}$ results in oxygen vacancies. The as-modified FTO electrode shows water oxidation activity at pH 7.2 with a turnover frequency of 29000 per cobalt site, at a current density of $0.16 \mathrm{~mA} \mathrm{~cm}^{-2}$ during an endurance test for $2 \mathrm{~h}$. Furthermore, the current density was enhanced by 5 fold by utilizing nanoporous FTO in place of planar FTO. Wang et al. reported Ba doping of $\mathrm{Y}_{2} \mathrm{Ru}_{2} \mathrm{O}_{7}$ pyrochlore oxide on the yttrium position (YBRO) as an efficient catalyst for the OER in an acid electrolyte. ${ }^{105}$ Among the doped samples, YBRO-0.15 shows superior activity, and the OER activity decreases in the following sequence: YBRO-0.15 $>$ YBRO$0.1>$ YBRO-0.25 > YBRO-0.4 $>$ YRO $>\mathrm{RuO}_{2}$. The enhanced activity is attributed to the oxygen vacancy-rich surface because of partial replacement of $\mathrm{Ba}^{2+}$ with $\mathrm{Y}^{3+}$ and simultaneous formation of multivalent $\mathrm{Ru}\left(\mathrm{Ru}^{5+} / \mathrm{Ru}^{4+}\right)$ species.

\section{Doping non-oxide catalysts}

Non-oxide catalysts include metal sulfides, metal selenides, metal phosphides, metal nitrides, and metal carbides. These catalysts are pre-catalysts, and the actual catalysts are the oxides of the corresponding cations generated on the surface during electrochemical water oxidation.

\subsection{Metal sulfides}

Transition metal sulfides are widely explored in electrocatalysis due to their high stability in acidic and alkaline electrolytes and abundant redox chemistry. ${ }^{138}$ Some doped metal sulfides and their catalytic performances are listed in Table 3. Like in metal oxides and hydroxides, Fe doping is effective in significantly improving the OER activity of TM sulfides. ${ }^{\mathbf{1 3 9 , 1 4 0}}$ For example,

Table 3 Summary of representative doped metal sulfides and selenides and their catalytic performances

\begin{tabular}{llll}
\hline Catalyst & $\begin{array}{l}\text { Overpotential at a specific } \\
\text { current density }\end{array}$ & $\begin{array}{l}\text { Tafel slope } \\
\left(\mathrm{mV} \mathrm{dec}^{-1}\right)\end{array}$ & Durability \\
\hline
\end{tabular}

\section{Metal sulfides}

Al-doped $\mathrm{Ni}_{3} \mathrm{~S}_{2} / \mathrm{NF}^{146}$

Ce-doped $\mathrm{Ni}_{3} \mathrm{~S}_{2}$ (ref. 147)

Co-doped $\mathrm{WS}_{2}$ (ref. 148)

CoFeS/CNT-P 1000 (ref. 149)

Fe-doped $\mathrm{CoS}^{141}$

Fe-doped $\mathrm{Co}_{9} \mathrm{~S}_{8}$ (ref. 142)

Fe-doped $\mathrm{NiS}_{2}$ (ref. 143)

Fe-doped $\mathrm{Ni}_{3} \mathrm{~S}_{2}$ (ref. 144)

Fe-doped $\mathrm{Ni}_{3} \mathrm{~S}_{2} / \mathrm{NF}^{139}$

$\mathrm{Fe}_{2.1 \%}$ doped $\mathrm{Ni}_{3} \mathrm{~S}_{2} / \mathrm{NF}^{140}$

Fe-doped $\mathrm{H}-\mathrm{CoMoS}^{145}$

$\mathrm{Ni}_{1.29} \mathrm{Co}_{1.49} \mathrm{Mn}_{0.22} \mathrm{~S}_{4}$ (ref. 150)

$\mathrm{N}$-doped $\mathrm{Co}_{9} \mathrm{~S}_{8} / \mathrm{G}^{151}$

Ni-doped $\mathrm{FeS}^{152}$

$\mathrm{N}_{2}-\mathrm{NiS}_{2}-500$ (ref. 153)

$\left(\mathrm{N}-\mathrm{Ni}_{3} \mathrm{~S}_{2} @ \mathrm{C}\right) / \mathrm{NF}^{154}$

$\mathrm{N}$-doped NiS/NiS ${ }_{2}$ (ref. 155)

P-doped Co-Ni-S nanosheets ${ }^{156}$

$\mathrm{P}-\mathrm{Ni}_{3} \mathrm{~S}_{2} / \mathrm{NF}^{157}$

$\mathrm{P}-\mathrm{Ni}_{3} \mathrm{~S}_{2} / \mathrm{NF}^{158}$

(P-(Ni,Fe) $)_{3} \mathrm{~S}_{2} / \mathrm{NF}^{159}$

Zn-doped $\mathrm{Ni}_{3} \mathrm{~S}_{2}$ (ref. 160)

\section{Metal selenides}

Fe-doped $\mathrm{CoSe}_{2} / \mathrm{NF}^{161}$

Ag-doped $\mathrm{CoSe}_{2}$ nanobelts ${ }^{162}$

B-doped $\mathrm{Fe}_{5} \mathrm{Co}_{4} \mathrm{Ni}_{20} \mathrm{Se}_{36}$ (ref. 163)

Co-doped NiSe ${ }^{164}$

Co-doped nickel selenide ${ }^{165}$

$\mathrm{Co}_{0.75} \mathrm{Fe}_{0.25}\left(\mathrm{~S}_{0.2} \mathrm{Se}_{0.8}\right)_{2}$ (ref. 166)

$\mathrm{Cu}-14-\mathrm{Co}_{3} \mathrm{Se}_{4} / \mathrm{GC}^{167}$

$\mathrm{Cu}$-doped $\mathrm{FeSe}_{2}$ (ref. 168)

FCS@N-CT ${ }^{169}$

Fe-doped NiSe ${ }^{170}$

Fe-doped $\mathrm{NiSe}_{2}$ (ref. 171)

Fe-doped $\mathrm{Ni}_{3} \mathrm{Se}_{4}$ (ref. 172)

Fe-doped $\mathrm{Ni}_{3} \mathrm{Se}_{2}$ (ref. 173)

$\mathrm{Ni}_{1.12} \mathrm{Fe}_{0.49} \mathrm{Se}_{2}$ (ref. 174)

$\mathrm{Ni}_{0.04} \mathrm{Fe}_{0.16} \mathrm{Co}_{0.8} \mathrm{Se}_{2}$ (ref. 175)

$\mathrm{V}_{\mathrm{Se}}-\mathrm{Ni}_{0.70} \mathrm{Fe}_{0.30} \mathrm{Se}_{2}$ (ref. 176)

Zn-doped $\mathrm{CoSe}_{2}$ (ref. 177)
$223 \mathrm{mV}$ @ $10 \mathrm{~mA} \mathrm{~cm}^{-2}$ $257 \mathrm{mV}$ @ $50 \mathrm{~mA} \mathrm{~cm}{ }^{-2}$ $303 \mathrm{mV}$ @ $10 \mathrm{~mA} \mathrm{~cm}^{-2}$ $309 \mathrm{mV}$ @ $100 \mathrm{~mA} \mathrm{~cm}^{-2}$ $290 \mathrm{mV}$ @ $10 \mathrm{~mA} \mathrm{~cm}{ }^{-2}$ $270 \mathrm{mV}$ (a) $10 \mathrm{~mA} \mathrm{~cm}^{-2}$ $231 \mathrm{mV}$ @ $100 \mathrm{~mA} \mathrm{~cm}^{-2}$ $223 \mathrm{mV}$ @ $200 \mathrm{~mA} \mathrm{~cm}^{-2}$ $249 \mathrm{mV}$ @ $100 \mathrm{~mA} \mathrm{~cm}^{-2}$ $213 \mathrm{mV}$ @ $100 \mathrm{~mA} \mathrm{~cm}^{-2}$ $282 \mathrm{mV}$ @ $10 \mathrm{~mA} \mathrm{~cm}^{-2}$ $348 \mathrm{mV}$ @ $10 \mathrm{~mA} \mathrm{~cm}^{-2}$ $409 \mathrm{mV}$ @ $10 \mathrm{~mA} \mathrm{~cm}^{-2}$ $228 \mathrm{mV}$ @ $10 \mathrm{~mA} \mathrm{~cm}^{-2}$ $270 \mathrm{mV}$ (a) $10 \mathrm{~mA} \mathrm{~cm}^{-2}$ $310 \mathrm{mV}$ @ $100 \mathrm{~mA} \mathrm{~cm}^{-2}$ $270 \mathrm{mV}$ @ $10 \mathrm{~mA} \mathrm{~cm}^{-2}$ $296 \mathrm{mV}$ @ $100 \mathrm{~mA} \mathrm{~cm}^{-2}$ $256 \mathrm{mV}$ @ $10 \mathrm{~mA} \mathrm{~cm}^{-2}$ $306 \mathrm{mV}$ @ $100 \mathrm{~mA} \mathrm{~cm}^{-2}$ $196 \mathrm{mV}$ @ $10 \mathrm{~mA} \mathrm{~cm}^{-2}$ $330 \mathrm{mV}$ @ $100 \mathrm{~mA} \mathrm{~cm}^{-2}$

$256 \mathrm{mV}$ @ $100 \mathrm{~mA} \mathrm{~cm}^{-2}$ $320 \mathrm{mV}$ @ $10 \mathrm{~mA} \mathrm{~cm}{ }^{-2}$ $279.8 \mathrm{mV}$ (a) $10 \mathrm{~mA} \mathrm{~cm}^{-2}$ $380 \mathrm{mV}$ @ $100 \mathrm{~mA} \mathrm{~cm}^{-2}$ $275 \mathrm{mV}$ (a $30 \mathrm{~mA} \mathrm{~cm}^{-2}$ $293 \mathrm{mV}$ @ $10 \mathrm{~mA} \mathrm{~cm}^{-2}$ $166 \mathrm{mV}$ @ $10 \mathrm{~mA} \mathrm{~cm}^{-2}$ $193 \mathrm{mV}$ @ $10 \mathrm{~mA} \mathrm{~cm}^{-2}$ $330 \mathrm{mV}$ @ $10 \mathrm{~mA} \mathrm{~cm}^{-2}$ $291 \mathrm{mV}$ @ $1000 \mathrm{~mA} \mathrm{~cm}{ }^{-2}$ $231 \mathrm{mV}$ @ $10 \mathrm{~mA} \mathrm{~cm}^{-2}$ $225 \mathrm{mV}$ @ $10 \mathrm{~mA} \mathrm{~cm}^{-2}$ $225 \mathrm{mV}$ @ $10 \mathrm{~mA} \mathrm{~cm}^{-2}$ $227 \mathrm{mV}$ @ $10 \mathrm{~mA} \mathrm{~cm}^{-2}$ $230 \mathrm{mV}$ @ $10 \mathrm{~mA} \mathrm{~cm}^{-2}$ $210 \mathrm{mV}$ @ $10 \mathrm{~mA} \mathrm{~cm}^{-2}$ $286 \mathrm{mV}$ @ $10 \mathrm{~mA} \mathrm{~cm}^{-2}$
37

81

79

47

52.6

70

43

55.7

42

33.2

58

65

82.7

53

75

99

61.1

30

99

30

87

35.6
56
59.5
111
63
77
111
59.2
74
43
83
41
35.3
37.9
39
61
37

$15 \mathrm{~h}$ @ $1.53 \mathrm{~V} v s . \mathrm{RHE}$ $24 \mathrm{~h}$ @ $0.6 \mathrm{~V} \mathrm{vs.} \mathrm{Ag} / \mathrm{AgCl}$

$12 \mathrm{~h}$ @ $20 \mathrm{~mA} \mathrm{~cm}^{-2}$

$10 \mathrm{~h}$ @ $10 \mathrm{~mA} \mathrm{~cm}{ }^{-2}$

$10 \mathrm{~h}$ @ $270 \mathrm{mV}$

$15 \mathrm{~h}$ @ $20 \mathrm{~mA} \mathrm{~cm}^{-2}$

$14 \mathrm{~h}$ @ $223 \mathrm{mV}$

$20 \mathrm{~h}$ (a) $270 \mathrm{mV}$

-

$40000 \mathrm{~s}$ @ $10 \mathrm{~mA} \mathrm{~cm}^{-2}$

-

$10 \mathrm{~h}$ (a) $1.47 \mathrm{~V} v s . \mathrm{RHE}$

$40 \mathrm{~h}$ @ $270 \mathrm{mV}$

$20 \mathrm{~h}$ @ $1.70 \mathrm{~V} v$ s. RHE

$20 \mathrm{~h}$ @ $270 \mathrm{mV}$

$16 \mathrm{~h}$ @ $10 \mathrm{~mA} \mathrm{~cm}{ }^{-2}$

$30 \mathrm{~h}$ (a) $1.525 \mathrm{~V} v$ s. RHE

$10 \mathrm{~h}$ (a) $1.54 \mathrm{~V} v s$. RHE

$15 \mathrm{~h}$ (a) $295 \mathrm{mV}$

$20 \mathrm{~h}$ @ $300 \mathrm{mV}$

$10 \mathrm{~h}$ @ $231 \mathrm{mV}$

$10 \mathrm{~h}$ @ $10 \mathrm{~mA} \mathrm{~cm}{ }^{-2}$

$>10 \mathrm{~h}$ @ $320 \mathrm{mV}$

$24 \mathrm{~h}$ @ $1.5 \mathrm{~V} v s$. RHE

-

$12000 \mathrm{~s}$ @ $166 \mathrm{mV}$

$10000 \mathrm{~s}$ @ $1.526 \mathrm{~V} v$ s. RHE

$22 \mathrm{~h}$ @ $217 \mathrm{mV}$

$20 \mathrm{~h}$ @ $15 \mathrm{~mA} \mathrm{~cm}^{-2}$

$26 \mathrm{~h}$ (a) $10 \mathrm{~mA} \mathrm{~cm}^{-2}$

$12 \mathrm{~h}$ @ $20 \mathrm{~mA} \mathrm{~cm}^{-2}$

$10 \mathrm{~h}$ @ $10 \mathrm{~mA} \mathrm{~cm}{ }^{-2}$

$15 \mathrm{~h}$ (a) $1.5 \mathrm{~V} v s$. RHE

$20 \mathrm{~h}$ @ $10 \mathrm{~mA} \mathrm{~cm}^{-2}$

$24 \mathrm{~h}$ @ 10,20 , and $50 \mathrm{~mA} \mathrm{~cm}{ }^{-2}$
$1 \mathrm{M} \mathrm{KOH}$

$1 \mathrm{M} \mathrm{KOH}$

$1 \mathrm{M} \mathrm{KOH}$

$1 \mathrm{M} \mathrm{KOH}$

$1 \mathrm{M} \mathrm{KOH}$

$1 \mathrm{M} \mathrm{KOH}$

$1 \mathrm{M} \mathrm{KOH}$

$1 \mathrm{M} \mathrm{KOH}$

$1 \mathrm{M} \mathrm{KOH}$

$1 \mathrm{M} \mathrm{KOH}$

$1 \mathrm{M} \mathrm{KOH}$

$1 \mathrm{M} \mathrm{KOH}$

$0.1 \mathrm{M} \mathrm{KOH}$

$1 \mathrm{M} \mathrm{KOH}$

$1 \mathrm{M} \mathrm{KOH}$

$1 \mathrm{M} \mathrm{KOH}$

$1 \mathrm{M} \mathrm{KOH}$

$1 \mathrm{M} \mathrm{KOH}$

$1 \mathrm{M} \mathrm{KOH}$

$1 \mathrm{M} \mathrm{KOH}$

$1 \mathrm{M} \mathrm{KOH}$

$1 \mathrm{M} \mathrm{KOH}$

$1 \mathrm{M} \mathrm{KOH}$

$0.1 \mathrm{M} \mathrm{KOH}$

$1 \mathrm{M} \mathrm{KOH}$

$1 \mathrm{M} \mathrm{KOH}$

$1 \mathrm{M} \mathrm{KOH}$

$1 \mathrm{M} \mathrm{KOH}$

$1 \mathrm{M} \mathrm{KOH}$

$1 \mathrm{M} \mathrm{KOH}$

$1 \mathrm{M} \mathrm{KOH}$

$1 \mathrm{M} \mathrm{KOH}$

$1 \mathrm{M} \mathrm{KOH}$

$1 \mathrm{M} \mathrm{KOH}$

$1 \mathrm{M} \mathrm{KOH}$

$1 \mathrm{M} \mathrm{KOH}$

$1 \mathrm{M} \mathrm{KOH}$

$1 \mathrm{M} \mathrm{KOH}$

$1 \mathrm{M} \mathrm{KOH}$ 
Zeng et al. synthesized Fe-doped CoS electrocatalysts via a simple hydrothermal method, and $20 \%$ Fe doping produced considerably the highest OER activity among them because of the high electrical conductivity by doping, which accelerated the charge transfer process by changing the local Co-S environment for easy adsorption of OER intermediates. ${ }^{\mathbf{1 4 1}}$ Dong and coworkers synthesized nano-micro spheres of Fe-doped $\mathrm{Co}_{9} \mathrm{~S}_{8}$ on nickel foam using a hydrothermal method; for comparison, they also synthesized Ni-doped $\mathrm{Co}_{9} \mathrm{~S}_{8} \cdot{ }^{142}$ The Fe-doped sample showed superior OER activity to the pristine and Ni-doped samples. It was found that the high activity was contributed by the synergetic effect of tuning the electronic structure of cobalt by an Fe dopant and high surface area induced by the nickel foam. Sun et al. synthesized Fe-doped $\mathrm{NiS}_{2}$ nanoarrays on a Ti mesh through sulfidation of a NiFe layered hydroxide as a precursor, and they found that the catalyst with $10 \% \mathrm{Fe}$ doping showed superior OER activity with an overpotential of $231 \mathrm{mV}$ at $100 \mathrm{~mA} \mathrm{~cm}{ }^{-2}$ current density. ${ }^{143} \mathrm{Wu}$ 's group reported Fe-doped $\mathrm{Ni}_{3} \mathrm{~S}_{2}$ nanowires synthesized on a $\mathrm{Ni}$ foam and found that $\mathrm{Ni}_{3} \mathrm{~S}_{2}$ nanowires with a $13.7 \%$ dopant level of Fe exhibit superior activity and only require $223 \mathrm{mV}$ overpotential to achieve $200 \mathrm{~mA} \mathrm{~cm}^{-2}$ in alkaline electrolyte. ${ }^{144}$ The incorporation of iron into the matrix of $\mathrm{Ni}_{3} \mathrm{~S}_{2}$ enhances the number of active site edges along with conductivity. Sugahara and coworkers prepared hollow iron-doped bimetallic CoMoS heterostructures, which show enhanced OER activity over the gold standard catalyst $\mathrm{RuO}_{2} \cdot{ }^{145}$

In addition to the Fe inclusion, doping other metals such as $\mathrm{Ni},{ }^{152,178} \mathrm{Co},{ }^{148} \mathrm{Mn},{ }^{150} \mathrm{Zn},{ }^{160} \mathrm{Ce},{ }^{147}$ and $\mathrm{Al}^{146}$ is also found to enhance the OER activity of metal sulfides. For instance, Lin et al. fabricated Ni-doped FeS nanosheets as an OER catalyst in alkaline electrolyte through a one-pot synthesis approach. ${ }^{152}$ The Ni-doped FeS nanosheets showed significant OER activity compared to commercial $\mathrm{IrO}_{2}$ with $228 \mathrm{mV}$ overpotential at 10 $\mathrm{mA} \mathrm{cm} \mathrm{cm}^{-2}$ current density, by the consequent doping effect of exposing more active sites. Similarly, Kuila et al. synthesized binder-free self-standing Ni-doped FeS OER catalysts on $\mathrm{Ni}$ foam via an electrodeposition method. ${ }^{178}$ The $\mathrm{Ni}$ doping amount is controlled by varying the electrodeposition time, and the electrode fabricated by electrodeposition at $0.9 \mathrm{~V}$ for $30 \mathrm{~min}$ shows superior activity among them. The change in the electronic structure and charge carrier density via the incorporation of $\mathrm{Ni}$ into the lattice domain of FeS significantly improves its electrocatalytic activity. Likewise, Wen and coworkers incorporated Ce into the lattice of $\mathrm{Ni}_{3} \mathrm{~S}_{2}$ via a one-step electrodeposition method. ${ }^{179}$ Doping with Ce preserves the original structure and morphology. Still, it promotes the OER activity by regulating the active sites and chemical states on the surface of $\mathrm{Ni}_{3} \mathrm{~S}_{2}$. Yang et al. significantly enhanced the electrocatalytic ability of $\mathrm{WS}_{2}$ by incorporating nearly $1 \%$ Co into its lattice. ${ }^{148}$ The overpotential was decreased from 492 to $303 \mathrm{mV}$ after incorporation of Co, and the improved activity was ascribed to the presence of $\mathrm{Co}(\mathrm{II} /$ III) species that improved the binding of reactants and facilitated the formation of the ${ }^{*} \mathrm{OOH}$ intermediate. Darr and coworkers optimized the OER activity of bimetallic cobaltnickel sulfides by doping with various TMs, such as Ag, Fe, Mn, $\mathrm{Cr}, \mathrm{V}$ and $\mathrm{Ti}{ }^{150}$ Among them, Mn-incorporated cobalt-nickel sulfide $\left(\mathrm{Ni}_{1.29} \mathrm{Co}_{1.49} \mathrm{Mn}_{0.22} \mathrm{~S}_{4}\right)$ shows enhanced activity through tuning of the electronic structure of the host by Mn(III) cations. Zn-doped $\mathrm{Ni}_{3} \mathrm{~S}_{2}$ nanoarrays on nickel foam grown by Sun et al. have better OER activity than their pristine counterpart, with excellent stability for $20 \mathrm{~h}$ at $300 \mathrm{mV}$ overpotential. ${ }^{\mathbf{1 6 0}}$ The extended endurance and comparable activity were caused by modulation of the electronic structure of the $\mathrm{Ni}_{3} \mathrm{~S}_{2}$ catalyst through $\mathrm{Zn}$ incorporation.

Recently, researchers reported incorporating non-metals, such as $\mathrm{N}, \mathrm{P}$, and $\mathrm{F}$, into the lattice of metal sulfides to improve their electrocatalytic capability. ${ }^{149,151,153-159,180} \mathrm{~N}$ doping of a $\mathrm{NiS}_{2}$ catalyst using $\mathrm{NH}_{3} \cdot \mathrm{H}_{2} \mathrm{O}$ as a precursor considerably increased its water oxidation ability by overcoming the intrinsic limits of reaction kinetics through optimizing d-states. ${ }^{153} 3 \mathrm{D} \mathrm{N}$ doped $\mathrm{Ni}_{3} \mathrm{~S}_{2}$ nanoflakes grown on $\mathrm{Ni}$ foam show superior durability for $20 \mathrm{~h}$ at $1.7 \mathrm{~V}$ with $\sim 93 \%$ retention of their initial activity. ${ }^{154}$ The experimental results indicate that $\mathrm{N}$ doping plays a key role in the quick discharging of OER intermediates and improved intrinsic activity. ${ }^{155}$ Dou et al. found that a $\mathrm{Co}_{9} \mathrm{~S}_{8} /$ graphene hybrid, doped with $\mathrm{N}$ using $\mathrm{NH}_{3}$ plasma etching, showed a significant improvement in its OER performance compared with a pristine sample. ${ }^{151}$ The synergetic effect of $\mathrm{N}$ doping and surface etching considerably tuned the electronic structure of the $\mathrm{Co}_{9} \mathrm{~S}_{8} /$ graphene hybrid and thus enhanced the number of active sites on the surface. He et al. synthesized 3D self-supported and P-doped $\mathrm{Ni}_{3} \mathrm{~S}_{2}$ on $\mathrm{Ni}$ foam by a one-step hydrothermal process by simultaneous phosphorization and sulfuration. ${ }^{157}$ The as-fabricated electrode exhibits enhanced OER activity with an overpotential of $256 \mathrm{mV}$ at $10 \mathrm{~mA} \mathrm{~cm}{ }^{-2}$. The inclusion of $\mathrm{P}$ anions optimizes the electronic structure and provides facile adsorption of reactants and thus enables a faster mass transfer. Similarly, P-doped bimetallic nickel-iron sulfide nanosheets on $\mathrm{Ni}$ foam were synthesized via a one-pot process. ${ }^{159}$ The incorporated $\mathrm{P}$ considerably enhances the electrochemical surface area and electrical conductivity by optimizing the adsorption of OER intermediates. F-doped $\mathrm{CoS}_{2}$ on $\mathrm{Ni}$ foam was synthesized using $\mathrm{NH}_{4} \mathrm{~F}$ as a fluorine source by a hydrothermal process. ${ }^{180}$ The $\mathrm{F}$ dopant significantly enhances the wettability of the catalyst, and thus facilitates the maximum interaction with electrolyte in both alkaline and neutral media.

\subsection{Metal selenides}

Some doped metal selenides and their performances are listed in Table 3. The electrocatalytic behavior of metal selenides depends on the number of exposed edge sites. ${ }^{21}$ Edge sites are step-like apertures or defects generated at the basal plane because of doping. ${ }^{\mathbf{1 8 1}}$ Besides the edge sites, the electrical conductivity and intrinsic activity of metal selenides are enhanced by doping; specifically, doping with TMs significantly improves the OER activity of metal selenides. ${ }^{169,171,173,174}$ For example, Zare et al. designed a self-supported electrocatalyst on $\mathrm{Ni}$ foam by doping Fe into the lattice domain of $\mathrm{CoSe}_{2}$, which only requires $256 \mathrm{mV}$ overpotential to attain $100 \mathrm{~mA} \mathrm{~cm}{ }^{-2}$ current density. ${ }^{161}$ Here, Fe improves the intrinsic electrical conductivity, and thus lowers the energy barrier for the OER. Zhao and coworkers improved the OER activity of $\mathrm{CoSe}_{2}$ 

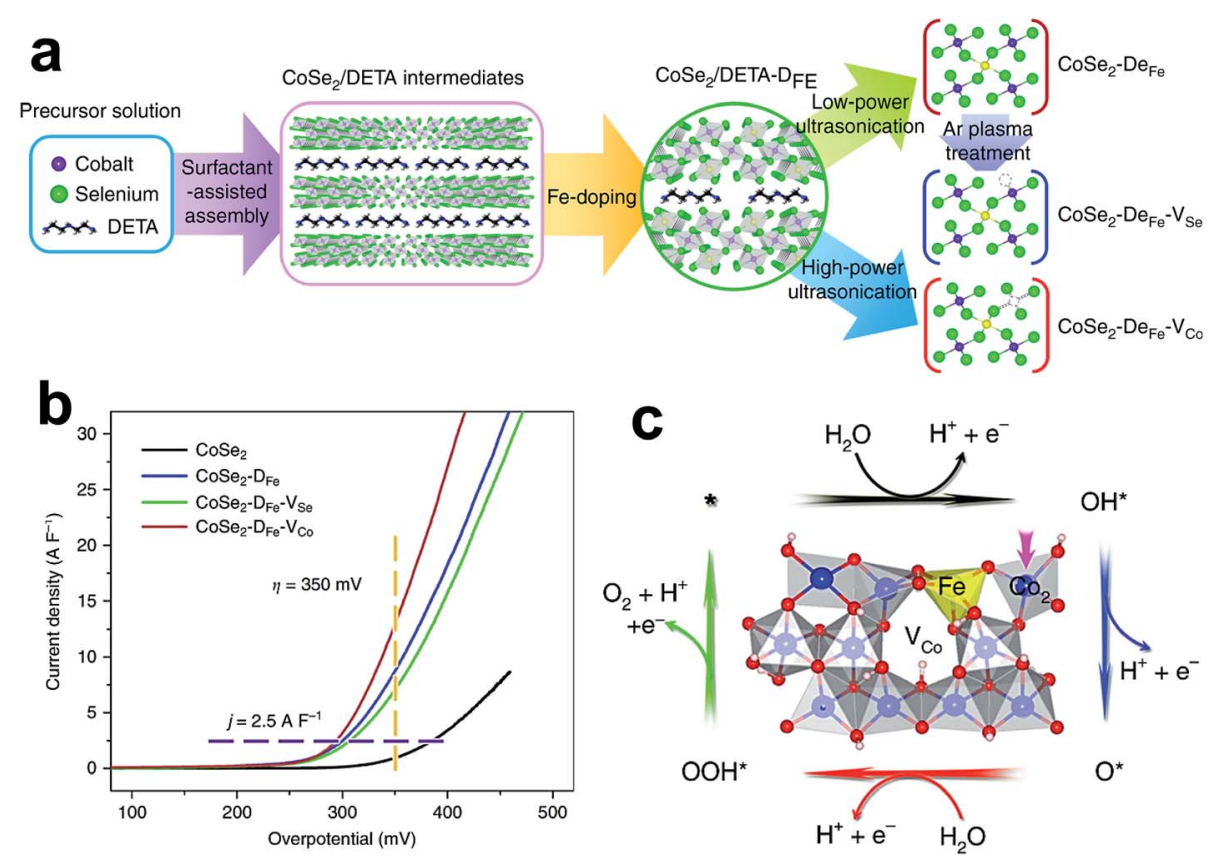

Fig. 13 (a) Schematic illustration of the synthetic methods for different catalysts; (b) LSV curves normalized by electrochemical double-layer capacitance; and (c) crystal structure of $\mathrm{FeCOOOH}-\mathrm{V}_{\mathrm{Co}}$ and the oxygen evolution reaction pathway on the (01-12) facets. ${ }^{182}$ Reproduced with open access.

nanobelts by simultaneous Fe doping and Co vacancy creation, as shown in Fig. 13a. ${ }^{182} \mathrm{LSV}$ curves of $\mathrm{CoSe}_{2}, \mathrm{CoSe}_{2}-\mathrm{D}_{\mathrm{Fe}}, \mathrm{CoSe}_{2}-$ $\mathrm{D}_{\mathrm{Fe}}-\mathrm{V}_{\mathrm{Se}}$, and $\mathrm{CoSe}_{2}-\mathrm{D}_{\mathrm{Fe}}-\mathrm{V}_{\mathrm{Co}}$ catalysts, normalized by electrochemical double-layer capacitance, are shown in Fig. 13b, and suggest that $\mathrm{CoSe}_{2}-\mathrm{D}_{\mathrm{Fe}}-\mathrm{V}_{\mathrm{Co}}$ has superior OER activity among the catalysts. Fig. 13c displays the $\mathrm{FeCOOOH}$ with $\mathrm{Co}$ vacancies and the OER mechanism occurring on its surface, which involves three OER intermediates $\left(* \mathrm{OH}, \mathrm{O}^{*}\right.$, and $\left.{ }^{*} \mathrm{OOH}\right)$ and four protoncoupled electron transfer steps. The Gibbs free energy profiles of this catalyst show different catalytic mechanisms for Co and Fe sites. The transformation of $\mathrm{OH}^{*}$ to $\mathrm{O}^{*}$ potentially limits the activity of Co active sites owing to the large Gibbs free energy difference $\left(\Delta G_{2}\right)$. In contrast, the conversion of $\mathrm{O} *$ to ${ }^{*} \mathrm{OOH}$ is the RDS $\left(\Delta G_{3}\right)$ in case of Fe sites, due to the high free energy difference. Theoretical simulations identified that the cobalt dimer $\left(\mathrm{CO}_{2}\right)$ is the most active site for the OER, and is present adjacent to the Co vacancy near the surface Fe site. The combinatorial effect of Co vacancy and Fe doping significantly intensifies the OER performance by reducing the peak intensity near the Fermi level, so the binding of ${ }^{*} \mathrm{OH}$ with active sites is weakened. Zou et al. found that the minimal amount of Fe $(7.4 \%)$ inclusion into the NiSe nanorod/nanosheet lattice significantly improved its OER activity. ${ }^{170}$ The Fe-doped NiSe only required $291 \mathrm{mV}$ overpotential to achieve $1000 \mathrm{~mA} \mathrm{~cm}{ }^{-2}$ current density. This superior activity is accredited to the increased electrical conductivity, active sites, and mass transfer. Xu et al. fabricated hierarchical Fe-doped $\mathrm{Ni}_{3} \mathrm{Se}_{4}$ on $\mathrm{Ni}$ foam using a hydrothermal method, and NiFe LDH was used as a precursor material. ${ }^{172}$ The doped sample shows superior OER activity than $\mathrm{IrO}_{2}$ and pristine catalysts, because of its higher electrical conductivity. Mohanty et al. reported an increase in
OER activity of nickel selenide, owing to the synergetic effect of Fe doping along with the creation of Se vacancies by chemical reduction with $\mathrm{NaBH}_{4} \cdot{ }^{176}$ Computational studies suggest an increase in DOS near the Fermi level because of Fe doping and Se vacancies, which helps in decreasing the energy barrier for OER intermediates.

Besides $\mathrm{Fe}$, Co was also used as a dopant to improve the OER performance of nickel selenides, ${ }^{165}$ and Co-doped NiSe nanoflowers grown on $\mathrm{Ni}$ foam exhibited considerable activity compared to their pristine counterpart. Here, Co doping generates more OER active sites via tuning the electronic structure of NiSe. Wang et al. showed MOF-derived Co-doped nickel selenide on Ni foam and analyzed its OER activity in alkaline electrolyte. ${ }^{164}$ The as-designed catalyst exhibits an overpotential of $275 \mathrm{mV}$ at $30 \mathrm{~mA} \mathrm{~cm} \mathrm{~cm}^{-2}$, and the high activity is ascribed to an increase in electrical conductivity because of Co doping. Zhang et al. co-doped $\mathrm{Ni}$ and $\mathrm{Fe}$ into the matrix of $\mathrm{CoSe}_{2}$, and noticed that the catalyst with a stoichiometric formula of $\mathrm{Ni}_{0.04} \mathrm{Fe}_{0.16} \mathrm{Co}_{0.8} \mathrm{Se}_{2}$ has remarkable OER activity among the prepared catalysts. ${ }^{175} \mathrm{Ni}$ doping does not alter the OER mechanism but reduces the energy barrier for the RDS and keeps Co-active sites intact, and Fe doping improves the charge transfer kinetics by transferring the active sites from Co to Fe. $\mathrm{FeSe}_{2}$ was doped with various transition elements (Co, Ni, Mn, and $\mathrm{Cu}$ ) by Wei et al. ${ }^{168}$ Among these dopants, $\mathrm{Cu}$ is found to be more effective and shows enhanced OER activity. The theoretical and experimental results reveal that $\mathrm{Cu}$ doping optimizes the electronic structure of the $\mathrm{FeSe}_{2}$ lattice to enable faster electron transfer and thus boosts the reaction kinetics of the OER. In cobalt selenide, the $\mathrm{Cu}$ doping results in a phase transformation from orthorhombic $\mathrm{CoSe}_{2}$ to monoclinic 
$\mathrm{Co}_{3} \mathrm{Se}_{4}$, causing improved OER performance of cobalt selenide. ${ }^{167}$ The electronic structure change in cobalt selenide by $\mathrm{Cu}$ doping is evident from X-ray photoelectron spectroscopy and theoretical simulations. DFT calculations further reveal that because of structural transformation from orthorhombic $\mathrm{CoSe}_{2}$ to monoclinic $\mathrm{Co}_{3} \mathrm{Se}_{4}$, and the Gibbs free energy for the RDS was drastically decreased from 2.64 to $1.90 \mathrm{eV}$.

The minimal amount of $\mathrm{Ag}(1 \%)$ doping into the lattice domain of $\mathrm{CoSe}_{2}$ nanobelts significantly increases its electrical conductivity without much loss of active sites (Co). ${ }^{\mathbf{1 6 2}} \mathrm{Ag}$-doped $\mathrm{CoSe}_{2}$ nanobelts exhibit high OER activity relative to pristine $\mathrm{CoSe}_{2}$ nanobelts, because of high electrical conductivity and active site retention. Incorporation of low-valence $\mathrm{Zn}$ into the $\mathrm{CoSe}_{2}$ lattice domain triggers subtle changes in the lattice and increases the number of active sites for the OER. ${ }^{177}$ Theoretical simulations suggest that $\mathrm{Zn}$ inclusion decreases the kinetic energy barrier for the adsorption of OER intermediates by encouraging adsorption on Co sites and neighboring $\mathrm{Zn}$ sites. Boron doping into the lattice of ternary pyrite selenide $\left(\mathrm{Fe}_{5^{-}}\right.$ $\mathrm{Co}_{4} \mathrm{Ni}_{20} \mathrm{Se}_{36}$ ) decreased its overpotential from 543 to $279.8 \mathrm{mV}$ at $10 \mathrm{~mA} \mathrm{~cm}^{-2}$, with the Tafel slope lowered from 161 to $59.5 \mathrm{mV}$ $\operatorname{dec}^{-1} \cdot{ }^{163}$ Fig. 14a and b show the schematic representation of $\mathrm{NiSe}_{2}$ and $\mathrm{Fe}_{5} \mathrm{Co}_{4} \mathrm{Ni}_{20} \mathrm{Se}_{36} \mathrm{~B}_{x}$ crystal structures, and the doped $\mathrm{B}$ atoms are incorporated into the interstitial positions and some $\mathrm{B}$ atoms even bond with metals ( $\mathrm{Ni}, \mathrm{Co}$, and $\mathrm{Fe}$ ). The proposed OER mechanisms on pristine and doped pyrite are shown in Fig. 14c and d, and reveal that B doping facilitates an easy discharge of ${ }^{*} \mathrm{OOH}$ from the active sites, as a consequence of lower Gibbs free energy. The PDOS reveals that B doping significantly reduces the total d electrons around metals, enhancing the interaction between them and thus weakening the bond between ${ }^{*} \mathrm{OOH}$ and active sites. Recently, anion doping, i.e., doping on the Se site, was also found to be beneficial in enhancing the OER activity. For example, Xu et al. reported doping of sulfur on the Se site, enhancing the OER activity of bimetallic cobalt iron selenide $\mathrm{Co}_{0.75} \mathrm{Fe}_{0.25}\left(\mathrm{~S}_{0.2} \mathrm{Se}_{0.8}\right)_{2}$ as compared to non-doped $\mathrm{Co}_{0.75} \mathrm{Fe}_{0.25} \mathrm{~S}_{2}$ and $\mathrm{Co}_{0.75} \mathrm{Fe}_{0.25} \mathrm{Se}_{2}$, since charge transfer and electrochemical surface area were increased by doping. ${ }^{166}$

\subsection{Metal phosphides}

In the past five years, metal phosphides have emerged as one of the most promising types of catalyst for water oxidation, even though the first metal phosphide catalyst was reported as early as in $1990 .^{183}$ Some doped metal phosphides and their performances are listed in Table 4. Incorporation of a second element into the matrix of a metal phosphide could enhance the OER performance, in terms of both activity and stability. ${ }^{\mathbf{1 8 4 , 1 8 5}}$ For instance, Chen et al. doped Fe into the matrix of CoP ultrathin nanosheets grown on $\mathrm{Ni}$ foam, which exhibited a very low overpotential of $67 \mathrm{mV}$ at $10 \mathrm{~mA} \mathrm{~cm}{ }^{-2}$ in $1 \mathrm{M} \mathrm{KOH.}{ }^{\mathbf{1 8 6}}$ The excellent OER activity is attributed to the interference of $\mathrm{Fe} / \mathrm{Co} /$ $\mathrm{Ni}$ in the low current density region. Post OER characterization revealed the complete absence of $\mathrm{P}$ because of the formation of CoOOH active species during the OER. Baek and coworkers synthesized Fe-doped porous CoP polyhedrons from MOFs by varying the $\mathrm{Fe} / \mathrm{Co}$ ratio. ${ }^{187}$ Among them, $\mathrm{Co}_{0.68} \mathrm{Fe}_{0.32} \mathrm{P}$ had better OER activity over its pristine counterparts, i.e., CoP and FeP. Fe doping accelerated the discharge of OER intermediates by optimizing their adsorption energy and stabilized the P species during contact with air. Peng's group initially conducted theoretical simulations to predict the $\mathrm{Fe}$ influence on the water oxidation capability of $\mathrm{Ni}_{2} \mathrm{P}$ by constructing partially oxidized
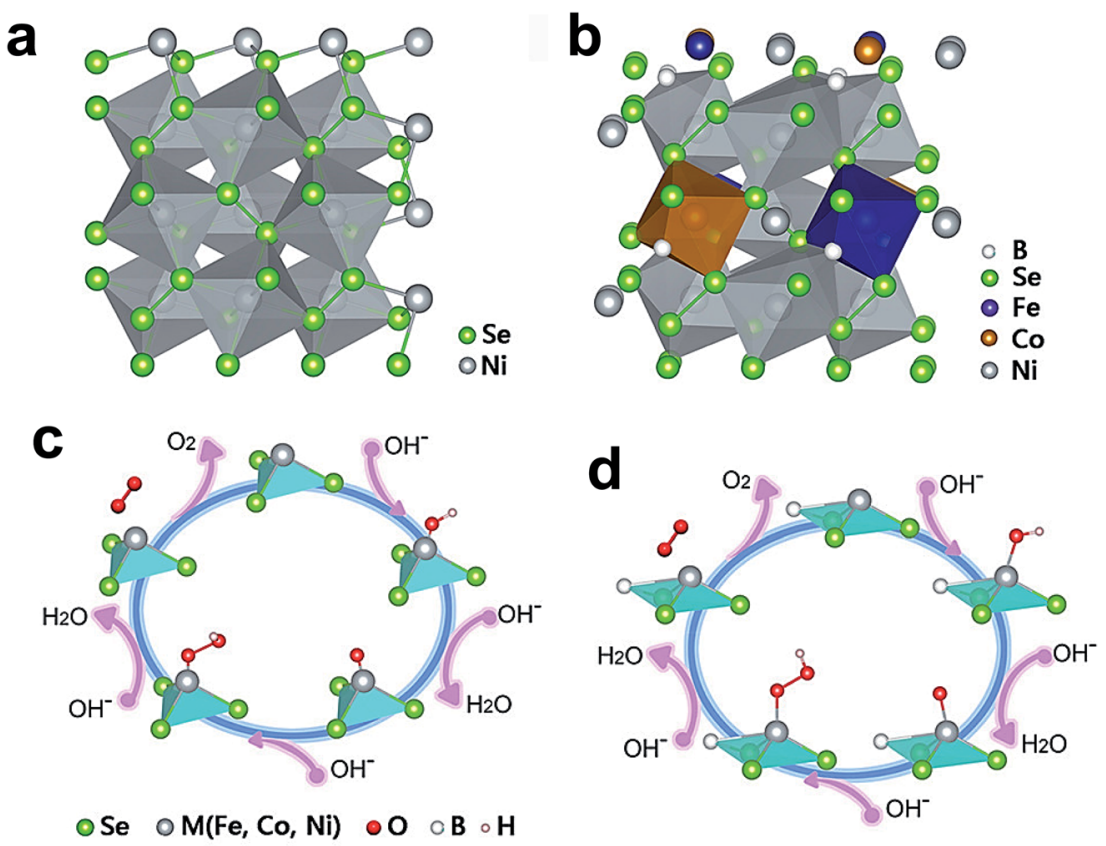

Fig. 14 (a and b) Schematic illustration of $\mathrm{NiSe}_{2}$ and $\mathrm{Fe}_{5} \mathrm{CO}_{4} \mathrm{Ni}_{20} \mathrm{Se}_{36} \mathrm{~B}_{x}$ crystal structures, and (c and d) proposed OER mechanisms for pyrite selenides before and after B dopant incorporation. ${ }^{163}$ Reproduced from ref. 163 with permission, (C) 2019 American Chemical Society. 
Table 4 Summary of representative doped phosphides, nitrides, and carbides and their catalytic performances

\begin{tabular}{|c|c|c|c|c|}
\hline Catalyst & $\begin{array}{l}\text { Overpotential at a specific } \\
\text { current density }\end{array}$ & $\begin{array}{l}\text { Tafel slope } \\
\left(\mathrm{mV} \mathrm{dec}^{-1}\right)\end{array}$ & Durability & Electrolyte \\
\hline \multicolumn{5}{|l|}{ Metal phosphides } \\
\hline Al-doped CoP ${ }^{193}$ & $360 \mathrm{mV} @ 200 \mathrm{~mA} \mathrm{~cm}{ }^{-2}$ & 38 & $150 \mathrm{~h}$ @ $10 \mathrm{~mA} \mathrm{~cm}^{-2}$ & $1 \mathrm{M} \mathrm{KOH}$ \\
\hline $\mathrm{Co}_{0.68} \mathrm{Fe}_{0.32} \mathrm{P}^{187}$ & $289 \mathrm{mV} @ 50 \mathrm{~mA} \mathrm{~cm}{ }^{-2}$ & 64 & $3600 \mathrm{~s} @ 10 \mathrm{~mA} \mathrm{~cm}{ }^{-2}$ & $1 \mathrm{M} \mathrm{KOH}$ \\
\hline $\mathrm{Fe}_{0.27} \mathrm{Co}_{0.73} \mathrm{P} / \mathrm{NF}^{184}$ & $251 \mathrm{mV}$ @ $10 \mathrm{~mA} \mathrm{~cm}{ }^{-2}$ & 59.1 & $40 \mathrm{~h}$ @ $40 \mathrm{~mA} \mathrm{~cm}-2$ & $1 \mathrm{M} \mathrm{KOH}$ \\
\hline Fe-doped $\mathrm{CoP}^{186}$ & $166 \mathrm{mV} @ 50 \mathrm{~mA} \mathrm{~cm} \mathrm{~cm}^{-2}$ & 65.82 & $50 \mathrm{~h}$ @ $50 \mathrm{~mA} \mathrm{~cm}{ }^{-2}$ & $1 \mathrm{M} \mathrm{KOH}$ \\
\hline Fe-doped $\mathrm{Ni}_{2} \mathrm{P}^{192}$ & $330 \mathrm{mV} @ 20 \mathrm{~mA} \mathrm{~cm}{ }^{-2}$ & 39 & $10 \mathrm{~h} @ 20 \mathrm{~mA} \mathrm{~cm}^{-2}$ & $1 \mathrm{M} \mathrm{KOH}$ \\
\hline Fe-doped $\mathrm{Ni}_{2} \mathrm{P}^{188}$ & $300 \mathrm{mV}$ @ $1000 \mathrm{~mA} \mathrm{~cm}{ }^{-2}$ & 52 & - & $1 \mathrm{M} \mathrm{KOH}$ \\
\hline $\mathrm{Fe}_{x} \mathrm{~V}_{y-x} \mathrm{PC} / \mathrm{NF}^{189}$ & $201 \mathrm{mV}$ @ $10 \mathrm{~mA} \mathrm{~cm}{ }^{-2}$ & 75 & $24 \mathrm{~h} @ 10 \mathrm{~mA} \mathrm{~cm}^{-2}$ & $1 \mathrm{M} \mathrm{KOH}$ \\
\hline Mn-doped $\mathrm{CoP}^{194}$ & $261 \mathrm{mV} @ 10 \mathrm{~mA} \mathrm{~cm} \mathrm{~cm}^{-2}$ & 44.9 & $24 \mathrm{~h}$ @ $10 \mathrm{~mA} \mathrm{~cm}{ }^{-2}$ & $1 \mathrm{M} \mathrm{KOH}$ \\
\hline Mn-doped $\mathrm{Ni}_{2} \mathrm{P}^{195}$ & $330 \mathrm{mV} @ 100 \mathrm{~mA} \mathrm{~cm} \mathrm{~cm}^{-2}$ & 116.7 & 18 h @ 320 mV & $1 \mathrm{M} \mathrm{KOH}$ \\
\hline $\mathrm{NiCoFeP} / \mathrm{NF}^{191}$ & $271 \mathrm{mV} @ 200 \mathrm{~mA} \mathrm{~cm}{ }^{-2}$ & 45 & $10 \mathrm{~h}$ @ $1.485 \mathrm{~V} v s . \mathrm{RHE}$ & $1 \mathrm{M} \mathrm{KOH}$ \\
\hline $\mathrm{NiCoFe}_{x} \mathrm{P} / \mathrm{CC}^{190}$ & $275 \mathrm{mV} @ 50 \mathrm{~mA} \mathrm{~cm}{ }^{-2}$ & 50 & $150 \mathrm{~h}$ @ $1.70 \mathrm{~V} v s . \mathrm{RHE}$ & $1 \mathrm{M} \mathrm{KOH}$ \\
\hline $\mathrm{NCNP}^{196}$ & $229 \mathrm{mV}$ @ $10 \mathrm{~mA} \mathrm{~cm}{ }^{-2}$ & 78.6 & $100 \mathrm{~h} @ 100 \mathrm{~mA} \mathrm{~cm}{ }^{-2}$ & $1 \mathrm{M} \mathrm{KOH}$ \\
\hline $\mathrm{Ni}_{1.85} \mathrm{Fe}_{0.15} \mathrm{P}$ NSAs $/ \mathrm{NF}^{185}$ & $270 \mathrm{mV}$ @ $20 \mathrm{~mA} \mathrm{~cm}{ }^{-2}$ & 96 & $10 \mathrm{~h}$ @ $330 \mathrm{mV}$ & $1 \mathrm{M} \mathrm{KOH}$ \\
\hline $\mathrm{Ni}_{2} \mathrm{P} /(\mathrm{NiFe}) 2 \mathrm{P}(\mathrm{O}) \mathrm{NAs}^{197}$ & $530 \mathrm{mV} @ 800 \mathrm{~mA} \mathrm{~cm}{ }^{-2}$ & 60 & $100 \mathrm{~h}$ @ $500 \mathrm{mV}$ & $1 \mathrm{M} \mathrm{KOH}$ \\
\hline $\mathrm{N}-\mathrm{NiVFeP} / \mathrm{NFF}^{198}$ & $229 \mathrm{mV} @ 10 \mathrm{~mA} \mathrm{~cm}{ }^{-2}$ & 78.6 & $100 \mathrm{~h} @ 100 \mathrm{~mA} \mathrm{~cm}{ }^{-2}$ & $1 \mathrm{M} \mathrm{KOH}$ \\
\hline O-doped $\mathrm{Co}_{2} \mathrm{P} / \mathrm{CuO} \mathrm{NWs} / \mathrm{CF} \mathrm{P}^{199}$ & $270 \mathrm{mV}$ @ $10 \mathrm{~mA} \mathrm{~cm}{ }^{-2}$ & 74.4 & $30 \mathrm{~h}$ @ $10 \mathrm{~mA} \mathrm{~cm}-2$ & $1 \mathrm{M} \mathrm{KOH}$ \\
\hline S-doped CoP/NF ${ }^{200}$ & $300 \mathrm{mV} @ 10 \mathrm{~mA} \mathrm{~cm}{ }^{-2}$ & 82 & $20 \mathrm{~h}$ @ $350 \mathrm{mV}$ & $1 \mathrm{M} \mathrm{KOH}$ \\
\hline \multicolumn{5}{|l|}{ Metal nitrides } \\
\hline Co-doped MoNi nitride ${ }^{201}$ & $294 \mathrm{mV} @ 10 \mathrm{~mA} \mathrm{~cm}{ }^{-2}$ & 73 & $10 \mathrm{~h}$ @ $317 \mathrm{mV}$ & $0.1 \mathrm{M} \mathrm{KOH}$ \\
\hline Fe-doped cobalt nitride ${ }^{202}$ & $200 \mathrm{mV}$ @ $10 \mathrm{~mA} \mathrm{~cm}{ }^{-2}$ & 42.44 & $10 \mathrm{~h}$ @ $200 \mathrm{mV}$ & $1 \mathrm{M} \mathrm{KOH}$ \\
\hline $\mathrm{Mn}_{0.15} \mathrm{Co}_{0.85} \mathrm{~N}^{203}$ & $265 \mathrm{mV} @ 10 \mathrm{~mA} \mathrm{~cm}{ }^{-2}$ & 48 & $30 \mathrm{~h}$ @ $280 \mathrm{mV}$ & $1 \mathrm{M} \mathrm{KOH}$ \\
\hline $\mathrm{Mn}_{0.15} \mathrm{Co}_{0.85} \mathrm{~N}^{203}$ & $285 \mathrm{mV} @ 10 \mathrm{~mA} \mathrm{~cm}{ }^{-2}$ & 64 & $30 \mathrm{~h}$ @ $285 \mathrm{mV}$ & $1 \mathrm{M}$ phosphate-buffered saline \\
\hline $\mathrm{P}, \mathrm{F}-\mathrm{Ni}_{1.5} \mathrm{Co}_{1.5} \mathrm{~N}^{204}$ & $350 \mathrm{mV}$ @ $100 \mathrm{~mA} \mathrm{~cm}{ }^{-2}$ & 66.1 & - & $1 \mathrm{M} \mathrm{KOH}$ \\
\hline $\mathrm{P}_{-N i M o} \mathrm{~N}_{5} @ \mathrm{Ni}^{205}$ & $435 \mathrm{mV}$ @100 mA cm ${ }^{-2}$ & 65 & $24 \mathrm{~h}$ @ $50 \mathrm{mV}$ & $1 \mathrm{M} \mathrm{KOH}$ \\
\hline \multicolumn{5}{|l|}{ Metal carbides } \\
\hline $\mathrm{B}, \mathrm{N}: \mathrm{Mo}_{2} \mathrm{C} @ \mathrm{BCN}^{206}$ & $360 \mathrm{mV} @ 100 \mathrm{~mA} \mathrm{~cm}{ }^{-2}$ & 61 & $20 \mathrm{~h}$ @ $350 \mathrm{mV}$ & $1 \mathrm{M} \mathrm{KOH}$ \\
\hline $\mathrm{Co}_{3} \mathrm{C}-\mathrm{NB}^{207}$ & $354 \mathrm{mV} @ 10 \mathrm{~mA} \mathrm{~cm}-2$ & 90 & $24 \mathrm{~h} @ 50 \mathrm{~mA} \mathrm{~cm}{ }^{-2}$ & $0.1 \mathrm{M} \mathrm{KOH}$ \\
\hline Co-doped $\beta-\mathrm{Mo}_{2} \mathrm{C}^{208}$ & $262.2 \mathrm{mV}$ @ $10 \mathrm{~mA} \mathrm{~cm}{ }^{-2}$ & 28.8 & $16 \mathrm{~h}$ @ $1.49 \mathrm{~V} v s . \mathrm{RHE}$ & $1 \mathrm{M} \mathrm{KOH}$ \\
\hline Co-doped Ni $\mathrm{C} / \mathrm{Ni@C} \mathrm{C}^{209}$ & $325 \mathrm{mV}$ @ $10 \mathrm{~mA} \mathrm{~cm}{ }^{-2}$ & 67.76 & $100000 \mathrm{~s} @ 10 \mathrm{~mA} \mathrm{~cm}-2$ & $1 \mathrm{M} \mathrm{KOH}$ \\
\hline FCC@CNOs/NF ${ }^{210}$ & $271 \mathrm{mV} @ 10 \mathrm{~mA} \mathrm{~cm}{ }^{-2}$ & 48.9 & $40 \mathrm{~h}$ @ $100 \mathrm{~mA} \mathrm{~cm}{ }^{-2}$ & $1 \mathrm{M} \mathrm{KOH}$ \\
\hline Fe-doped $\mathrm{Ni}_{3} \mathrm{C}^{211}$ & $275 \mathrm{mV}$ @ $10 \mathrm{~mA} \mathrm{~cm}{ }^{-2}$ & 62 & $10 \mathrm{~h} @ 1.5 \mathrm{~V} v s . \mathrm{RHE}$ & $1 \mathrm{M} \mathrm{KOH}$ \\
\hline $\mathrm{V}_{0.28} \mathrm{Co}_{2.72} \mathrm{C} / \mathrm{CNFs}^{212}$ & $210 \mathrm{mV} @ 10 \mathrm{~mA} \mathrm{~cm}{ }^{-2}$ & 147 & $10 \mathrm{~h} @ 1.4 \mathrm{~V} v s . \mathrm{RHE}$ & $1 \mathrm{M} \mathrm{KOH}$ \\
\hline
\end{tabular}

surfaces of $\mathrm{Ni}$ (111), $\mathrm{Ni}_{2} \mathrm{P}$ (111), and Fe-doped $\mathrm{Ni}_{2} \mathrm{P}$ (111) models. ${ }^{188}$ The Gibbs free energy studies reveal that the Fedoped sample requires an energy $0.14 \mathrm{eV}$ lower than that of $\mathrm{Ni}_{2} \mathrm{P}$ for the RDS $(\mathrm{O} *$ to $* \mathrm{OOH})$. Experimental results were in accordance with the theoretical calculations, and they observed the formation of Fe, $\mathrm{P}$ co-doped $\gamma$-NiOOH during the electrochemical water oxidation reaction from the Fe-doped $\mathrm{Ni}_{2} \mathrm{P}$. Fe, $\mathrm{P}$ co-doped $\gamma$-NiOOH is a good catalyst for improved OER activity, and Fe doping primarily enhances the active sites for the OER. Xiang et al. tuned the electronic structure of vanadium phosphide by including Fe into its lattice domain, which demonstrated remarkable OER activity. ${ }^{189}$ Among all the samples, the sample with a $1: 3$ ratio of $\mathrm{Fe} / \mathrm{V}$ has the highest activity. XPS analysis identifies increased valency of $\mathrm{V}$ because of the incorporation of $\mathrm{Fe}$, which optimizes the adsorption of $* \mathrm{OH}$ on active sites. Fe doping of bimetallic phosphides was also found to significantly contribute to improving electrochemical water oxidation.

Like monometallic phosphides, bimetallic phosphides can also convert into their respective oxyhydroxides at high anodic potentials. Fe-doped NiCoP converts into Fe-doped NiOOH and
$\mathrm{CoOOH}$, and Fe doping improves the OER activity by accelerating the discharge of OER intermediates. ${ }^{190,191}$ Simultaneously, the conductive metallic phosphide support improves OER kinetics by promoting the proton transfer. Tsang and coworkers studied the comparative doping effects of TMs (Co, Fe, Mn, and Mo) on the OER activity of NiP. ${ }^{192}$ Among them, the Fe doped sample was found to have more prominent activity since $\mathrm{Fe}$ is able to tune the electronic structure of $\mathrm{Ni}$ to interact optimally with OER intermediates.

Mn doping of cobalt phosphide and nickel phosphide improves their catalytic activity for electrochemical water oxidation. In cobalt phosphide, Mn doping enhances the electrochemical surface area by increasing the number of exposed active sites. ${ }^{194}$ The optimal $\mathrm{Mn} / \mathrm{Ni}$ ratio of 0.053 is found to provide superior activity, as the $\mathrm{Ni}_{2} \mathrm{P}$ electronic structure is optimized. ${ }^{195} \mathrm{Al}$ doping was also used to enhance the electrochemical surface area of cobalt phosphide by dissolution during the OER. Al-doped cobalt phosphide shows a fourfold increase in electrochemical surface area compared to the pristine sample by the formation of $\mathrm{Al} / \mathrm{Co}$ spinel oxide and partial leaching of Al. ${ }^{193}$ 
Along with doping of metals, doping of non-metals such as $\mathrm{N}, \mathrm{O}$, and $\mathrm{S}$ can also enhance the electrocatalytic activity of phosphide catalysts for the OER. ${ }^{196,198-200} \mathrm{~N}$ doping in the anionic site (P) of NiCoP improved its OER performance, with better activity compared to NiCoP and NiCoN. The high activity was induced by the formation of abundant oxygen vacancies, improving the charge transfer during oxygen generation. ${ }^{196}$ Likewise, oxygen and sulfur were also doped on the anionic sites to increase the OER activity of metallic phosphides. Oxygen doping of cobalt phosphide generates abundant defects and electroactive sites on the surface by optimizing the adsorption energy of reactants. ${ }^{199}$ In the case of bimetallic nickel-iron phosphide, the OER activity is enhanced by oxygen doping on account of an efficient decrease in the energy barrier of OER intermediates and products. ${ }^{197}$ Electronegative sulfur doping in the anionic site of cobalt phosphide significantly improved its OER activity, owing to the tuning of the electronic structure and increased number of active sites. ${ }^{200}$

\subsection{Metal nitrides and carbides}

Metal nitrides belong to an interstitial compound family, which contains nitrogen atoms on the interstitial sites of parent compounds. The presence of $\mathrm{N}$ atoms on the interstitial sites increases the distance between metal atoms; thus, it tunes the $\mathrm{d}$ band structure.$^{20}$ Some doped metal nitrides and carbides and their performances are listed in Table 4 . Recent studies on the electrochemical activity of metal nitrides suggest that they are highly active for the OER owing to their high electrical conductivity. ${ }^{\mathbf{2 0 4 , 2 0 5}}$ However, the OER activity and stability were further improved by tuning their electronic structure by doping with TMs and non-metals. For instance, Mn-doped CoN nanowires grown on carbon cloth exhibit good OER activity in alkaline and neutral electrolytes. ${ }^{203}$ Among the doped catalysts, $\mathrm{Mn}_{0.15} \mathrm{Co}_{0.85} \mathrm{~N}$ shows superior activity, and $\mathrm{Mn}$ doping considerably increases the charge transfer kinetics and facilitates the optimized discharge of OER intermediates. Zhou et al. investigated the doping effect of various metal atoms, such as $\mathrm{Zn}, \mathrm{Ni}$, $\mathrm{Fe}$, and $\mathrm{Mn}$, on the OER activity of cobalt nitride nanosheets. ${ }^{\mathbf{2 0 2}}$ The Fe doped one has better OER activity, and XPS analysis suggests more $\mathrm{Co}^{4+}$ OER active species because of the doping effect of Lewis acid $\mathrm{Fe}^{3+}$.

Cobalt doping into the lattice of bimetallic MoNi nitride nanowires shows a considerable increase in their OER activity by reduced charge transfer resistance and augmentation of the electrochemically active surface area. ${ }^{201}$ The dual modulation in the electronic structure of Mo and Ni was induced by cobalt doping that improved the electrical conductivity for highly active OER sites. Liang et al. theoretically studied the doping effect of first-row TMs (Sc to $\mathrm{Zn}$ ) for improving the OER activity of $\mathrm{Al} / \mathrm{GaN} .^{213}$ The inclusion of transition metals from Sc to $\mathrm{Fe}$ resulted in low OER activity because they bonded to OER intermediates too firmly and resulted in high overpotentials. Meanwhile, $\mathrm{Cu}$ and $\mathrm{Zn}$ also displayed no or low OER activity, as they attached to the intermediates very weakly. Only Ni doping had significant OER activity because it could switch from a high spin state to a low spin state and stabilized the $\mathrm{OOH}$ adsorbate.
Tong and coworkers synthesized $\mathrm{P}$ and Co dual-doped vanadium nitride nanowires using a combined hydrothermal and annealing approach. ${ }^{214}$ The dual-doped vanadium nitrate catalyst showed better activity and durability for the OER, compared to the single-doped or pristine sample, or $\mathrm{IrO}_{2}$. Dual doping of Co and $\mathrm{P}$ synergistically tunes the number of active sites on the catalyst surface by moving the d states of vanadium closer to the Fermi level.

Zhang and coworkers demonstrated an increase in the OER performance of bi-metallic nitrides by co-doping with phosphorus and fluorine. ${ }^{204}$ Fig. 15a shows the schematic representation of the fabrication process for $\mathrm{P}$ and $\mathrm{F}$ co-doped nickel-cobalt nitride $\left(\mathrm{PF} / \mathrm{Ni}_{1.5} \mathrm{Co}_{1.5} \mathrm{~N}\right)$ nanorods using an ionic liquid. The $\mathrm{PF} / \mathrm{Ni}_{1.5} \mathrm{Co}_{1.5} \mathrm{~N}$ prepared without using any ionic liquid results in a lamellar structure, as displayed in Fig. 15b. The SEM and elemental mapping analysis results of $\mathrm{PF} /$ $\mathrm{Ni}_{1.5} \mathrm{Co}_{1.5} \mathrm{~N}$ nanorods are presented in Fig. $15 \mathrm{c}$ and $\mathrm{d}$, which indicates the uniform distribution of $\mathrm{N}$ and $\mathrm{F}$ dopants all over the catalyst. Fig. 15e and f show the IR uncompensated LSV curves and comparison of $\eta_{10}$ values (potentials required to reach $10 \mathrm{~mA} \mathrm{~cm}{ }^{-2}$ ) for $\mathrm{PF} / \mathrm{Co}_{x} \mathrm{Ni}_{3-x} \mathrm{~N}$ catalysts. Electrochemical studies reveal that the $\mathrm{PF} / \mathrm{Ni}_{1.5} \mathrm{Co}_{1.5} \mathrm{~N}$ catalyst shows augmented OER activity as well as facile reaction kinetics among the prepared catalysts. DFT calculations suggest that co-doping of $\mathrm{P}$ and $\mathrm{F}$ atoms into the lattice of the $\mathrm{Ni}_{1.5} \mathrm{Co}_{1.5} \mathrm{~N}$ catalyst considerably decreases the free energy barrier for OER intermediates, thus helps in improving the electrocatalytic performance.

Recently, researchers found that metal carbides, specifically transition metal carbides, can be applied as electrocatalysts for the OER owing to their high stability. ${ }^{215}$ Some doped metal carbides and their performances are listed in Table 4. The activity of TM carbides was improved by including one or more foreign dopants into their lattice domain. Yan et al. improved the OER activity of $\mathrm{Ni}_{3} \mathrm{C}$ by doping $2 \%$ atomic iron, which yields an overpotential of $275 \mathrm{mV}$ at $10 \mathrm{~mA} \mathrm{~cm}{ }^{-2} \cdot{ }^{211}$ The optimized doping of Fe tuned the electronic structure of $\mathrm{Ni}$ and thus improved the number of active sites on the surface. Similarly, Jia et al. tuned the water oxidation ability of $\mathrm{Ni}_{3} \mathrm{C}$ via incorporation of a small amount of Co into it using a MOF-derived method..$^{209}$ The as-fabricated catalyst had better activity than the $\mathrm{IrO}_{2}$ catalyst in the alkaline electrolyte, and the improved activity was associated with the active surface sites through optimization of electronic properties. In general, the $\mathrm{Mo}_{2} \mathrm{C}$ catalyst is inactive for the OER, but doping $10 \%$ cobalt into the $\mathrm{Mo}_{2} \mathrm{C}$ catalyst was found to increase its OER performance through significant enhancement in the density of active sites of the catalyst. ${ }^{208}$ Zhao et al. optimized the electronic structure of $\mathrm{Co}_{3} \mathrm{C}$ by doping with low electronegativity vanadium element. ${ }^{212}$ Specifically, $\mathrm{V}_{0.28} \mathrm{Co}_{2.72} \mathrm{C}$ shows superior activity by forming local negative Co centers through the intake of electrons from vanadium dopants. $\mathrm{Xu}$ et al. doped TMs such as $\mathrm{Mn}, \mathrm{Co}$, and $\mathrm{Ni}$ into the matrix of $\mathrm{Fe}_{3} \mathrm{C}$ and evaluated its OER performance. ${ }^{210}$ They noticed that Co-doped iron carbide had enhanced activity, and the Gibbs free energy was estimated in the different steps in the OER process. The free energy profiles of the Co and Fe sites were compared, and the Gibbs free energy required for the Co site $(2.35 \mathrm{eV})$ was lower than that for the Fe site $(2.75 \mathrm{eV})$, for the 

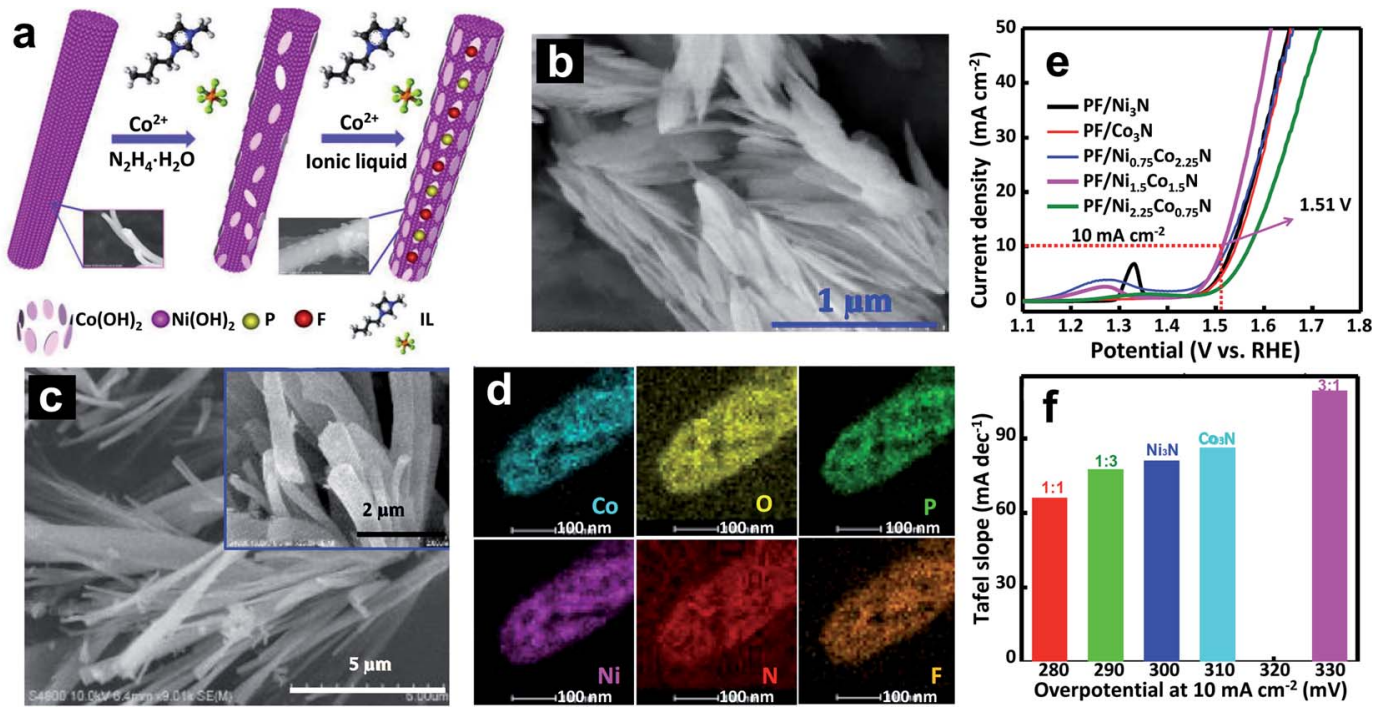

Fig. 15 (a) Schematic illustration of the fabrication processes for PF/ $\mathrm{Ni}_{1.5} \mathrm{CO}_{1.5} \mathrm{~N}$ nanorods; (b) SEM; (c) highly magnified SEM; (d) HAADF-STEM elemental mapping results of the heteroatom doped $\mathrm{Ni}-\mathrm{Co}(1: 1)$ precursor; (e) LSV curves of PF/Co ${ }_{x} \mathrm{Ni}_{3-x} \mathrm{~N}$ catalysts for the OER (400 mg of ionic liquid, without IR compensation); and (f) comparison of $\eta_{10}$ values (potentials required to reach $10 \mathrm{~mA} \mathrm{~cm}^{-2}$ ) for various catalysts (Ni : Co = $1: 1,1: 3,1: 0,0: 1$, and $3: 1)^{204}$ Reproduced from ref. 204 with permission, @ 2017 John Wiley and Sons.

conversion of * $\mathrm{O}$ to $* \mathrm{OOH}(\mathrm{RDS})$. From the comparison, Fe has a stronger affinity towards ${ }^{*} \mathrm{O}$ compared to $\mathrm{Co}$, hence doping of Co into the $\mathrm{Fe}_{3} \mathrm{C}$ facilitates the discharge of intermediates, thus lowering the potential.

Doping of metal carbides on the anionic site also improves their activity for electrocatalytic oxygen evolution. Generally, WC is a poor OER catalyst; however, when the carbon site is doped with nitrogen, it shows even better OER performance than $\mathrm{IrO}_{2}$ in an acid electrolyte. ${ }^{216}$ The $\mathrm{N}$ doping helps in accelerating the discharge of intermediates and thus improves activity, but its poor stability is still a concern. Dual doping of $\mathrm{N}$ and $\mathrm{B}$ on the anionic site of $\mathrm{Co}_{3} \mathrm{C}$ considerably increases its water oxidation ability compared to the pristine or single-doped sample, or $\mathrm{IrO}_{2}$. The synergetic effect of $\mathrm{N}$ and $\mathrm{B}$ dopants improves both activity and stability by boosting the charge transfer kinetics of intermediates. ${ }^{207}$ Likewise, Lee and coworkers synthesized dual-doped $\mathrm{N}$ and $\mathrm{B}$ into the matrix of $\mathrm{Mo}_{2} \mathrm{C}$ embedded in the $\mathrm{B}, \mathrm{N}$ doped carbon network (B, $\mathrm{N}: \mathrm{Mo}_{2}-$ $\mathrm{C} @ \mathrm{BCN}$ ), which shows a considerable increase in OER activity compared to the mono-doped or pristine sample, or $\mathrm{IrO}_{2}{ }^{206}$ The significant improvement in electrocatalytic performance is accredited to the formation of active B- and N-doped molybdenum oxide at high anodic potentials.

\section{Tuning carbon-based catalysts}

Although metal-based catalysts are employed in electrocatalytic OER applications widely because of their promising capabilities to deliver efficient catalytic activity by variable oxidation states,${ }^{217}$ these catalysts suffer from relatively poor endurance, low selectivity, susceptibility towards potential gas poisoning, and hazardous environmental effects. In 2009, the first carbonbased catalyst was reported by Dai's group in fuel cells as an alternative to the platinum catalyst. ${ }^{218}$ Since then, carbon-based catalysts, particularly those doped with various heteroatoms or metals, have received extensive attention and tremendous progress has been made in electrocatalysis. ${ }^{219,220}$ Table 5 provides a summary of some representative doped carbonbased electrocatalysts and their catalytic performances.

\subsection{Graphene}

Graphene is a thin layer of single atoms packed with $\mathrm{sp}^{2}$ hybridized carbon atoms in a hexagonal lattice. It is considered either a zero-bandgap semiconductor or conductor because of its symmetric band structure. ${ }^{244}$ Hence, pristine graphene shows low or no catalytic activity; however, the unique structural flexibility of graphene allows extensive functionalization via doping to improve catalytic activity. The dopants could interrupt the $\mathrm{sp}^{2}$ hybridized network and induce the formation of $\mathrm{sp}^{3}$ in the lattice, resulting in an electronic density change that imparts catalytic activity to it. ${ }^{244}$ For instance, doping of $\mathrm{N}$ into the lattice of graphene disrupts the charge distribution and spin density of neighboring carbon atoms and, consequently, imparts OER activity. Yang et al. conducted a study to gain mechanistic insights into N-doped graphene in the OER. ${ }^{230}$ They identified the formation of electron-withdrawing pyridinic $\mathrm{N}$ functionalities, which is the key reason for the superior OER performance of $\mathrm{N}$-doped graphene. Xia's group studied the active sites in $\mathrm{N}$-doped graphene nanoribbons combined with other dopants, such as B, Cl, P, and S, using DFT calculations. ${ }^{245}$ Gibbs free energy analysis for the OER on doped graphene nanoribbons suggests that the conversion of $* \mathrm{O}$ to $* \mathrm{OOH}$ is the RDS. The co-doping shows better activity than mono-doping, and the synergetic effect of co-doping is mostly related to the distance between them. In another report, $\mathrm{N}$ doping was done by using polyaniline and graphene oxide as precursors, which 
Table 5 Summary of representative doped carbon-based electrocatalysts and their catalytic performances

\begin{tabular}{|c|c|c|c|c|}
\hline Catalyst & Overpotential at a specific current density & $\begin{array}{l}\text { Tafel slope } \\
\left(\mathrm{mV} \mathrm{dec}{ }^{-1}\right)\end{array}$ & Durability & Electrolyte \\
\hline 20-NMWNT ${ }^{221}$ & $320 \mathrm{mV}$ @ $10 \mathrm{~mA} \mathrm{~cm}{ }^{-2}$ & 68 & - & $1 \mathrm{M} \mathrm{NaOH}$ \\
\hline $\mathrm{B}, \mathrm{N}-$ carbon $^{222}$ & $340 \mathrm{mV}$ @ $10 \mathrm{~mA} \mathrm{~cm}{ }^{-2}$ & 84 & - & $1 \mathrm{M} \mathrm{KOH}$ \\
\hline $\mathrm{Co}-\mathrm{C}_{3} \mathrm{~N}_{4} / \mathrm{CNT}^{223}$ & $380 \mathrm{mV}$ @ $10 \mathrm{~mA} \mathrm{~cm} \mathrm{~cm}^{-2}$ & 68.4 & - & $1 \mathrm{M} \mathrm{KOH}$ \\
\hline Co-N/GF 224 & $313 \mathrm{mV} @ 10 \mathrm{~mA} \mathrm{~cm}{ }^{-2}$ & 84.1 & $30 \mathrm{~h}$ @ $1.6 \mathrm{~V} v s . \mathrm{RHE}$ & $1 \mathrm{M} \mathrm{KOH}$ \\
\hline Co-TA ${ }^{225}$ & $460 \mathrm{mV}$ @ $10 \mathrm{~mA} \mathrm{~cm}{ }^{-2}$ & 66 & - & $0.1 \mathrm{M} \mathrm{KOH}$ \\
\hline GO-PANi31-FP ${ }^{226}$ & $300 \mathrm{mV} @ 10 \mathrm{~mA} \mathrm{~cm}{ }^{-2}$ & 136 & - & $0.1 \mathrm{M} \mathrm{KOH}$ \\
\hline $\mathrm{N} / \mathrm{C}^{227}$ & $380 \mathrm{mV} @ 10 \mathrm{~mA} \mathrm{~cm} \mathrm{~cm}^{-2}$ & - & - & $0.1 \mathrm{M} \mathrm{KOH}$ \\
\hline $\mathrm{NCHCs}^{228}$ & $290 \mathrm{mV}$ onset potential & 90 & $12 \mathrm{~h}$ @ $1.6 \mathrm{~V} v s . \mathrm{RHE}$ & $0.1 \mathrm{M} \mathrm{KOH}$ \\
\hline NCNTFs $^{229}$ & $370 \mathrm{mV}$ @ $10 \mathrm{~mA} \mathrm{~cm} \mathrm{~cm}^{-2}$ & 93 & $10000 \mathrm{~s} @ 1.70 \mathrm{~V} v s . \mathrm{RHE}$ & $1 \mathrm{M} \mathrm{KOH}$ \\
\hline N-GRW ${ }^{230}$ & $360 \mathrm{mV} @ 10 \mathrm{~mA} \mathrm{~cm}{ }^{-2}$ & 47 & $24 \mathrm{~h}$ @ $10 \mathrm{~mA} \mathrm{~cm}^{-2}$ & $1 \mathrm{M} \mathrm{KOH}$ \\
\hline N-HC@G-900 (ref. 231) & $350 \mathrm{mV}$ @ $10 \mathrm{~mA} \mathrm{~cm}{ }^{-2}$ & 88.1 & $25000 \mathrm{~s} @ 10 \mathrm{~mA} \mathrm{~cm}-2$ & $1 \mathrm{M} \mathrm{KOH}$ \\
\hline N-HC@G-900 (ref. 231) & $350 \mathrm{mV} @ 10 \mathrm{~mA} \mathrm{~cm}{ }^{-2}$ & 297.5 & $7500 \mathrm{~s}$ @ $1 \mathrm{~mA} \mathrm{~cm}{ }^{-2}$ & $0.5 \mathrm{M} \mathrm{H}_{2} \mathrm{SO}_{4}$ \\
\hline 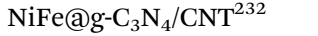 & $326 \mathrm{mV}$ @ $10 \mathrm{~mA} \mathrm{~cm}{ }^{-2}$ & 67 & $16 \mathrm{~h}$ @ $10 \mathrm{~mA} \mathrm{~cm}{ }^{-2}$ & $1 \mathrm{M} \mathrm{KOH}$ \\
\hline Ni, Fe@PCN ${ }^{233}$ & $310 \mathrm{mV}$ @ $10 \mathrm{~mA} \mathrm{~cm} \mathrm{~cm}^{-2}$ & 38 & $2 \mathrm{~h}$ (a) $1.53 \mathrm{~V} v s . \mathrm{RHE}$ & $1 \mathrm{M} \mathrm{KOH}$ \\
\hline $\mathrm{Ni}, \mathrm{N}$ doped graphene $\mathrm{e}^{234}$ & $270 \mathrm{mV}$ @ $10 \mathrm{~mA} \mathrm{~cm} \mathrm{~cm}^{-2}$ & 59 & $40 \mathrm{~h}$ @ $1.40 \mathrm{~V} v s . \mathrm{RHE}$ & $1 \mathrm{M} \mathrm{KOH}$ \\
\hline Ni-O-G SACs ${ }^{235}$ & $224 \mathrm{mV} @ 10 \mathrm{~mA} \mathrm{~cm} \mathrm{~cm}^{-2}$ & 42 & $50 \mathrm{~h}$ @ $115 \mathrm{~mA} \mathrm{~cm}{ }^{-2}$ & $1 \mathrm{M} \mathrm{KOH}$ \\
\hline N, S-CNT ${ }^{236}$ & $360 \mathrm{mV} @ 10 \mathrm{~mA} \mathrm{~cm}{ }^{-2}$ & 56 & - & $1 \mathrm{M} \mathrm{KOH}$ \\
\hline N, S doped graphene $e^{237}$ & $310 \mathrm{mV} @ 10 \mathrm{~mA} \mathrm{~cm}{ }^{-2}$ & 65 & $25 \mathrm{~h}$ @ $1.55 \mathrm{~V} v s . \mathrm{RHE}$ & $0.1 \mathrm{M} \mathrm{KOH}$ \\
\hline $\mathrm{O}-\mathrm{CNTs}^{238}$ & $360 \mathrm{mV} @ 10 \mathrm{~mA} \mathrm{~cm} \mathrm{~cm}^{-2}$ & 47.7 & $24 \mathrm{~h}$ @ $5 \mathrm{~mA} \mathrm{~cm}-2$ & $1 \mathrm{M} \mathrm{KOH}$ \\
\hline O Doped MWCNTs ${ }^{239}$ & $450 \mathrm{mV}$ @ $10 \mathrm{~mA} \mathrm{~cm}{ }^{-2}$ & 72 & $10000 \mathrm{~s} @ 5 \mathrm{~mA} \mathrm{~cm}{ }^{-2}$ & $0.1 \mathrm{M} \mathrm{KOH}$ \\
\hline P-doped $\mathrm{C}_{3} \mathrm{~N}_{4}$ (ref. 240) & $400 \mathrm{mV} @ 10 \mathrm{~mA} \mathrm{~cm} \mathrm{~cm}^{-2}$ & 61.6 & $15 \mathrm{~h} @ 10 \mathrm{~mA} \mathrm{~cm}-2$ & $0.1 \mathrm{M} \mathrm{KOH}$ \\
\hline P-doped graphene ${ }^{241}$ & $330 \mathrm{mV} @ 10 \mathrm{~mA} \mathrm{~cm} \mathrm{~cm}^{-2}$ & 62 & - & $1 \mathrm{M} \mathrm{KOH}$ \\
\hline $\mathrm{S}, \mathrm{N}-\mathrm{Fe} / \mathrm{N} / \mathrm{C}-\mathrm{CNT}^{242}$ & $370 \mathrm{mV} @ 10 \mathrm{~mA} \mathrm{~cm}{ }^{-2}$ & 82 & $40000 \mathrm{~s} @ 10 \mathrm{~mA} \mathrm{~cm}{ }^{-2}$ & $0.1 \mathrm{M} \mathrm{KOH}$ \\
\hline $\mathrm{S}, \mathrm{S}^{\prime}-\mathrm{CNT}^{243}$ & $350 \mathrm{mV}$ @ $10 \mathrm{~mA} \mathrm{~cm} \mathrm{~cm}^{-2}$ & 95 & $75 \mathrm{~h}$ @ $10 \mathrm{~mA} \mathrm{~cm}-2$ & $1 \mathrm{M} \mathrm{KOH}$ \\
\hline
\end{tabular}

produced nanoporous layered and $\mathrm{N}$-doped graphene that exhibits enhanced OER activity. ${ }^{246}$ Nearly $51 \%$ quaternary N plays a significant role in the considerable increase in OER activity. Wang et al. demonstrated a significant improvement in the OER performance of graphene by $\mathrm{P}$ doping. ${ }^{241}$ They found that the stronger oxygen adsorbing ability of $\mathrm{P}$, which was present at the edges of graphene, played a crucial part in stabilizing OER intermediates.

Besides single atom doping of graphene, dual- and multiatom doping were also found to deliver significant results in improving OER activity by their synergistic effects. Zhao and Xia studied several combinations of dual doping such as N-N, N-P, $\mathrm{N}-\mathrm{S}, \mathrm{N}-\mathrm{B}$, and $\mathrm{N}-\mathrm{Cl}$ in optimizing the OER activity of graphene using first-principles modeling. ${ }^{247}$ They suggested that optimizing the distance between dopants, selecting the right combination of dopants, and efficient utilization of edge effect are the vital factors in designing a highly efficient electrocatalyst. For example, the co-doping of $\mathrm{P}$ and $\mathrm{N}$ into the graphene lattice results in graphene formation with $\mathrm{P}, \mathrm{N}$ population at the edges, as a consequence of the large atomic size of $\mathrm{P}$ that always moves away from the planar surface. This co-doped catalyst exhibits a significant improvement in OER performance, and the elevated activity is attributed to the synergetic effect of both dopants, the high oxidation ability of the P-site that initially adsorbs $\mathrm{O}_{2}$, and the $\mathrm{N}$-site that stabilizes the OER intermediates and promotes desorption. ${ }^{248}$

Qiao's group synthesized $\mathrm{N}$ and $\mathrm{S}$ dual-doped graphene microwires using an ionic liquid assisted method, which showed an overpotential of $310 \mathrm{mV}$ at $10 \mathrm{~mA} \mathrm{~cm}{ }^{-2}$, stability for $25 \mathrm{~h}$ and $95 \%$ faradaic efficiency. ${ }^{237}$ Moreover, this electrode was employed as an efficient cathode for $\mathrm{Zn}$-air batteries, and this superior OER activity is attributed to the numerous active sites created by $\mathrm{C}-\mathrm{N}-\mathrm{S}$ spin density. Furthermore, Zhang and Dai demonstrated tri-doping of graphene with $\mathrm{N}, \mathrm{P}$ and $\mathrm{F}$ atoms, yielding a multifunctional electrocatalyst. ${ }^{226}$ The $\mathrm{N}$ and $\mathrm{P}$ doping roles in improving OER performance were elaborated. Still, it is inconclusive how $\mathrm{F}$ inclusion into the graphene lattice contributes to the electrocatalytic activity. Li et al. demonstrated a significant improvement of the OER performance of graphene by including single nickel atoms. ${ }^{235}$ The single-atom doped graphene displayed $50 \mathrm{~h}$ of long-term stability at a very high current density of $115 \mathrm{~mA} \mathrm{~cm}{ }^{-2}$. This unusual activity is accredited to the bonding between single nickel atoms and oxygen sites of graphene. Chen et al. doped Ni single atoms on $\mathrm{N}$-doped nano-porous graphene via a chemical vapor deposition (CVD) method, followed by chemical etching. ${ }^{234}$ The dual-doped catalyst showed superior OER activity to other catalysts, and even outperformed the $\mathrm{IrO}_{2}$ catalyst. The DFT calculations suggest that $\mathrm{Ni}, \mathrm{N}$ co-doping significantly decreased the stability difference between $\mathrm{O}^{*}$ and ${ }^{*} \mathrm{OH}$ intermediates by $0.3 \mathrm{eV}$.

\subsection{Carbon nanotubes (CNTs)}

CNTs are 1D structural allotropes of carbon that consist of hexagons of carbons arranged in a concentric fashion. CNTs possess good electrical-thermal properties due to their unique hollow geometry and conjugated long-range $\pi$ electron structure. ${ }^{249}$ However, CNTs in their pristine form exhibit poor electrocatalytic properties. To improve the electrocatalytic properties, CNTs need to be functionalized with several dopants. ${ }^{250}$ This functionalization can be done through two 
methodologies, i.e., covalent and non-covalent methods. The covalent functionalization proceeds via forming a covalent bond between the functional group and CNTs, which could disrupt the unique structure of CNTs. In the non-covalent method, the functionalization happens through physical processes such as electrostatic, hydrogen bonding, $\pi$ stacking and van der Waals interactions, which leaves the CNT structure undisturbed. ${ }^{249}$ For example, Tian et al. doped nitrogen into CNTs and synthesized highly active CNT@NCNT for the OER as a catalyst. ${ }^{251}$ The superior OER activity is ascribed to the highly exposed integrated $\mathrm{N}$ atoms present on the surface with the combined mechanical stability of the undisrupted inner walls of CNTs. Likewise, the Kallio group doped nitrogen into multiwalled CNTs (MWCNTs) and observed a considerable increase in OER performance after doping, compared with pristine MWCNTs. ${ }^{221}$ The significant OER activity of N-doped MWCNTs is induced by pyridinic $\mathrm{N}$ functionalities that are electronwithdrawing. Wang's group designed a generalized approach to make highly efficient hollow N-doped CNTs as a catalyst for the OER from a MOF. The remarkable electrochemical activity is attributed to the synergistic effects from interconnected $\mathrm{N}$ doped CNT structures and chemical compositions with high mechanical stability. ${ }^{229}$

Qiao's group synthesized dual-doped CNTs with nitrogen and sulfur inspired by the features of polydopamine (PDA), as depicted in Fig. 16a. ${ }^{236} \mathrm{~N}$ and S doped CNTs were prepared through a two-step "graft-and-pyrolyze" route using PDA. Initially, PDA was deposited on the surface of multiwalled CNTs and sulfur was incorporated at room temperature via chemical grafting, and subsequent pyrolysis at $700{ }^{\circ} \mathrm{C}$ resulted in a $\mathrm{N}$ and $\mathrm{S}$ uniformly co-doped carbon framework with enhanced Sdoping efficiency. Even after doping and pyrolysis, the nanotube morphology of CNTs was preserved, as shown in Fig. 16b. The OER performance of pristine and doped CNT catalysts is displayed in Fig. 16c, which shows that the N, S-CNT catalyst exhibited superior OER activity among them with an overpotential of $360 \mathrm{mV}$ and a Tafel slope of $56 \mathrm{mV} \mathrm{dec}^{-1}$ (Fig. 16d). Theoretical studies show a considerable increase in spin-charge
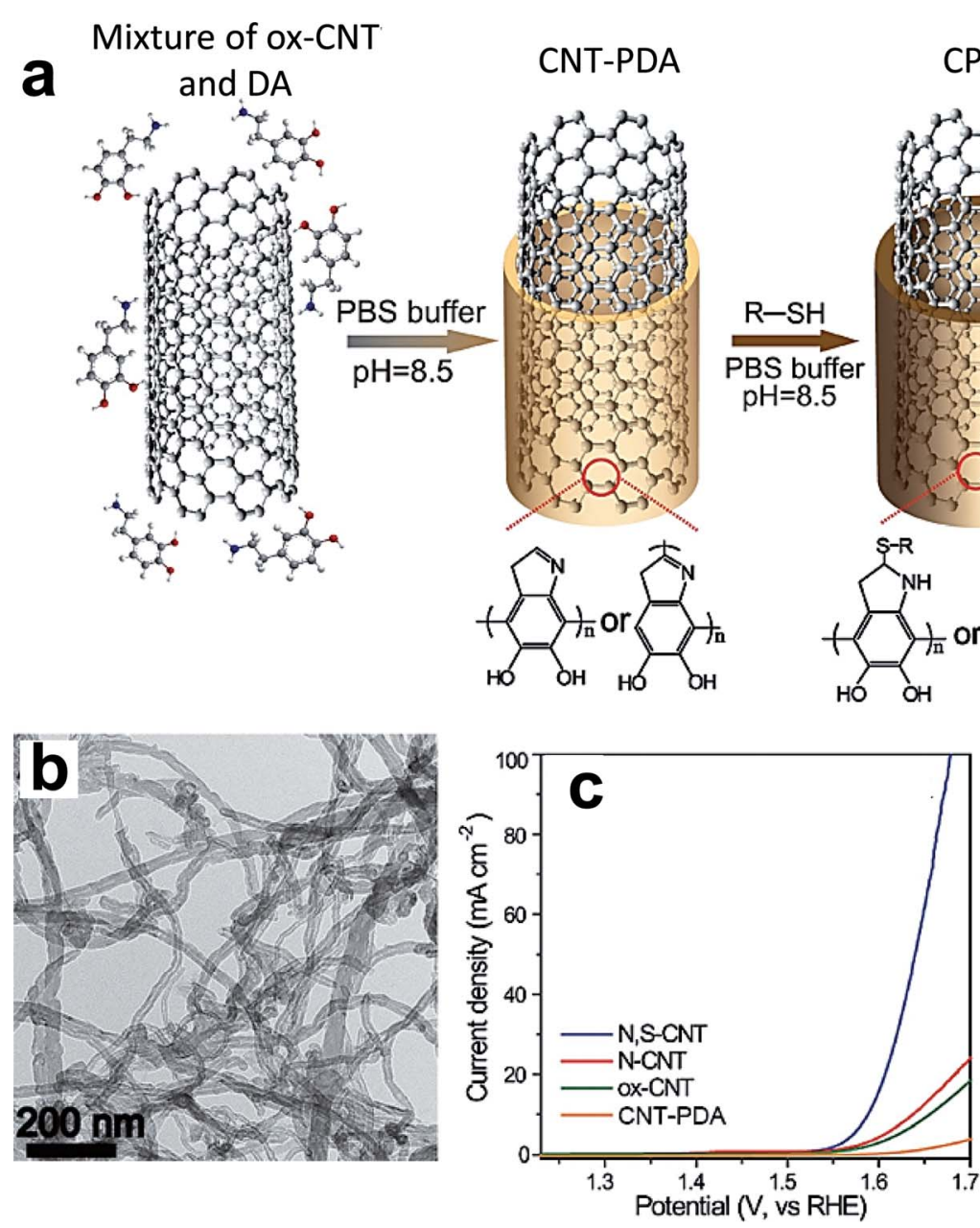

CPS
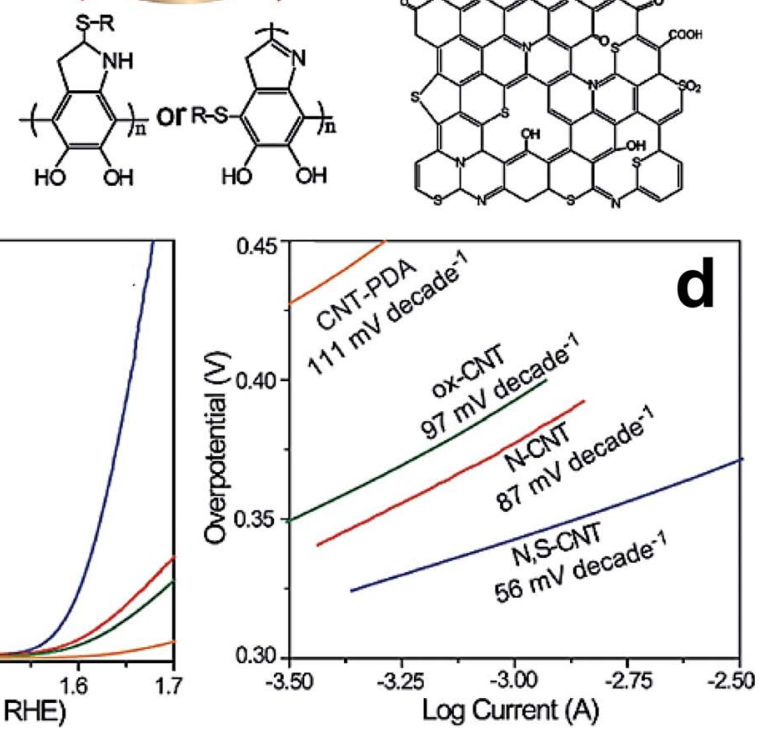

Fig. 16 (a) Fabrication of the N, S-CNT following a two-step "graft-and-pyrolyze" route. The oxidized CNT (ox-CNT) was mixed with dopamine (DA) in PBS buffer to obtain a CNT-PDA hybrid. After the addition of R-SH, CNT-PDA modified with thiol (CPS) was synthesized, which produced N, S-CNT after pyrolysis. R-SH = 2-mercaptoethanol; (b) TEM image of the N, S-CNT; (c) OER polarization curves; and (d) corresponding Tafel plots of CNT-PDA, ox-CNT, N-CNT, and N, S-CNT in 1 M KOH solution. ${ }^{236}$ Reproduced from ref. 236 with permission, @ 2017 John Wiley and Sons. 
density difference among carbon atoms with doping; these carbon atoms act as electrocatalytically active sites. As a consequence, the apparent OER activity improved with dual doping compared to single doping. Liu's group has extensively studied the doping effect of oxygen on the OER performance of CNTs by synthesis via two different methods, i.e., oxygen plasma oxidation (O-CNTs) and thermal reduction (R-CNTs). ${ }^{238}$ O-CNTs exhibit enhanced OER activity over R-CNTs and pristine CNTs, and DFT calculations reveal that both O-CNTs and R-CNTs have the same active sites, i.e., carbon near $\mathrm{C}=\mathrm{O}$. The high-water oxidation ability of O-CNTs was thought to be possible due to the presence of a high density of active sites, with high $E_{\mathrm{a}, \mathrm{app}}$ at the specific reaction temperature.

Lu et al. oxidized the surface of MWCNTs through hydrothermal annealing and electrochemical activation, which results in a highly active OER catalyst. ${ }^{239}$ The superior OER activity originated from the formation of carbonyl functionalities on the outer wall, which altered the electronic structure of neighboring carbon atoms and facilitated adsorption of OER intermediates. Suib et al. fabricated a highly stable metal-free catalyst at high anodic potentials by successive two-step doping of sulfur into the MWCNTs, displaying two orders of magnitude higher turnover frequency (TOF) compared to the Ir/ C catalyst. ${ }^{243}$ The enhanced OER activity was caused by the inclusion of heterocyclic sulfur into the hexagonal rings of CNTs. Wu and co-workers developed a single-atom doped catalyst for the water oxidation reaction by coating CNTs with Fe salt and 2,2 bipyridine, followed by pyrolysis and acid leaching, yielding $\mathrm{FeN}_{x}$ species on the $\mathrm{S}$ and $\mathrm{N}$ co-doped CNT catalyst. ${ }^{242}$ This catalyst exhibits superior OER activity in alkaline medium, as a result of high exposure of Fe atoms and synergetic effects of $\mathrm{S}$ and $\mathrm{N}$ doping.

\subsection{Other carbon-based catalysts}

In addition to graphene and CNTs, other forms of carbon-based catalysts were also reported for OER activity. Graphitic carbon nitride $\left(\mathrm{g}-\mathrm{C}_{3} \mathrm{~N}_{4}\right)$ has a $\mathrm{C}-\mathrm{N}$ structure with graphite like $\mathrm{sp}^{2}$ bonding, which exhibits semiconducting behavior due to $\pi$ conjugation. ${ }^{252}$ Like graphene and CNTs, g- $\mathrm{C}_{3} \mathrm{~N}_{4}$ is also inactive in its pristine form, and tuning its electronic structure by doping non-metal or metal elements significantly improves its water oxidation ability. ${ }^{233,240}$ For instance, Huang et al. dualdoped $\mathrm{N}$ and $\mathrm{B}$ into $3 \mathrm{D}$ porous $\mathrm{g}-\mathrm{C}_{3} \mathrm{~N}_{4}$ and observed superior OER activity in alkaline solution, compared to $\mathrm{N}$-doped or $\mathrm{N}$ and $\mathrm{P}$ co-doped $3 \mathrm{D} \mathrm{g}-\mathrm{C}_{3} \mathrm{~N}_{4} \cdot{ }^{253}$ It was found that the $\mathrm{N}$ and $\mathrm{B}$ co-doped $\mathrm{g}-\mathrm{C}_{3} \mathrm{~N}_{4}$ has a high population of pyrrolic and pyridinic nitrogen for enhanced OER. ${ }^{22}$ Based on DFT calculations, Jiang and coworkers proposed doping single transition elements such as $\mathrm{Pt}, \mathrm{Pd}, \mathrm{Co}, \mathrm{Ni}$, and $\mathrm{Cu}$ into carbon nitride $(\mathrm{CN})$ that could lead to a cost-efficient, highly efficient OER catalyst. ${ }^{254}$ Specifically, the electrocatalysts of non-noble metal Co/Ni@CN and Co-O@CN exhibit excellent activity and function with extremely low overpotential. Qiao's group conducted the theoretical study and experimental validation on cobalt inclusion on $\mathrm{g}-\mathrm{C}_{3} \mathrm{~N}_{4}$ for OER activity in alkaline medium. ${ }^{223}$ The combinative evaluation of theoretical and experimental methods reveals that metal- nitrogen $\mathrm{M}-\mathrm{N}_{2}$ coordination in the matrix of $\mathrm{g}-\mathrm{C}_{3} \mathrm{~N}_{4}$ is the origin of high electrocatalytic activity compared to the pristine sample. Song et al. studied the effect of dual metal doping in enhancing the OER activity, and doped $\mathrm{Ni}$ and Fe metals in tri-s-triazine units of $\mathrm{g}-\mathrm{C}_{3} \mathrm{~N}_{4}$ enveloped by CNTs. ${ }^{232}$ Synchrotron-based X-ray absorption with combination of atomic microscopy indicated that the electronic configuration of both $\mathrm{Fe}$ and Ni was reconfigured, and the valence state of $\mathrm{Ni}$ was increased, and thus more OER active sites were created compared to single doping. Sun and coworkers dual-doped $\mathrm{Ni}$ and Fe into the framework of polymeric carbon nitride (Ni, Fe@PCN), in which superior activity was found. ${ }^{233}$ Computational studies suggest that the enhanced OER activity of NiFeOH@PCN is a consequence of the vastly reduced energy barrier $\left(0.10\right.$ or $0.22 \mathrm{eV}$ for $\left.\mathrm{U} \frac{1}{4} 1.58 \mathrm{~V}\right)$ through synergetic contribution of adjacent $\mathrm{Ni}$ and $\mathrm{Fe}$ atoms.

In 2013, Zhao et al. reported N-doped carbon nanomaterials as metal-free OER catalysts other than graphene and CNTs for the first time. ${ }^{227}$ In alkaline electrolyte, the catalyst exhibits $380 \mathrm{mV}$ overpotential at a current density of $10 \mathrm{~mA} \mathrm{~cm}{ }^{-2}$, which is comparable to iridium and cobalt oxide catalysts. The pyridinic and quaternary nitrogen species shorten the diffusion path of OER intermediates. The N-doped carbon hollow cubes (NCHCs) for the OER were synthesized from biomass lysine using a NaCl-template method by Yang and coworkers. ${ }^{228}$ The NCHCs show comparable OER activity and high endurance compared with the $\mathrm{RuO}_{2} / \mathrm{C}$ catalyst in alkaline medium. Synergetic effects of $\mathrm{N}$-doping and high specific surface area were found. Ozkan et al. demonstrated the OER activity of $\mathrm{N}$ doped carbon nanostructures $\left(\mathrm{CN}_{x}\right)$ in an acidic medium, which showed significantly higher OER performance than the Ir/C catalyst. $^{255}$ XPS results suggested the presence of pyridinic $\mathrm{N}$ species for the enhanced OER activity of the $\mathrm{CN}_{x}$ catalyst. Zhao's group demonstrated a novel strategy to fabricate a highly efficient OER catalyst by synthesizing an ultra-thin $\mathrm{N}$ doped holey carbon layer (HCL) on graphene through a twostep process as displayed in Fig. 17a. ${ }^{231}$ Fig. $17 \mathrm{~b}$ presents the HR-TEM image of Zn@G-hydro annealed at $900{ }^{\circ} \mathrm{C}$, which exhibits nanoholes with an approximate diameter of $2 \mathrm{~nm}$, as a result of $\mathrm{Zn}$ evaporation (N-HC@G-900). The nano-holes are not observed when zinc gluconate is not used in the synthesis (N-C@G-900). N-HC@G-900 displayed enhanced OER activity, as observed in Fig. 17c, because of pyridinic $\mathrm{N}$ moieties at the edges of the HCL, and the sandwiched graphene sheet provided mechanical support.

The combination of $\mathrm{N}$ and transition metal doping into the carbon materials effectively improved the OER performance and stability by creating more active sites. ${ }^{224,225,256}$ For instance, $\mathrm{Mu}$ et al. co-doped Co and $\mathrm{N}$ into the matrix of graphene-like porous carbon nanosheets (Co@N-PGCS), which possess a high specific surface area of $1716 \mathrm{~cm}^{2} \mathrm{~g}^{-1} \cdot{ }^{256}$ The Co@N-PGCS catalyst showed comparable activity over the state-of-the-art catalyst $\mathrm{IrO}_{2}$ by a synergetic effect of Co and N co-doping, and the porous surfaces open more diffusion channels. In another report, Tong and coworkers designed an efficient self-standing OER catalyst by dual doping Co and $\mathrm{N}$ into a graphite foam matrix (Co-N/GF). ${ }^{224}$ The Co-N/GF catalyst prepared at $700{ }^{\circ} \mathrm{C}$ could deliver significant OER activity, compared to the catalyst 


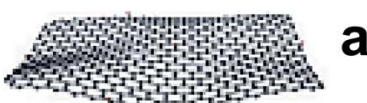

a

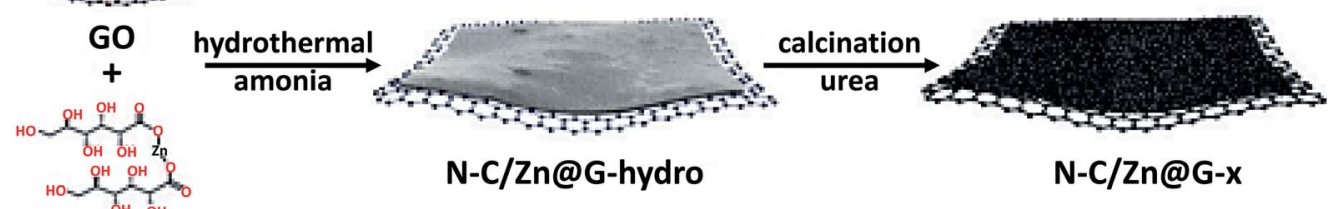

zinc gluconate
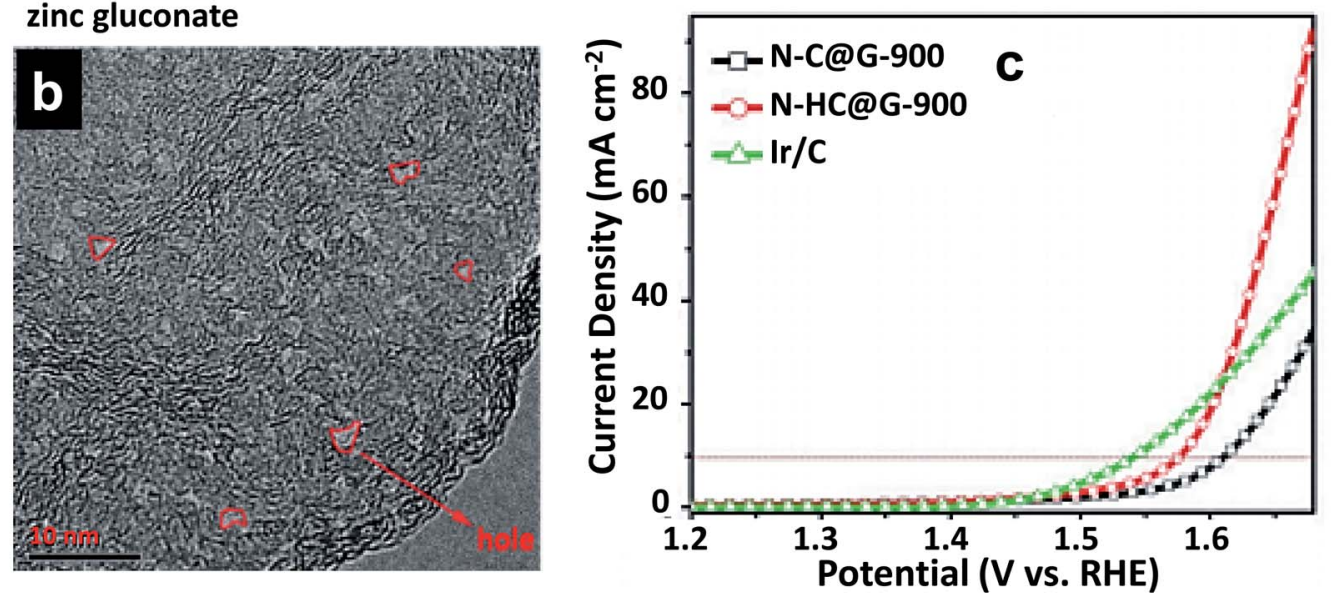

Fig. 17 (a) Schematic representation of the N-HCaGax synthesis procedure; (b) HRTEM image of N-HC(aG-900 (nanoholes marked in red); (c) LSV curves of N-C@G-900, N-HC@G-900 and Ir/C in 1 M KOH. ${ }^{231}$ Reproduced from ref. 231 with permission, (C) 2018 John Wiley and Sons.

prepared at other temperatures in alkaline electrolyte. Initially, $\mathrm{Co}-\mathrm{N}$ species were partly oxidized to $\mathrm{CoOOH} / \mathrm{Co}-\mathrm{N}$. At higher anodic potentials, $\mathrm{CoOOH}$ was further oxidized to the most active $\mathrm{CoO}_{2}$, which considerably promoted the oxidation of $\mathrm{OH}^{-}$ species. Wang's group, for the first time, fabricated a Co/N codoped carbon composite for water oxidation from metal-polyphenol (Tanin) crystals, which are highly abundant in nature. ${ }^{225}$ $\mathrm{Co} / \mathrm{N}$ co-doping in a carbon composite was found to produce a synergistic effect with a high specific surface area $\left(180 \mathrm{~m}^{2} \mathrm{~g}^{-1}\right)$, producing excellent OER activity in the alkaline electrolyte. Lee et al. demonstrated the synthesis of a tri-doped carbon catalyst for acidic OER. ${ }^{257}$ Here, they doped N, O, and TMs, such as Fe, $\mathrm{Co}$, and $\mathrm{Ni}$, onto the carbon, and they noticed that $\mathrm{N} / \mathrm{Fe} / \mathrm{O}$ and $\mathrm{N} / \mathrm{Ni} / \mathrm{O}$ doped carbon catalysts showed high OER activity, and $\mathrm{N} / \mathrm{Co} / \mathrm{O}$ displayed better stability.

\section{Summary and concluding remarks}

Searching for eco-friendly renewable energy that can replace carbon-based fossil fuels for future fuel is a prime goal of the research community. Electrochemical oxygen evolution plays a crucial role in energy storage by converting renewable energies, such as solar, wind, and tidal forms, into storable chemical fuel of hydrogen. Hence, the fundamental priority is to fabricate efficient OER catalysts that can be applied in the real world. This review summarized the research on the tuning of OER catalyst properties by doping. Doping of foreign elements can significantly alter the electrical conductivity and binding ability of OER intermediates by optimizing the host electronic structure. The considerable changes in the OER activity of metal oxides, non-metal oxides, and carbon-based catalysts via doping were reviewed. Experimental and theoretical studies were discussed to explain the OER mechanisms. Among the catalysts discussed above, doping in hydroxides, sulfides, selenides, and phosphides has been shown to be relatively more effective compared to the others discussed in this paper. Overall, this review outlines the systematic understanding of experimental and theoretical effects of doping on OER catalysts, which is associated with several challenges involving energy processes such as carbon dioxide reduction, nitrogen reduction, and production of hydrogen peroxide.

Considering the studies reported in this paper, an efficient OER catalyst should have optimum adsorption ability for OER intermediates, neither too weak nor too strong, and possess a good electrical conductivity. The optimized $e_{g}$ filling value $(\sim 1.2)$ can be obtained by tuning the electronic structure of TM ions present in metal oxides, and optimizing the covalency of metal and oxygen orbitals, including other metal ions along with TM ions. An optimized surface area can be achieved by preparing nanoforms. Furthermore, the catalyst should possess excellent resistance under extreme OER conditions with high anodic potentials and a good redox center that can lose or gain electrons.

In future, the development of advanced characterization techniques, such as in situ XPS, Fourier-transform infrared spectroscopy (FT-IR), X-ray absorption spectroscopy, XRD, etc., will provide more insights into OER intermediates on the surface of a catalyst. To design a highly stable catalyst for industrial-scale applications, it is essential to have the metric of long-term stability without dropping its initial activity evidently. 
Several catalysts display high activity, but a few of them can reach long-term endurance. Besides, large surface area and porosity are the other vital parameters in producing catalysts for large-scale use, which could provide high activity with a small catalyst. Most of the catalysts described in this paper were synthesized on a lab scale, while mass production of the same type of catalyst will be challenging in terms of cost effectiveness to fulfill the practical needs. Interdisciplinary collaborative research efforts are needed in science and engineering towards widespread applications of fuel cells.

\section{Conflicts of interest}

There are no conflicts to declare.

\section{Acknowledgements}

This work was supported by the National Science Foundation (DMR-1827731).

\section{References}

1 S. Chu and A. Majumdar, Nature, 2012, 488, 294-303.

2 J. Yin, A. Molini and A. Porporato, Nat. Commun., 2020, 11, 4781.

3 J. Jurasz, F. A. Canales, A. Kies, M. Guezgouz and A. Beluco, Sol. Energy, 2020, 195, 703-724.

4 Z. Yan, J. L. Hitt, J. A. Turner and T. E. Mallouk, Proc. Natl. Acad. Sci. U.S.A., 2020, 117, 12558-12563.

5 N.-T. Suen, S.-F. Hung, Q. Quan, N. Zhang, Y.-J. Xu and H. M. Chen, Chem. Soc. Rev., 2017, 46, 337-365.

6 K. Scott, in Electrochemical Methods for Hydrogen Production, ed. K. Scott, Royal Society of Chemistry, London, UK, 2019, ch. 1, pp. 1-27.

7 T. Schuler, T. Kimura, T. J. Schmidt and F. N. Büchi, Energy Environ. Sci., 2020, 13, 2153-2166.

8 K. S. Exner, I. Sohrabnejad-Eskan and H. Over, ACS Catal., 2018, 8, 1864-1879.

9 W. Yang, Z. Wang, W. Zhang and S. Guo, Trends Chem., 2019, 1, 259-271.

10 E. Fabbri and T. J. Schmidt, ACS Catal., 2018, 8, 9765-9774.

11 K. Kannimuthu, K. Sangeetha, S. S. Sankar, A. Karmakar, R. Madhu and S. Kundu, Inorg. Chem. Front., 2021, 8, 234-272.

12 F. Song, L. Bai, A. Moysiadou, S. Lee, C. Hu, L. Liardet and X. Hu, J. Am. Chem. Soc., 2018, 140, 7748-7759.

13 Z. Chen, X. Duan, W. Wei, S. Wang and B.-J. Ni, Nano Energy, 2020, 78, 105392.

14 J. Huang, Y. Jiang, T. An and M. Cao, J. Mater. Chem. A, 2020, 8, 25465-25498.

15 F. Lu, M. Zhou, Y. Zhou and X. Zeng, Small, 2017, 13, 1701931.

16 I. Roger, M. A. Shipman and M. D. Symes, Nat. Rev. Chem., 2017, 1, 1-13.

17 F. Dionigi and P. Strasser, Adv. Energy Mater., 2016, 6, 1600621.
18 W.-J. Yin, B. Weng, J. Ge, Q. Sun, Z. Li and Y. Yan, Energy Environ. Sci., 2019, 12, 442-462.

19 A. Dutta and N. Pradhan, J. Phys. Chem. Lett., 2017, 8, 144152.

20 N. Han, P. Liu, J. Jiang, L. Ai, Z. Shao and S. Liu, J. Mater. Chem. A, 2018, 6, 19912-19933.

21 X. Peng, Y. Yan, X. Jin, C. Huang, W. Jin, B. Gao and P. K. Chu, Nano Energy, 2020, 78, 105234.

22 Q. Zhao, Z. Yan, C. Chen and J. Chen, Chem. Rev., 2017, 117, 10121-10211.

23 J. Song, C. Wei, Z.-F. Huang, C. Liu, L. Zeng, X. Wang and Z. J. Xu, Chem. Soc. Rev., 2020, 49, 2196-2214.

24 M. J. Craig, G. Coulter, E. Dolan, J. Soriano-López, E. MatesTorres, W. Schmitt and M. García-Melchor, Nat. Commun., 2019, 10, 4993.

25 Z.-P. Wu, X. F. Lu, S.-Q. Zang and X. W. (David) Lou, Adv. Funct. Mater., 2020, 30, 1910274.

26 J. O. Bockris, J. Chem. Phys., 1956, 24, 817-827.

27 Y. Matsumoto and E. Sato, Mater. Chem. Phys., 1986, 14, 397-426.

28 W. H. Wade and N. Hackerman, Trans. Faraday Soc., 1957, 53, 1636-1647.

29 M. R. Tarasevich, A. Sadkowski and E. Yeager, in Comprehensive Treatise of Electrochemistry: Kinetics and Mechanisms of Electrode Processes, ed. B. E. Conway, J. O. Bockris, E. Yeager, S. U. M. Khan and R. E. White, Springer US, Boston, MA, 1983, vol. 7, pp. 301-398.

30 J. O. Bockris and T. Otagawa, J. Electrochem. Soc., 1984, 131, 290.

31 M. Kim, J. Park, M. Kang, J. Y. Kim and S. W. Lee, ACS Cent. Sci., 2020, 6, 880-891.

32 S. T. Dix, S. Lu and S. Linic, ACS Catal., 2020, 10, 1073510741.

33 Y. Liu, Y. Ying, L. Fei, Y. Liu, Q. Hu, G. Zhang, S. Y. Pang, W. Lu, C. L. Mak, X. Luo, L. Zhou, M. Wei and H. Huang, J. Am. Chem. Soc., 2019, 141, 8136-8145.

34 A. Zunger and O. I. Malyi, Chem. Rev., 2021, 121, 3031-3060.

35 A. Goryachev, M. Etzi Coller Pascuzzi, F. Carlà, T. Weber, H. Over, E. J. M. Hensen and J. P. Hofmann, Electrochim. Acta, 2020, 336, 135713.

36 O. Kasian, J.-P. Grote, S. Geiger, S. Cherevko and K. J. J. Mayrhofer, Angew. Chem., Int. Ed., 2018, 57, 24882491.

37 T. D. Nguyen, H. H. Nguyen, C. Dai, J. Wang and G. G. Scherer, Int. J. Hydrogen Energy, 2020, 45, 46-55.

38 J. Su, R. Ge, K. Jiang, Y. Dong, F. Hao, Z. Tian, G. Chen and L. Chen, Adv. Mater., 2018, 30, 1801351.

39 W. Sun, Y. Song, X.-Q. Gong, L. Cao and J. Yang, Chem. Sci., 2015, 6, 4993-4999.

40 J. Feng, F. Lv, W. Zhang, P. Li, K. Wang, C. Yang, B. Wang, Y. Yang, J. Zhou, F. Lin, G.-C. Wang and S. Guo, Adv. Mater., 2017, 29, 1703798.

41 Y. Tian, S. Wang, E. Velasco, Y. Yang, L. Cao, L. Zhang, X. Li, Y. Lin, Q. Zhang and L. Chen, iScience, 2020, 23, 100756.

42 S. Chen, H. Huang, P. Jiang, K. Yang, J. Diao, S. Gong, S. Liu, M. Huang, H. Wang and Q. Chen, ACS Catal., 2020, 10, 1152-1160. 
43 W. Gou, M. Zhang, Y. Zou, X. Zhou and Y. Qu, ChemCatChem, 2019, 11, 6008-6014.

44 Y. Lin, Z. Tian, L. Zhang, J. Ma, Z. Jiang, B. J. Deibert, R. Ge and L. Chen, Nat. Commun., 2019, 10, 162.

45 Y. Wang, S. Hao, X. Liu, Q. Wang, Z. Su, L. Lei and X. Zhang, ACS Appl. Mater. Interfaces, 2020, 12, 37006-37012.

46 F. Lv, J. Feng, K. Wang, Z. Dou, W. Zhang, J. Zhou, C. Yang, M. Luo, Y. Yang, Y. Li, P. Gao and S. Guo, ACS Cent. Sci., 2018, 4, 1244-1252.

47 Z. Li, S. Wang, Y. Tian, B. Li, H. jun Yan, S. Zhang, Z. Liu, Q. Zhang, Y. Lin and L. Chen, Chem. Commun., 2020, 56, 1749-1752.

48 R. Ge, L. Li, J. Su, Y. Lin, Z. Tian and L. Chen, Adv. Energy Mater., 2019, 9, 1901313.

49 H. Sun, G. Chen, J. Sunarso, J. Dai, W. Zhou and Z. Shao, ACS Appl. Mater. Interfaces, 2018, 10, 16939-16942.

50 G. Chen, W. Zhou, D. Guan, J. Sunarso, Y. Zhu, X. Hu, W. Zhang and Z. Shao, Sci. Adv., 2017, 3, e1603206.

51 Y.-Q. Lyu and F. Ciucci, ACS Appl. Mater. Interfaces, 2017, 9, 35829-35836.

52 L. Yang, H. Chen, L. Shi, X. Li, X. Chu, W. Chen, N. Li and X. Zou, ACS Appl. Mater. Interfaces, 2019, 11, 42006-42013.

53 A. Grimaud, K. J. May, C. E. Carlton, Y.-L. Lee, M. Risch, W. T. Hong, J. Zhou and Y. Shao-Horn, Nat. Commun., 2013, 4, 1-7.

54 B. Zhao, L. Zhang, D. Zhen, S. Yoo, Y. Ding, D. Chen, Y. Chen, Q. Zhang, B. Doyle, X. Xiong and M. Liu, Nat. Commun., 2017, 8, 14586.

55 Z. Li, L. Lv, J. Wang, X. Ao, Y. Ruan, D. Zha, G. Hong, Q. Wu, Y. Lan, C. Wang, J. Jiang and M. Liu, Nano Energy, 2018, 47, 199-209.

56 G. Chen, Z. Hu, Y. Zhu, Z.-G. Chen, Y. Zhong, H.-J. Lin, C.-T. Chen, L. H. Tjeng, W. Zhou and Z. Shao, J. Mater. Chem. A, 2018, 6, 9854-9859.

57 S. R. Ede, C. N. Collins, C. D. Posada, G. George, H. Wu, W. D. Ratcliff, Y. Lin, J. Wen, S. Han and Z. Luo, ACS Catal., 2021, 4327-4337.

58 Y. Zhu, W. Zhou, J. Sunarso, Y. Zhong and Z. Shao, Adv. Funct. Mater., 2016, 26, 5862-5872.

59 Z. Wu, L.-P. Sun, T. Xia, L.-H. Huo, H. Zhao, A. Rougier and J.-C. Grenier, J. Power Sources, 2016, 334, 86-93.

60 C. Su, W. Wang, Y. Chen, G. Yang, X. Xu, M. O. Tadé and Z. Shao, ACS Appl. Mater. Interfaces, 2015, 7, 17663-17670.

61 Y. Guo, Y. Tong, P. Chen, K. Xu, J. Zhao, Y. Lin, W. Chu, Z. Peng, C. Wu and Y. Xie, Adv. Mater., 2015, 27, 5989-5994.

62 H. Jin, Y. Hong, J. Yoon, A. Oh, N. K. Chaudhari, H. Baik, S. H. Joo and K. Lee, Nano Energy, 2017, 42, 17-25.

$63 \mathrm{~J} . \mathrm{Xu}, \mathrm{C}$. Chen, Z. Han, Y. Yang, J. Li and Q. Deng, Nanomaterials, 2019, 9, 1161.

64 G. George, S. R. Ede and Z. Luo, Fundamentals of Perovskite Oxides: Synthesis, Structure, Properties and Applications, CRC Press, Boca Raton, Florida, 2020.

65 J. Suntivich, W. T. Hong, Y.-L. Lee, J. M. Rondinelli, W. Yang, J. B. Goodenough, B. Dabrowski, J. W. Freeland and Y. Shao-Horn, J. Phys. Chem. C, 2014, 118, 1856-1863.

66 G. George, S. L. Jackson, C. Q. Luo, D. Fang, D. Luo, D. Hu, J. Wen and Z. Luo, Ceram. Int., 2018, 44, 21982-21992.
67 M. Retuerto, L. Pascual, F. Calle-Vallejo, P. Ferrer, D. Gianolio, A. G. Pereira, Á. García, J. Torrero, M. T. Fernández-Díaz, P. Bencok, M. A. Peña, J. L. G. Fierro and S. Rojas, Nat. Commun., 2019, 10, 2041.

68 Y. Zhao, L. Xu, L. Mai, C. Han, Q. An, X. Xu, X. Liu and Q. Zhang, Proc. Natl. Acad. Sci. U.S.A., 2012, 109, 1956919574.

69 B. Hua, Y.-F. Sun, M. Li, N. Yan, J. Chen, Y.-Q. Zhang, Y. Zeng, B. Shalchi Amirkhiz and J.-L. Luo, Chem. Mater., 2017, 29, 6228-6237.

70 X. Cheng, E. Fabbri, M. Nachtegaal, I. E. Castelli, M. El Kazzi, R. Haumont, N. Marzari and T. J. Schmidt, Chem. Mater., 2015, 27, 7662-7672.

71 Y. Zhou, S. Sun, C. Wei, Y. Sun, P. Xi, Z. Feng and Z. J. Xu, Adv. Mater., 2019, 31, 1902509.

72 J. Li, D. Chu, H. Dong, D. R. Baker and R. Jiang, J. Am. Chem. Soc., 2020, 142, 50-54.

73 K.-L. Yan, J.-Q. Chi, J.-Y. Xie, B. Dong, Z.-Z. Liu, W.-K. Gao, J.-H. Lin, Y.-M. Chai and C.-G. Liu, Renewable Energy, 2018, 119, 54-61.

74 C.-C. Lin and C. C. L. McCrory, ACS Catal., 2017, 7, 443-451. 75 Y. Tian, L. Cao and P. Qin, ChemCatChem, 2019, 11, 44204426.

76 S. L. Zhang, B. Y. Guan, X. F. Lu, S. Xi, Y. Du and X. W. (David) Lou, Adv. Mater., 2020, 32, 2002235.

77 J. Swaminathan, A. B. Puthirath, M. R. Sahoo, S. K. Nayak, G. Costin, R. Vajtai, T. Sharifi and P. M. Ajayan, ACS Appl. Mater. Interfaces, 2019, 11, 39706-39714.

78 C. W. Cady, G. Gardner, Z. O. Maron, M. Retuerto, Y. B. Go, S. Segan, M. Greenblatt and G. C. Dismukes, ACS Catal., 2015, 5, 3403-3410.

79 K. Lankauf, K. Cysewska, J. Karczewski, A. MielewczykGryń, K. Górnicka, G. Cempura, M. Chen, P. Jasiński and S. Molin, Int. J. Hydrogen Energy, 2020, 45, 14867-14879.

80 J. S. Hong, H. Seo, Y. H. Lee, K. H. Cho, C. Ko, S. Park and K. T. Nam, Small Methods, 2020, 4, 1900733.

81 X. Liu, W. Xi, C. Li, X. Li, J. Shi, Y. Shen, J. He, L. Zhang, L. Xie, X. Sun, P. Wang, J. Luo, L.-M. Liu and Y. Ding, Nano Energy, 2018, 44, 371-377.

82 Z. Wang, H. Liu, R. Ge, X. Ren, J. Ren, D. Yang, L. Zhang and X. Sun, ACS Catal., 2018, 8, 2236-2241.

83 Z. Xiao, Y. Wang, Y.-C. Huang, Z. Wei, C.-L. Dong, J. Ma, S. Shen, Y. Li and S. Wang, Energy Environ. Sci., 2017, 10, 2563-2569.

84 R. Li, Y. Guo, H. Chen, K. Wang, R. Tan, B. Long, Y. Tong, P. Tsiakaras, S. Song and Y. Wang, ACS Sustainable Chem. Eng., 2019, 7, 11901-11910.

85 R. Wei, X. Bu, W. Gao, R. A. B. Villaos, G. Macam, Z.-Q. Huang, C. Lan, F.-C. Chuang, Y. Qu and J. C. Ho, ACS Appl. Mater. Interfaces, 2019, 11, 33012-33021.

86 H. Xu, B. Wang, C. Shan, P. Xi, W. Liu and Y. Tang, ACS Appl. Mater. Interfaces, 2018, 10, 6336-6345.

87 X. Zhang, L. An, J. Yin, P. Xi, Z. Zheng and Y. Du, Sci. Rep., 2017, 7, 43590.

88 L. Chen, H. Zhang, L. Chen, X. Wei, J. Shi and M. He, J. Mater. Chem. A, 2017, 5, 22568-22575. 
89 B. Cao, C. Luo, J. Lao, H. Chen, R. Qi, H. Lin and H. Peng, ACS Omega, 2019, 4, 16612-16618.

90 Y. Dou, C.-T. He, L. Zhang, M. Al-Mamun, H. Guo, W. Zhang, Q. Xia, J. Xu, L. Jiang, Y. Wang, P. Liu, X.-M. Chen, H. Yin and H. Zhao, Cell Rep. Phys. Sci., 2020, 1, 100077.

91 J. Lv, X. Yang, K. Li, X. Chen, S. Sun, H.-Y. Zang, Y.-F. Chang, Y.-H. Wang and Y.-G. Li, Nanoscale Adv., 2019, 1, 4099-4108.

92 Z. Chen, C. X. Kronawitter, Y.-W. Yeh, X. Yang, P. Zhao, N. Yao and B. E. Koel, J. Mater. Chem. A, 2017, 5, 842-850.

93 V. P. Tolstoy, L. I. Kuklo and L. B. Gulina, J. Alloys Compd., 2019, 786, 198-204.

94 Q. Zhou, Y. Chen, G. Zhao, Y. Lin, Z. Yu, X. Xu, X. Wang, H. K. Liu, W. Sun and S. X. Dou, ACS Catal., 2018, 8, 5382-5390.

95 S. Niu, W.-J. Jiang, Z. Wei, T. Tang, J. Ma, J.-S. Hu and L.-J. Wan, J. Am. Chem. Soc., 2019, 141, 7005-7013.

96 J. Yan, L. Kong, Y. Ji, J. White, Y. Li, J. Zhang, P. An, S. Liu, S.-T. Lee and T. Ma, Nat. Commun., 2019, 10, 2149.

97 J. W. D. Ng, M. García-Melchor, M. Bajdich, P. Chakthranont, C. Kirk, A. Vojvodic and T. F. Jaramillo, Nat. Energy, 2016, 1, 1-8.

98 X. Xiong, C. You, Z. Liu, A. M. Asiri and X. Sun, ACS Sustainable Chem. Eng., 2018, 6, 2883-2887.

99 Y. Zhao, J. Zhang, W. Wu, X. Guo, P. Xiong, H. Liu and G. Wang, Nano Energy, 2018, 54, 129-137.

100 C. Meng, Y.-F. Gao, X.-M. Chen, Y.-X. Li, M.-C. Lin and Y. Zhou, ACS Sustainable Chem. Eng., 2019, 7, 18055-18060.

101 W. Li, M. Li, C. Wang, Y. Wei and X. Lu, Appl. Surf. Sci., 2020, 506, 144680.

102 R. Mondal, H. Ratnawat, S. Kumar, A. Kumar and P. Singh, RSC Adv., 2020, 10, 17845-17853.

103 Y. Yang, X. Su, L. Zhang, P. Kerns, L. Achola, V. Hayes, R. Quardokus, S. L. Suib and J. He, ChemCatChem, 2019, 11, 1689-1700.

104 Z. Ye, T. Li, G. Ma, Y. Dong and X. Zhou, Adv. Funct. Mater., 2017, 27, 1704083.

105 Q. Feng, J. Zou, Y. Wang, Z. Zhao, M. C. Williams, H. Li and H. Wang, ACS Appl. Mater. Interfaces, 2020, 12, 4520-4530.

106 M. Huo, Z. Yang, C. Yang, Z. Gao, J. Qi, Z. Liang, K. Liu, H. Chen, H. Zheng and R. Cao, ChemCatChem, 2019, 11, 1480-1486.

107 F. Cheng, J. Shen, B. Peng, Y. Pan, Z. Tao and J. Chen, Nat. Chem., 2011, 3, 79-84.

108 T. Maiyalagan, K. R. Chemelewski and A. Manthiram, ACS Catal., 2014, 4, 421-425.

109 M. H. Mendonça, M. I. Godinho, M. A. Catarino, M. I. da Silva Pereira and F. M. Costa, Solid State Sci., 2002, 4, 175-182.

110 A. S. Anindita and R. N. Singh, Int. J. Hydrogen Energy, 2010, 35, 3243-3248.

111 R. N. Singh, J. P. Singh, B. Lal, M. J. K. Thomas and S. Bera, Electrochim. Acta, 2006, 51, 5515-5523.

112 M. Cui, X. Ding, X. Huang, Z. Shen, T.-L. Lee, F. E. Oropeza, J. P. Hofmann, E. J. M. Hensen and K. H. L. Zhang, Chem. Mater., 2019, 31, 7618-7625.
113 I. Nikolov, R. Darkaoui, E. Zhecheva, R. Stoyanova, N. Dimitrov and T. Vitanov, J. Electroanal. Chem., 1997, 429, 157-168.

114 D. Chanda, J. Hnát, M. Paidar and K. Bouzek, Int. J. Hydrogen Energy, 2014, 39, 5713-5722.

115 B. Chi, H. Lin and J. Li, Int. J. Hydrogen Energy, 2008, 33, 4763-4768.

116 T. Sun, P. Liu, Y. Zhang, Z. Chen, C. Zhang, X. Guo, C. Ma, Y. Gao and S. Zhang, Chem. Eng. J., 2020, 390, 124591.

117 Z. Cai, X. Bu, P. Wang, J. C. Ho, J. Yang and X. Wang, J. Mater. Chem. A, 2019, 7, 5069-5089.

118 A. Karmakar, K. Karthick, S. S. Sankar, S. Kumaravel, R. Madhu and S. Kundu, J. Mater. Chem. A, 2021, 9, 13141352.

119 S. Anantharaj, S. Kundu and S. Noda, Nano Energy, 2021, 80, 105514.

120 M. Gong and H. Dai, Nano Res., 2015, 8, 23-39.

121 Y.-F. Li and A. Selloni, ACS Catal., 2014, 4, 1148-1153.

122 L. Trotochaud, S. L. Young, J. K. Ranney and S. W. Boettcher, J. Am. Chem. Soc., 2014, 136, 6744-6753.

123 J. M. P. Martirez and E. A. Carter, J. Am. Chem. Soc., 2019, 141, 693-705.

124 M. S. Burke, M. G. Kast, L. Trotochaud, A. M. Smith and S. W. Boettcher, J. Am. Chem. Soc., 2015, 137, 3638-3648.

125 L. Trotochaud, J. K. Ranney, K. N. Williams and S. W. Boettcher, J. Am. Chem. Soc., 2012, 134, 17253-17261.

126 M. S. Burke, L. J. Enman, A. S. Batchellor, S. Zou and S. W. Boettcher, Chem. Mater., 2015, 27, 7549-7558.

127 T. A. Edison, US Pat., US876445A, 1908.

128 R. L. Tichenor, Ind. Eng. Chem., 1952, 44, 973-977.

129 G. Młynarek, M. Paszkiewicz and A. Radniecka, J. Appl. Electrochem., 1984, 14, 145-149.

130 D. A. Corrigan, J. Electrochem. Soc., 1987, 134, 377.

131 S. Klaus, Y. Cai, M. W. Louie, L. Trotochaud and A. T. Bell, J. Phys. Chem. C, 2015, 119, 7243-7254.

132 J. Landon, E. Demeter, N. İnoğlu, C. Keturakis, I. E. Wachs, R. Vasić, A. I. Frenkel and J. R. Kitchin, ACS Catal., 2012, 2, 1793-1801.

133 M. W. Louie and A. T. Bell, J. Am. Chem. Soc., 2013, 135, 12329-12337.

134 G. Fu, X. Wen, S. Xi, Z. Chen, W. Li, J.-Y. Zhang, A. Tadich, R. Wu, D.-C. Qi, Y. Du, J. Cheng and K. H. L. Zhang, Chem. Mater., 2019, 31, 419-428.

135 D. A. Corrigan and R. M. Bendert, J. Electrochem. Soc., 1989, 136, 723.

136 N. Li, D. K. Bediako, R. G. Hadt, D. Hayes, T. J. Kempa, F. von Cube, D. C. Bell, L. X. Chen and D. G. Nocera, Proc. Natl. Acad. Sci. U.S.A., 2017, 114, 1486-1491.

137 C. A. Kent, J. J. Concepcion, C. J. Dares, D. A. Torelli, A. J. Rieth, A. S. Miller, P. G. Hoertz and T. J. Meyer, J. Am. Chem. Soc., 2013, 135, 8432-8435.

138 Y. Sun, T. Zhang, C. Li, K. Xu and Y. Li, J. Mater. Chem. A, 2020, 8, 13415-13436.

139 G. Zhang, Y.-S. Feng, W.-T. Lu, D. He, C.-Y. Wang, Y.-K. Li, X.-Y. Wang and F.-F. Cao, ACS Catal., 2018, 8, 5431-5441.

140 L. Wang, Y. Li, Q. Sun, Q. Qiang, Y. Shen, Y. Ma, Z. Wang and C. Zhao, ChemCatChem, 2019, 11, 2011-2016. 
141 Y. Zhou, M. Luo, Z. Zhang, W. Li, X. Shen, W. Xia, M. Zhou and X. Zeng, Appl. Surf. Sci., 2018, 448, 9-15.

142 W.-K. Gao, J.-F. Qin, K. Wang, K.-L. Yan, Z.-Z. Liu, J.-H. Lin, Y.-M. Chai, C.-G. Liu and B. Dong, Appl. Surf. Sci., 2018, 454, 46-53.

143 N. Yang, C. Tang, K. Wang, G. Du, A. M. Asiri and X. Sun, Nano Res., 2016, 9, 3346-3354.

144 X. Wang, W. Zhang, J. Zhang and Z. Wu, ChemElectroChem, 2019, 6, 4550-4559.

145 Y. Guo, X. Zhou, J. Tang, S. Tanaka, Y. V. Kaneti, J. Na, B. Jiang, Y. Yamauchi, Y. Bando and Y. Sugahara, Nano Energy, 2020, 75, 104913.

146 W. He, F. Wang, D. Jia, Y. Li, L. Liang, J. Zhang, Q. Hao, C. Liu, H. Liu and J. Zhao, Nanoscale, 2020, 12, 2424424250.

147 W. Gao, F. Ma, C. Wang and D. Wen, J. Power Sources, 2020, 450, 227654.

148 R. Xu, Z. Xu, X. Zhang, Y. Ling, M. Li and Z. Yang, ChemElectroChem, 2020, 7, 148-154.

149 L. Huang, H. Wu, H. Liu and Y. Zhang, Electrochim. Acta, 2019, 318, 892-900.

150 Y. Xu, A. Sumboja, A. Groves, T. Ashton, Y. Zong and J. A. Darr, RSC Adv., 2020, 10, 41871-41882.

151 S. Dou, L. Tao, J. Huo, S. Wang and L. Dai, Energy Environ. Sci., 2016, 9, 1320-1326.

152 Z. Jing, Q. Zhao, D. Zheng, L. Sun, J. Geng, Q. Zhou and J. Lin, J. Mater. Chem. A, 2020, 8, 20323-20330.

153 J. Hao, W. Yang, J. Hou, B. Mao, Z. Huang and W. Shi, J. Mater. Chem. A, 2017, 5, 17811-17816.

154 Q. Hao, S. Li, H. Liu, J. Mao, Y. Li, C. Liu, J. Zhang and C. Tang, Catal. Sci. Technol., 2019, 9, 3099-3108.

155 H. Liu, Z. Liu, F. Wang and L. Feng, Chem. Eng. J., 2020, 397, 125507.

156 F. Zhang, Y. Ge, H. Chu, P. Dong, R. Baines, Y. Pei, M. Ye and J. Shen, ACS Appl. Mater. Interfaces, 2018, 10, 70877095.

157 W. He, D. Jia, J. Cheng, F. Wang, L. Zhang, Y. Li, C. Liu, Q. Hao and J. Zhao, Catal. Sci. Technol., 2020, 10, 75817590.

158 Y. Ding, H. Li and Y. Hou, Int. J. Hydrogen Energy, 2018, 43, 19002-19009.

159 C. Liu, D. Jia, Q. Hao, X. Zheng, Y. Li, C. Tang, H. Liu, J. Zhang and X. Zheng, ACS Appl. Mater. Interfaces, 2019, 11, 27667-27676.

160 Q. Liu, L. Xie, Z. Liu, G. Du, A. M. Asiri and X. Sun, Chem. Commun., 2017, 53, 12446-12449.

161 A. Zare, A. Bayat, E. Saievar-Iranizad and H. NaffakhMoosavy, J. Electroanal. Chem., 2020, 878, 114595.

162 X. Zhao, H. Zhang, Y. Yan, J. Cao, X. Li, S. Zhou, Z. Peng and J. Zeng, Angew. Chem., 2017, 129, 334-338.

163 Y. Zuo, D. Rao, S. Ma, T. Li, Y. H. Tsang, S. Kment and Y. Chai, ACS Nano, 2019, 13, 11469-11476.

164 D. Liang, J. Mao, P. Liu, J. Li, J. Yan and W. Song, Int. J. Hydrogen Energy, 2020, 45, 27047-27055.

165 F. Ming, H. Liang, H. Shi, X. Xu, G. Mei and Z. Wang, J. Mater. Chem. A, 2016, 4, 15148-15155.
166 H. Kang, H. Li, X. Zhao, L. Yang and S. Xu, Ceram. Int., 2020, 46, 2792-2797.

167 J. Dai, D. Zhao, W. Sun, X. Zhu, L.-J. Ma, Z. Wu, C. Yang, Z. Cui, L. Li and S. Chen, ACS Catal., 2019, 9, 10761-10772.

168 X. Wei, Y. Xie, M. Liu, J. Zhou, A. Zhou, P. He, Y. Dou and J.-R. Li, APL Mater., 2019, 7, 101106.

169 J. Li, G. Liu, B. Liu, Z. Min, D. Qian, J. Jiang and J. Li, Electrochim. Acta, 2018, 265, 577-585.

170 Z. Zou, X. Wang, J. Huang, Z. Wu and F. Gao, J. Mater. Chem. A, 2019, 7, 2233-2241.

171 L. Lin, M. Chen and L. Wu, ACS Appl. Energy Mater., 2019, 2, 4737-4744.

172 J. Du, Z. Zou, C. Liu and C. Xu, Nanoscale, 2018, 10, 51635170 .

173 M. Ghaemmaghami, Y. Yamini, E. Saievar-Iranizad and A. Bayat, Sustainable Energy Fuels, 2020, 4, 1150-1156.

174 Y. Du, G. Cheng and W. Luo, Nanoscale, 2017, 9, 6821-6825. 175 Y. Tuo, X. Wang, C. Chen, X. Feng, Z. Liu, Y. Zhou and J. Zhang, Electrochim. Acta, 2020, 335, 135682.

176 B. Mohanty, B. K. Jena, M. Kandasamy, N. Dalai, R. K. Sahu, R. M. Kadam, B. Chakraborty and B. Jena, Sustainable Energy Fuels, 2020, 4, 3058-3065.

177 K. Zhang, G. Zhang, J. Qu and H. Liu, Small, 2020, 16, 1907001.

178 S. Shit, S. Bolar, N. C. Murmu and T. Kuila, ACS Sustainable Chem. Eng., 2019, 7, 18015-18026.

179 W. Gao, F. Ma, C. Wang and D. Wen, J. Power Sources, 2020, 450, 227654.

180 L. Lei, D. Huang, C. Zhang, R. Deng, S. Chen and Z. Li, J. Catal., 2020, 385, 129-139.

181 B. Garlyyev, J. Fichtner, O. Piqué, O. Schneider, A. S. Bandarenka and F. Calle-Vallejo, Chem. Sci., 2019, 10, 8060-8075.

182 Y. Dou, C.-T. He, L. Zhang, H. Yin, M. Al-Mamun, J. Ma and H. Zhao, Nat. Commun., 2020, 11, 1664.

183 J. Kupka and A. Budniok, J. Appl. Electrochem., 1990, 20, 1015-1020.

184 C. Lin, P. Wang, H. Jin, J. Zhao, D. Chen, S. Liu, C. Zhang and S. Mu, Dalton Trans., 2019, 48, 16555-16561.

185 P. Wang, Z. Pu, Y. Li, L. Wu, Z. Tu, M. Jiang, Z. Kou, I. S. Amiinu and S. Mu, ACS Appl. Mater. Interfaces, 2017, 9, 26001-26007.

186 Y. Li, F. Li, Y. Zhao, S.-N. Li, J.-H. Zeng, H.-C. Yao and Y. Chen, J. Mater. Chem. A, 2019, 7, 20658-20666.

187 F. Li, Y. Bu, Z. Lv, J. Mahmood, G.-F. Han, I. Ahmad, G. Kim, Q. Zhong and J.-B. Baek, Small, 2017, 13, 1701167.

188 H. Sun, Y. Min, W. Yang, Y. Lian, L. Lin, K. Feng, Z. Deng, M. Chen, J. Zhong, L. Xu and Y. Peng, ACS Catal., 2019, 9, 8882-8892.

189 N. Suo, X. Han, C. Chen, X. He, Z. Dou, Z. Lin, L. Cui and J. Xiang, Electrochim. Acta, 2020, 333, 135531.

190 C. Ray, S. C. Lee, B. Jin, A. Kundu, J. H. Park and S. C. Jun, ACS Sustainable Chem. Eng., 2018, 6, 6146-6156.

191 Q. Zhang, D. Yan, Z. Nie, X. Qiu, S. Wang, J. Yuan, D. Su, G. Wang and Z. Wu, ACS Appl. Energy Mater., 2018, 1, 571-579. 
192 H.-W. Man, C.-S. Tsang, M. M.-J. Li, J. Mo, B. Huang, L. Y. S. Lee, Y. Leung, K.-Y. Wong and S. C. E. Tsang, Chem. Commun., 2018, 54, 8630-8633.

193 T. E. Rosser, J. P. S. Sousa, Y. Ziouani, O. Bondarchuk, D. Y. Petrovykh, X.-K. Wei, J. J. L. Humphrey, M. Heggen, Y. V. Kolen'ko and A. J. Wain, Catal. Sci. Technol., 2020, 10, 2398-2406.

194 M. Wang, W. Fu, L. Du, Y. Wei, P. Rao, L. Wei, X. Zhao, Y. Wang and S. Sun, Appl. Surf. Sci., 2020, 515, 146059.

195 P. Xu, L. Qiu, L. Wei, Y. Liu, D. Yuan, Y. Wang and P. Tsiakaras, Catal. Today, 2020, 355, 815-821.

196 Z. Shao, J. Sun, N. Guo, F. He, K. Huang, F. Tian and Q. Wang, J. Power Sources, 2019, 422, 33-41.

197 W. Xi, G. Yan, Z. Lang, Y. Ma, H. Tan, H. Zhu, Y. Wang and Y. Li, Small, 2018, 14, 1802204.

198 H. Fan, W. Chen, G. Chen, J. Huang, C. Song, Y. Du, C. Li and K. (Ken) Ostrikov, Appl. Catal., B, 2020, 268, 118440.

199 T. L. Luyen Doan, D. T. Tran, D. C. Nguyen, H. Tuan Le, N. H. Kim and J. H. Lee, Appl. Catal., B, 2020, 261, 118268. 200 M. A. R. Anjum, M. D. Bhatt, M. H. Lee and J. S. Lee, Chem. Mater., 2018, 30, 8861-8870.

201 Z. Yin, Y. Sun, Y. Jiang, F. Yan, C. Zhu and Y. Chen, ACS Appl. Mater. Interfaces, 2019, 11, 27751-27759.

202 T. Liu, M. Li, X. Bo and M. Zhou, ACS Sustainable Chem. Eng., 2018, 6, 11457-11465.

203 Y. Sun, T. Zhang, X. Li, D. Liu, G. Liu, X. Zhang, X. Lyu, W. Cai and Y. Li, Chem. Commun., 2017, 53, 13237-13240.

204 X. Bai, Q. Wang, G. Xu, Y. Ning, K. Huang, F. He, Z. Wu and J. Zhang, Chem.-Eur. J., 2017, 23, 16862-16870.

205 F.-C. Shen, S.-N. Sun, Z.-F. Xin, S.-L. Li, L.-Z. Dong, Q. Huang, Y.-R. Wang, J. Liu and Y.-Q. Lan, Appl. Catal., $B, 2019,243,470-480$.

206 M. A. R. Anjum, M. H. Lee and J. S. Lee, ACS Catal., 2018, 8, 8296-8305.

207 X. Ma, K. Li, X. Zhang, B. Wei, H. Yang, L. Liu, M. Zhang, X. Zhang and Y. Chen, J. Mater. Chem. A, 2019, 7, 1490414915.

208 X. Zhu, X. Zhang, L. Huang, Y. Liu, H. Zhang and S. Dong, Chem. Commun., 2019, 55, 9995-9998.

209 X. Jia, M. Wang, G. Liu, Y. Wang, J. Yang and J. Li, Int. J. Hydrogen Energy, 2019, 44, 24572-24579.

210 S. Xu, M. Wang, G. Saranya, N. Chen, L. Zhang, Y. He, L. Wu, Y. Gong, Z. Yao, G. Wang, Z. Wang, S. Zhao, H. Tang, M. Chen and H. Gou, Appl. Catal., B, 2020, 268, 118385.

211 H. Fan, H. Yu, Y. Zhang, Y. Zheng, Y. Luo, Z. Dai, B. Li, Y. Zong and Q. Yan, Angew. Chem., Int. Ed., 2017, 56, 12566-12570.

212 S. Zhang, G. Gao, J. Hao, M. Wang, H. Zhu, S. Lu, F. Duan, W. Dong, M. Du and Y. Zhao, ACS Appl. Mater. Interfaces, 2019, 11, 43261-43269.

213 Q. Liang, G. Brocks, X. Zhang and A. Bieberle-Hütter, J. Phys. Chem. C, 2019, 123, 26289-26298.

214 H. Yang, Y. Hu, D. Huang, T. Xiong, M. Li, M.-S. Balogun and Y. Tong, Mater. Today Chem., 2019, 11, 1-7.

215 Y. Wang, Q. Wu, B. Zhang, L. Tian, K. Li and X. Zhang, Catalysts, 2020, 10, 1164.
216 N. Han, K. R. Yang, Z. Lu, Y. Li, W. Xu, T. Gao, Z. Cai, Y. Zhang, V. S. Batista, W. Liu and X. Sun, Nat. Commun., 2018, 9, 924.

217 Y. Xu, M. Kraft and R. Xu, Chem. Soc. Rev., 2016, 45, 30393052.

218 K. Gong, F. Du, Z. Xia, M. Durstock and L. Dai, Science, 2009, 323, 760-764.

219 J. Wang, H. Kong, J. Zhang, Y. Hao, Z. Shao and F. Ciucci, Prog. Mater. Sci., 2021, 116, 100717.

220 X. Liu and L. Dai, Nat. Rev. Mater., 2016, 1, 1-12.

221 F. Davodi, M. Tavakkoli, J. Lahtinen and T. Kallio, J. Catal., 2017, 353, 19-27.

222 T. Sun, J. Wang, C. Qiu, X. Ling, B. Tian, W. Chen and C. Su, Adv. Sci., 2018, 5, 1800036.

223 Y. Zheng, Y. Jiao, Y. Zhu, Q. Cai, A. Vasileff, L. H. Li, Y. Han, Y. Chen and S.-Z. Qiao, J. Am. Chem. Soc., 2017, 139, 33363339.

224 Y. Tong, X. Yu, H. Wang, B. Yao, C. Li and G. Shi, ACS Catal., 2018, 8, 4637-4644.

225 J. Wei, Y. Liang, Y. Hu, B. Kong, J. Zhang, Q. Gu, Y. Tong, X. Wang, S. P. Jiang and H. Wang, Angew. Chem., Int. Ed., 2016, 55, 12470-12474.

226 J. Zhang and L. Dai, Angew. Chem., Int. Ed., 2016, 55, 1329613300.

227 Y. Zhao, R. Nakamura, K. Kamiya, S. Nakanishi and K. Hashimoto, Nat. Commun., 2013, 4, 2390.

228 X. Zheng, X. Cao, X. Li, J. Tian, C. Jin and R. Yang, Nanoscale, 2017, 9, 1059-1067.

229 B. Y. Xia, Y. Yan, N. Li, H. B. Wu, X. W. (David) Lou and X. Wang, Nat. Energy, 2016, 1, 1-8.

230 H. B. Yang, J. Miao, S.-F. Hung, J. Chen, H. B. Tao, X. Wang, L. Zhang, R. Chen, J. Gao, H. M. Chen, L. Dai and B. Liu, Sci. Adv., 2016, 2, e1501122.

231 J. Sun, S. E. Lowe, L. Zhang, Y. Wang, K. Pang, Y. Wang, Y. Zhong, P. Liu, K. Zhao, Z. Tang and H. Zhao, Angew. Chem., Int. Ed., 2018, 57, 16511-16515.

232 D. Liu, S. Ding, C. Wu, W. Gan, C. Wang, D. Cao, Z. ur Rehman, Y. Sang, S. Chen, X. Zheng, Y. Wang, B. Ge and L. Song, J. Mater. Chem. A, 2018, 6, 6840-6846.

233 C. Wu, X. Zhang, Z. Xia, M. Shu, H. Li, X. Xu, R. Si, A. I. Rykov, J. Wang, S. Yu, S. Wang and G. Sun, J. Mater. Chem. A, 2019, 7, 14001-14010.

234 H.-J. Qiu, P. Du, K. Hu, J. Gao, H. Li, P. Liu, T. Ina, K. Ohara, Y. Ito and M. Chen, Adv. Mater., 2019, 31, 1900843.

235 Y. Li, Z.-S. Wu, P. Lu, X. Wang, W. Liu, Z. Liu, J. Ma, W. Ren, Z. Jiang and X. Bao, Adv. Sci., 2020, 7, 1903089.

236 K. Qu, Y. Zheng, Y. Jiao, X. Zhang, S. Dai and S.-Z. Qiao, Adv. Energy Mater., 2017, 7, 1602068.

237 S. Chen, J. Duan, Y. Zheng, X. Chen, X. W. Du, M. Jaroniec and S.-Z. Qiao, Energy Storage Mater., 2015, 1, 17-24.

238 L. Li, H. Yang, J. Miao, L. Zhang, H.-Y. Wang, Z. Zeng, W. Huang, X. Dong and B. Liu, ACS Energy Lett., 2017, 2, 294-300.

239 X. Lu, W.-L. Yim, B. H. R. Suryanto and C. Zhao, J. Am. Chem. Soc., 2015, 137, 2901-2907.

240 T. Y. Ma, J. Ran, S. Dai, M. Jaroniec and S. Z. Qiao, Angew. Chem., 2015, 127, 4729-4733. 
241 Z. Xiao, X. Huang, L. Xu, D. Yan, J. Huo and S. Wang, Chem. Commun., 2016, 52, 13008-13011.

242 P. Chen, T. Zhou, L. Xing, K. Xu, Y. Tong, H. Xie, L. Zhang, W. Yan, W. Chu, C. Wu and Y. Xie, Angew. Chem., Int. Ed., 2017, 56, 610-614.

243 A. M. El-Sawy, I. M. Mosa, D. Su, C. J. Guild, S. Khalid, R. Joesten, J. F. Rusling and S. L. Suib, Adv. Energy Mater., 2016, 6, 1501966.

244 D. G. Papageorgiou, I. A. Kinloch and R. J. Young, Prog. Mater. Sci., 2017, 90, 75-127.

245 Z. Zhao, M. Li, L. Zhang, L. Dai and Z. Xia, Adv. Mater., 2015, 27, 6834-6840.

246 Z. Lin, G. H. Waller, Y. Liu, M. Liu and C. Wong, Carbon, 2013, 53, 130-136.

247 Z. Zhao and Z. Xia, ACS Catal., 2016, 6, 1553-1558.

248 G.-L. Chai, K. Qiu, M. Qiao, M.-M. Titirici, C. Shang and Z. Guo, Energy Environ. Sci., 2017, 10, 1186-1195.

249 V. N. Popov, Mater. Sci. Eng., R, 2004, 43, 61-102.
250 Z. Luo, A. Oki, L. Carson, L. Adams, G. Neelgund, N. Soboyejo, G. Regisford, M. Stewart, K. Hibbert, G. Beharie, C. Kelly-Brown and P. Traisawatwong, Chem. Phys. Lett., 2011, 513, 88-93.

251 G.-L. Tian, Q. Zhang, B. Zhang, Y.-G. Jin, J.-Q. Huang, D. S. Su and F. Wei, Adv. Funct. Mater., 2014, 24, 5956-5961.

252 M. Inagaki, T. Tsumura, T. Kinumoto and M. Toyoda, Carbon, 2019, 141, 580-607.

253 X. Huang, Q. Wang, D. Jiang and Y. Huang, Catal. Commun., 2017, 100, 89-92.

254 X. Li, P. Cui, W. Zhong, J. Li, X. Wang, Z. Wang and J. Jiang, Chem. Commun., 2016, 52, 13233-13236.

255 K. Mamtani, D. Jain, D. Dogu, V. Gustin, S. Gunduz, A. C. Co and U. S. Ozkan, Appl. Catal., B, 2018, 220, 88-97.

256 X. Liu, I. S. Amiinu, S. Liu, K. Cheng and S. Mu, Nanoscale, 2016, 8, 13311-13320.

257 S. Yang, T. Zhang, G. Li, L. Yang and J. Y. Lee, Energy Storage Mater., 2017, 6, 140-148. 